Paulo Jannuzzi Cunha

\title{
Alterações neuropsicológicas em dependentes de cocaína
}

Tese apresentada à Faculdade de Medicina da Universidade de São Paulo para obtenção do título de Doutor em Ciências

Área de concentração: Fisiopatologia Experimental

Orientador: Prof. Dr. Arthur Guerra de Andrade

São Paulo

2005 
Paulo Jannuzzi Cunha

\section{Alterações neuropsicológicas em dependentes de cocaína}

Tese apresentada à Faculdade de Medicina da Universidade de São Paulo para obtenção do título de Doutor em Ciências

Área de concentração: Fisiopatologia Experimental

Orientador: Prof. Dr. Arthur Guerra de Andrade

São Paulo

2005 


\section{FICHA CATALOGRÁFICA}

Preparada pela Biblioteca da

Faculdade de Medicina da Universidade de São Paulo

Creprodução autorizada pelo autor

Cunha, Paulo Jannuzzi

Alterações neuropsicológicas em dependentes de cocaína / Paulo Jannuzzi Cunha. -- São Paulo, 2005.

Tese(doutorado)--Faculdade de Medicina da Universidade de São Paulo para obtenção do título de Doutor em Ciências.

Área de concentração: Fisiopatologia Experimental.

Orientador: Arthur Guerra de Andrade.

Descritores: 1.COCAÍNA 2.TRANSTORNOS RELACIONADOS AO USO DE COCAÍNA 3.COGNIÇÃO/efeitos de drogas 4.TESTES NEUROPSICOLÓGICOS

USP/FM/SBD-268/05 


\section{Dedicatória}

Aos meus pais, pelos ensinamentos, carinho e apoio, em todos os momentos de minha vida. 


\section{Agradecimentos}

Ao Dr. Sergio Nicastri, co-orientador, pelos estímulos, sugestões, críticas, paciência, tolerância e valiosos ensinamentos que sempre me proporcionou, desde o período gestacional deste trabalho.

A Dr. Cândida Helena Pires de Camargo, pela introdução ao campo e formação obtida em Neuropsicologia, sem a qual esta tese não seria planejada e executada.

A todo o Serviço de Psicologia e Neuropsicologia do Instituto de Psiquiatria do Hospital das Clínicas da Faculdade de Medicina (IPq-HC-FM) da USP, incluindo os profissionais e professores que me ensinaram, supervisionaram e auxiliaram significativamente em todo o percurso de estudos, atendimentos e pesquisas na área de Neuropsicologia.

Ao Grupo Interdisciplinar de Estudos de Álcool e Drogas (GREA) do IPq-HC-FMUSP, incluindo o Dr. Arthur Guerra de Andrade, Dr. André Malbergier, Dra. Sandra Scivoletto, Dr. Marco Aurélio Peluso, além dos outros médicos, psicólogos, fonoaudiólogos e funcionários exemplares (Roberta, Celi, Ednei e Daniela), que sempre estiveram presentes, atentos e solícitos às demandas da pesquisa.

Ao Serviço de Psicologia do Hospital Israelita Albert Einstein (HIAE), instituição que me acolheu e vem apoiando as atividades relacionadas a minha formação (Doutorado), especialmente a coordenadora dos psicólogos, Dra. Paola Bruno A. Andreoli, e a neuropsicóloga Sandra Lie Ribeiro do Valle, pelo auxílio constante e ajuda valiosa. 
A psicóloga Laura Fracasso e ao padre Haroldo J. Rahm, ambos da Comunidade Terapêutica Associação Promocional Oração e Trabalho (APOT), situada em Campinas (SP), pelo trabalho árduo e apoio irrestrito nas atividades de pesquisa e coleta de dados no trabalho.

A Dra. Karen I. Bolla, coordenadora da neuropsicologia no Departamento de Neurologia e Neurocirurgia da Faculdade de Medicina da Universidade Johns Hopkins (Baltimore, MD, EUA) e ao Dr. Jean Lud Cadet, coordenador do Intramural Research Program (IRP) do National Institute on Drug Abuse (NIDA), pois vêm acreditando também em nosso trabalho e proporcionando momentos valiosíssimos de aprendizagem e crescimento profissional.

A todas as pessoas especiais que, em momentos diferentes, direta ou indiretamente, foram muito importantes (ou imprescindíveis) para o cumprimento de todas as etapas desta jornada, como Cláudia S. Caligioni, Dr. Rogério S. Morihisa, Dr. Cláudio E. Duarte, Dr. Ronaldo R. Laranjeira, Dr. Marcos Romano, Dr. Marco Antonio S. Annes e psicóloga Cristiane A. Dameto.

E, por fim, mais não menos importantes, a todos os pacientes (grupo experimental-GREA e APOT) e indivíduos do grupo controle que aceitaram participar como voluntários da pesquisa, sem os quais este trabalho não seria realizado. Todos foram fundamentais e igualmente importantes. 


\section{Agradecimentos}

(instituições responsáveis pelo apoio financeiro)

A Fundação de Amparo a Pesquisa do Estado de São Paulo (FAPESP), pelo auxílio pesquisa concedido, em nome do Dr. Sergio Nicastri, co-orientador do trabalho.

Ao Fundo de Aprimoramento Acadêmico (FUAA) do IPq-HC-FMUSP.

Ao National Institute on Drug Abuse (NIDA), College on Problems of Drug Dependence $(C P D D)$ e World Health Organization (WHO), pelo International Fellowship concedido, que trouxe apoio e incentivo aos trabalhos e pesquisas, particularmente em colaboração com a Universidade de Johns Hopkins e o próprio NIDA. 


\section{Esta tese está de acordo com:}

Referências: adaptado de International Committee of Medical Journals Editors (Vancouver)

Universidade de São Paulo. Faculdade de Medicina. Serviço de Biblioteca e Documentação. Guia de Apresentação de dissertações, teses e monografias. Elaborado por Anneliese Carneiro da Cunha, Maria Julia de A. L. Freddi, Maria F. Crestana, Marinalva de Souza Aragão, Suely Campos Cardoso, Valéria Vilhena. São Paulo: Serviço de Biblioteca e Documentação; 2004. 
Resumo

Summary

1. INTRODUÇÃO 12

2. REVISÃO DA LITERATURA 14

3. OBJETIVOS 26

4. MÉTODOS 27

5. RESULTADOS 33

6. DISCUSSÃO 53

7. CONCLUSÕES 60

8. REFERÊNCIAS 62

Apêndices $\quad 75$

Escalas e Inventários

Bateria de Avaliação Neuropsicológica (Folhas de Respostas)

Testes Neuropsicológicos (Descrição) 


\section{Resumo}

Cunha PJ. Alterações neuropsicológicas em dependentes de cocaína [tese]. São Paulo: Faculdade de Medicina, Universidade de São Paulo; 2005. 126p.

INTRODUÇÃO: Embora o uso de cocaína seja um problema significativo de saúde pública, há uma relativa escassez de dados científicos sobre as conseqüências neurocognitivas decorrentes da exposição à substância. OBJETIVO: Este estudo avaliou a associação entre dependência de cocaína e desempenho cognitivo. MÉTODOS: Uma ampla bateria de testes neuropsicológicos, incluindo o Trail Making Test (TMT), Stroop Color Word Test (SCWT), Dígitos Diretos e Inversos (WMS-R), Memória Lógica I e II (WMS-R), Reprodução Visual I e II (WMS-R), Teste da Figura Complexa de Rey-Osterrieth (TFCRO), Buschke Selective Reminding Test (BSRT), Wisconsin Card Sorting Test (WCST), Desenhos Alternados (Luria), Códigos (WAIS-R), Cubos (WAIS-R), Vocabulário (WAIS-R), Controlled Word Association Test (COWAT), Boston Naming Test (BNT), Bateria de Avaliação Frontal (BAF) e o lowa Gambling Task (IGT), foi aplicada a 30 dependentes de cocaína, em abstinência por duas semanas, em tratamento, e em 32 sujeitos controles, não usuários de drogas, pareados por idade, sexo, escolaridade, nível sócio-econômico, lateralidade e QI. RESULTADOS: Os resultados mostraram significação estatística $(p<0,05)$ em testes de atenção, fluência verbal, memória visual, memória verbal, capacidade de aprendizagem, funções executivas, memória operacional, funções viso-motoras e na tomada de decisões. CONCLUSÕES: Esses dados mostram evidências de que o abuso de cocaína está associado a déficits cognitivos, semelhantes aos que ocorrem em transtornos cognitivos, possivelmente relacionados a problemas em regiões cerebrais pré-frontais e temporais. $O$ conhecimento dos danos neuropsicológicos específicos pode ser útil no planejamento de programas de prevenção e tratamento mais efetivo para abuso de cocaína.

Descritores: 1.Cocaína 2.Transtornos relacionados ao uso de cocaína 3.Cognição/efeitos de drogas 4.Testes Neuropsicológicos 


\section{Summary}

Cunha PJ. Neuropsychological impairments in cocaine-dependent patients [thesis]. São Paulo: "Faculdade de Medicina, Universidade de São Paulo"; 2005. 126p.

INTRODUCTION: Although cocaine use is a significant public health problem, there is relative paucity of scientific data on long-term neurocognitive consequences of the exposure to the substance. OBJECTIVE: This study examined the association between cocaine dependence and neuropsychological performance. METHODS: An extended battery of neuropsychological tests, including Trail Making Test (TMT), Stroop Color Word Test (SCWT), Forward and Backward Digits (WMS-R), Logical Memory I and II (WMS-R), Visual Reproduction I and II (WMS-R), Rey-Osterrieth Complex Figure Test (ROCFT), Buschke Selective Reminding Test (BSRT), Wisconsin Card Sorting Test (WCST), Alternate Designs (Luria), Symbol-Digit (WAIS-R), Block Design (WAIS-R), Vocabulary (WAIS-R), Controlled Word Association Test (COWAT), Boston Naming Test (BNT), Frontal Assessment Battery (FAB) and lowa Gambling Task (IGT), was administered to 30 abstinent cocaine abusers, inpatients in abstinence for two weeks, and 32 non-drug-using control subjects matched for age, gender, education, socio-economic status, handedness and IQ. RESULTS: The findings showed statistical significance $(p<0,05)$ on differences of performance in attention, verbal fluency, verbal memory, visual memory, learning ability, executive functions, working memory, visuomotor functioning and decision-making. CONCLUSIONS: These results represent evidences that cocaine abuse is associated with decrements in cognitive functioning, similar to cognitive disorders associated to prefrontal and temporal brain impairments. Knowledge of specific cognitive deficits in cocaine abusers may be useful for designing more effective substance abuse prevention and treatment programs.

Descriptors: 1. Cocaine 2.Cocaine - Related Disorders 3.Cognition/drug effects 4. Neuropsychological Tests 


\section{INTRODUÇÃO}

O uso abusivo crônico da cocaína ou do crack pode trazer vários problemas ao indivíduo, tanto complicações médicas (psiquiátricas e clínicas), quanto sociais e psicológicas (Washton et al., 1984; Nappo et al., 1994; Lacayo, 1995; Leite, 1999). São inúmeras as complicações médicas decorrentes do uso da cocaína: entre elas estão a hipertensão, hemorragia intracraniana, arritmia cardíaca, isquemias, infarto do miocárdio, insuficiência cardíaca, morte súbita, convulsões, cefaléia, déficits neurológicos transitórios, coma, infarto cerebral, parada respiratória, edema pulmonar, hipertermia, aborto espontâneo, deslocamento de placenta, malformações congênitas, retardo do desenvolvimento psicomotor da criança, AIDS e tétano (Leite et al., 1999). Segundo a quarta edição do Manual Estatístico e Diagnóstico (DSM-IV) da Associação Psiquiátrica Americana (APA), entre os transtornos mentais e de comportamento devidos ao uso da cocaína estão a Dependência, Abuso, Intoxicação, Abstinência, Delirium, Transtornos Psicóticos, Transtornos do Humor, de Ansiedade, Disfunções Sexuais e Transtornos do Sono (APA, 1994).

O problema referente ao uso de cocaína em nosso país é bastante perturbador. Hoje em dia, estima-se que 13.3 milhões de pessoas tenham consumido cocaína na década passada (UNODCCP, 2002) e, no Brasil, de acordo com o I Levantamento Domiciliar sobre o uso de Drogas, realizado pelo Centro Brasileiro de Informações sobre Drogas Psicotrópicas (CEBRID), 
constatou-se que $7,2 \%$ dos indivíduos do sexo masculino, entre 25 e 34 anos de idade, já usaram a droga (Carlini et al., 2001).

Segundo o IV Levantamento sobre o Uso de Drogas entre Estudantes de $1^{\circ}$ e $2^{\circ}$ graus em 10 Capitais Brasileiras, publicado em 1997 por Galduróz et al., o consumo de cocaína tem crescido de modo significativo. Os estudantes passaram a usar mais essa droga e, ao contrário do que se pensava anteriormente, de que a maior proporção de usuários concentrariam-se em São Paulo e Rio de Janeiro, o uso está bem distribuído nas dez capitais estudadas (Galduróz et al., 1997). Para se ter uma noção mais clara desse crescimento, no levantamento feito sobre o consumo de drogas realizado em 1993 por Galduróz et al. (1994), a cocaína aparecia em nono lugar na preferência entre os estudantes, enquanto que nesta última avaliação, esta droga já ocupa a quinta posição entre as drogas mais usadas, excluindo-se álcool e tabaco (Galduróz et al., 1997). Além disso, o uso de cocaína vem crescendo, também, entre os pacientes que procuram atendimento nas clínicas especializadas (Laranjeira et al., 1996). Dados preocupantes mostram também a gravidade do problema relacionado às crianças que vivem nas ruas de São Paulo: 35,5\% delas já usaram o crack (Noto et al., 1994). É uma realidade preocupante, já que o crack parece ser a forma mais arrasadora de uso da cocaína (Nappo et al., 1994). 


\section{REVISÃO DA LITERATURA}

A cocaína é uma substância altamente reforçadora no Sistema Nervoso Central (SNC). Após a administração e absorção pela corrente sanguínea, ela chega rapidamente ao cérebro, mais especificamente no circuito da recompensa (sistema meso-límbico), região onde predominantemente exerce os efeitos estimulantes. Ela causa o bloqueio da recaptação de neurotransmissores na fenda pré-sináptica, levando a um aumento na quantidade de serotonina, dopamina e noradrenalina nas sinapses, que por sua vez estimulam os receptores pós-sinápticos. A dopamina continua então bombardeando os receptores, levando o usuário à sensação de prazer. Em longo prazo, no entanto, acredita-se que ocorra uma diminuição na disponibilidade de dopamina e serotonina nestas áreas, que tem sido associada à anedonia (ausência de prazer) e aos outros sintomas de abstinência que o usuário vivencia (Lacayo, 1995).

Assim, são comuns os problemas cerebrais em decorrência do abuso desta droga, como mostram os estudos envolvendo a utilização de técnicas de neuroimagem estrutural (Fein et al., 2002; Matochik et al., 2003) e funcional (Volkow et al., 1992; Nicastri et al., 2000; Gottschalk et al., 2001; Bolla et al., 2003).

Um estudo mais recente, realizado pelo grupo do Departamento de Neurologia na Universidade Johns Hopkins observou disfunções corticais pré- 
frontais em dependentes de cocaína no período de abstinência, no momento em que eram submetidos a um teste neuropsicológico envolvendo as funções executivas (Bolla et al., 2004).

Dadas estas informações, considera-se cada vez mais importante a descrição dos riscos neurocognitivos a que os dependentes de cocaína estão expostos. A maioria dos tratamentos se baseia no emprego de estratégias cognitivo-comportamentais, em que o uso do processamento mental é um mediador para a mudança dos hábitos. Assim, aqueles dependentes de cocaína que não conseguem compreender as intervenções (ex: análise funcional, treinamento de habilidades), tendem a obter pouco sucesso ou abandonar o tratamento precocemente (Aharonovich et al., 2003). Informações como estas são importantes para a elaboração de programas efetivos de tratamento para os dependentes químicos (Hoff et al., 1996; Strickland et al., 1993; Cleaveland e Denier, 1998; Gillen, 1998; Bolla et al., 1999; Aharonovich et al., 2003; Bolla et al., 2003; Bolla et al., 2004).

Um dos trabalhos que aumentou a consciência dos riscos e perigos do uso da cocaína, o primeiro a citar a possibilidade de dano neuropsicológico, que acabou abrindo as perspectivas de estudo dos déficits cognitivos associados à droga foi o de Washton et al. (1984). Os autores realizaram um levantamento, a partir de um serviço de ajuda telefônica para usuários de cocaína, englobando 500 indivíduos, com o objetivo de formular o seu perfil demográfico e obter dados sobre a natureza, extensão e as conseqüências do uso da droga. Além 
de muitos problemas sociais, físicos e psicológicos, verificou-se que $65 \%$ dos indivíduos referiam dificuldade de concentração e 57\% problemas de memória.

Sevy et al. (1990) analisaram 16 esquizofrênicos dependentes de cocaína e 35 esquizofrênicos não-dependentes, pesquisando medidas psicopatológicas, demográficas, cognitivas e históricas. A avaliação foi realizada após três semanas de internação numa Unidade Psiquiátrica. Os esquizofrênicos dependentes de cocaína tiveram um desempenho pior em testes de codificação conceitual e memória verbal, enquanto que foram melhores em tarefas atencionais do que os não-dependentes.

Ardila et al. (1991) estudaram 37 dependentes de cocaína, com a média de 30 dias em abstinência, usando uma bateria neuropsicológica básica e comparando os resultados com tabelas normativas dos testes. Encontraram um prejuízo neuropsicológico moderado nos pacientes, em tarefas de memória verbal, visual, atenção, nomeação e capacidade de abstração. Foi observado também que quanto maior a quantidade de uso da droga durante a vida, pior o desempenho neuropsicológico.

O'Malley et al. (1992) pesquisaram 20 dependentes de cocaína, que foram comparados a 20 sujeitos normais, pareados em idade e nível educacional. Os dependentes estavam em média há 23,6 dias em abstinência. Os dependentes da droga demonstraram um pior desempenho em atividades que Ihes exigiam concentração, memória, resolução de problemas não-verbais, capacidade de abstração, destreza visomotora e cálculo. Em contrapartida, um 
dado inesperado foi encontrado pelos autores: os sujeitos dependentes apresentaram uma fluência verbal melhor do que os controles.

Berry et al. (1993) estudaram 16 dependentes de cocaína em tratamento, em dois momentos: 72 horas e 14 dias após a abstinência, comparando-os a 21 controles normais pareados em idade, sexo, raça e educação. Verificaram que o uso recente de cocaína estava relacionado a prejuízos na memória, habilidades visuoespaciais e concentração durante a fase aguda da retirada da droga, e que estes persistiam por pelo menos duas semanas após a cessação do uso. A despeito dos dois grupos terem obtido uma melhoria significativa na maioria das medidas neuropsicológicas, os sujeitos dependentes falharam em demonstrar um grau de recuperação similar aos sujeitos normais, principalmente nas tarefas de velocidade visomotora, memória e concentração.

Strickland et al. (1993) estudaram 8 pacientes dependentes de cocaína internados, buscando avaliar a relação entre fluxo sangüíneo cerebral e o funcionamento neuropsicológico desses sujeitos, após um período significativo de abstinência à droga (pelo menos 6 meses). Todos os pacientes manifestaram alterações no fluxo sangüíneo cerebral e disfunção cognitiva persistente, particularmente em tarefas que requeriam sustentação da atenção, concentração, novas aprendizagens, memória visual e verbal, fluência verbal e integração visomotora. Os déficits neuropsicológicos observados foram associados com o padrão multifocal de hipoperfusão cerebral constatado. A 
despeito da relevância deste estudo, Nicastri et al. (2000) aponta a dificuldade em se generalizar seus dados, visto que a amostra avaliada foi pequena e não houve a inclusão de um grupo controle.

Beatty et al. (1995) estudaram 69 sujeitos, sendo 24 alcoólatras, 23 abusadores de cocaína e 22 controles, pareados em idade e grau de escolaridade. Tanto os alcoólatras como os abusadores obtiveram desempenho pior do que os controles nas medidas de aprendizagem e memória, velocidade percepto-motora, resolução de problemas e capacidade de abstração. Sugerem que o abuso de álcool ou cocaína estão associados com déficits em testes neuropsicológicos, e que estes não podem ser atribuídos a fatores prémórbidos ou co-mórbidos específicos, tais como depressão, infância ou transtorno de déficit de atenção residual.

Rosseli e Ardila (1996), num estudo realizado com 183 participantes, sendo 63 sujeitos não usuários, 59 dependentes de várias drogas e 61 dependentes de cocaína, em abstinência de pelo menos 2 meses, encontraram um déficit cognitivo médio associado ao abuso crônico de cocaína e de várias drogas. Nos sujeitos dependentes de drogas, escores baixos foram encontrados em alguns subtestes de memória verbal e, em menor grau, em subtestes de memória não-verbal. A capacidade de abstração e flexibilidade cognitiva também estavam abaixo das observadas nos indivíduos do grupo controle. A partir dos resultados, os autores sugerem que a memória representa a função cognitiva mais sensível ao uso crônico de cocaína, seguida pela 
abstração e atenção, e que o padrão de déficits neuropsicológicos produzido pela cocaína não difere de outras drogas psicoativas.

Hoff et al. (1996) pesquisaram 38 sujeitos dependentes de crack, comparando-os com 54 controles. O uso da cocaína foi associado a uma diminuição na habilidade de nomeação de objetos, na capacidade de resolver problemas complexos, memória espacial, velocidade percepto-motora e flexibilidade cognitiva. Por outro lado, o uso da cocaína foi relacionado a um aumento da fluência verbal e na formação de conceitos abstratos. No entanto, este foi um estudo que comparou grupos com níveis educacionais e sociais diferentes, além de diferentes raças e níveis de depressão também, o que indica que a interpretação dos dados deve ser feita com cautela.

Mattos e Biscaia (1998) realizaram um estudo com 21 dependentes de cocaína intranasal, internados, abstinentes por três semanas, sem o uso de quaisquer psicofármacos, que foram comparados com 30 controles. O único prejuízo significativo encontrado nos dependentes foi na recuperação de material visual complexo. O estudo sugere a persistência do déficit por até três semanas após a interrupção da droga, havendo a necessidade de outros estudos que avaliem o grau de recuperação dos mesmos com um seguimento maior. Neste trabalho, no entanto, não foram medidas outras habilidades que poderiam ser afetadas pelo uso da cocaína, como a capacidade de abstração, funções motoras e os processos atencionais.

Gillen et al. (1998) estudaram 19 dependentes de cocaína e os 
compararam a 16 sujeitos não dependentes numa bateria de testes neuropsicológicos. O desempenho dos dependentes foi inferior ao grupo controle, principalmente em tarefas que recrutaram tarefas de alto nível verbal (informação e vocabulário) e numa outra de sequenciamento lógico de um estímulo visual complexo. Usuários de cocaína também foram pior em memória visual tardia e em fluência verbal, mas foram melhor numa tarefa de velocidade visomotora simples.

Selby e Azrin (1998) pesquisaram 60 abusadores e dependentes de cocaína, 101 de álcool e 56 de várias substâncias, comparando-os a 138 indivíduos normais. Não foram encontradas diferenças significativas entre o desempenho dos sujeitos dependentes de cocaína e do grupo controle. Nota-se que o período de abstinência foi bem mais alto que nos outros estudos, pois compreendeu um período médio de 36 meses ( 3 anos). Os autores sugerem que após um longo período de abstinência, talvez a atividade neuroquímica e cerebrovascular retorne aos níveis pré-mórbidos de funcionamento e desta forma as capacidades neuropsicológicas também.

Bolla et al. (1999) investigaram 30 usuários de cocaína e os compararam a 21 controles. Seus resultados sugerem que o uso de cocaína por si só não desencadeia déficits cognitivos, mas quanto maior o uso desta droga (gramas por semana), maior o decréscimo dos desempenhos dos sujeitos em testes neuropsicológicos, principalmente em testes que medem o funcionamento executivo, visuopercepção, velocidade psicomotora e destreza 
manual.

Em um estudo preliminar, nosso grupo de pesquisa avaliou sete pacientes dependentes de cocaína, com um mês de abstinência à droga (Cunha et al., 2001). Foram observados déficits em atenção, memória visual, memória verbal, funções executivas, capacidade de aprendizagem e coordenação visomotora, embora inteligência, fluência verbal, nomeação, capacidade de abstração e praxia construtiva estivessem preservadas. Posteriormente, Cunha et al. (2004) avaliaram 15 dependentes de cocaína, em regime de internação, comparando-os a um grupo controle, pareado em diversas variáveis, como idade, gênero, nível sócio-econômico, lateralidade, etnia e nível intelectual. Os resultados apontaram diferenças estatisticamente significantes em testes que envolviam a atenção, memória (visual e verbal), aprendizagem, funções executivas e fluência verbal fonológica.

Toomey et al. (2003) realizaram uma investigação com 50 abusadores de cocaína e outros estimulantes, com um ano de abstinência, utilizando vários instrumentos de avaliação neuropsicológica, e um grupo controle formado por gêmeos não abusadores de drogas, e constataram a permanência de déficits cognitivos, mesmo após um longo período sem o uso da droga, sugerindo a presença de danos residuais nestes indivíduos.

Bolla et al. (2004) avaliaram 13 dependentes de cocaína, cujo desempenho foi comparado ao de 13 controles, através de um teste que avalia a capacidade de tomada de decisões. Os grupos foram pareados quanto ao 
nível intelectual estimado.

$\mathrm{Na}$ tabela a seguir (TABELA 1), observam-se resumidamente as características gerais dos estudos citados, com a atualização dos dados mais recentes e os achados principais de cada um. 


\section{TABELA 1. ESTUDOS NEUROPSICOLÓGICOS REALIZADOS SOBRE A RELAÇÃO ENTRE COCAÍNA E DÉFICITS COGNITIVOS}

\begin{tabular}{|c|c|c|c|c|c|}
\hline \multirow[t]{2}{*}{ AUTORES E ANO } & \multirow[t]{2}{*}{$\begin{array}{l}\quad N \\
\text { (cocaína/ } \\
\text { normais) }\end{array}$} & \multirow[t]{2}{*}{$\begin{array}{l}\text { ABSTINÊN- } \\
\text { CIA } \\
\text { (média) }\end{array}$} & \multirow[t]{2}{*}{$\begin{array}{l}\text { PADRÃO DE } \\
\text { USO** }\end{array}$} & \multicolumn{2}{|c|}{$\begin{array}{c}\text { RESULTADOS }{ }^{\star \star \star} \\
\text { (Desempenho dos dependentes e/ou abusadores de cocaína } \\
\text { nos testes neuropsicológicos) }\end{array}$} \\
\hline & & & & PIOR & MELHOR \\
\hline $\begin{array}{l}\text { Washton et al. } \\
\text { (1984) }\end{array}$ & $500 / 0$ & 0 dias & $\mathrm{U}$ & Memória e Concentração & --- \\
\hline $\begin{array}{l}\text { Sevy et al.* } \\
\quad(1990)\end{array}$ & $16 / 35$ & 21 dias & $\mathrm{D}$ & $\begin{array}{c}\text { Codificação conceitual e memória } \\
\text { verbal }\end{array}$ & Atenção \\
\hline $\begin{array}{l}\text { Ardila et al. } \\
\quad(1991)\end{array}$ & $37 / 0$ & 30 dias & D & $\begin{array}{l}\text { memória verbal, memória visual, } \\
\text { atenção, nomeação e capacidade } \\
\text { de abstração }\end{array}$ & ---- \\
\hline $\begin{array}{l}\text { O'Malley et al. } \\
\quad(1992)\end{array}$ & $20 / 20$ & 23,6 dias & $\mathrm{D}$ & $\begin{array}{l}\text { Concentração, memória, resolução } \\
\text { de problemas não-verbais, } \\
\text { capacidade de abstração, destreza } \\
\text { visomotora e cálculo. }\end{array}$ & Fluência verbal \\
\hline \multirow{2}{*}{$\begin{array}{l}\text { Berry et al. } \\
\text { (1993) }\end{array}$} & $16 / 21$ & 3 dias & $\mathrm{D}$ & Memória, habilidades & --- \\
\hline & $16 / 21$ & 14 dias & D & $\begin{array}{l}\text { visuoespaciais e concentração. } \\
\text { Memória, habilidades } \\
\text { visuoespaciais e concentração. }\end{array}$ & ---- \\
\hline $\begin{array}{l}\text { Strickland et al. } \\
\text { (1993) }\end{array}$ & $8 / 0$ & $\begin{array}{l}>180 \text { dias } \\
(6 \text { meses })\end{array}$ & $\mathrm{D}$ & $\begin{array}{l}\text { Atenção, concentração, novas } \\
\text { aprendizagens, memória visual, } \\
\text { memória verbal, fluência verbal e } \\
\text { integração visomotora }\end{array}$ & ---- \\
\hline $\begin{array}{l}\text { Beatty et al. } \\
\quad(1995)\end{array}$ & $23 / 20$ & 21-35 dias & A & $\begin{array}{l}\text { Aprendizagem, memória, resolução } \\
\text { de problemas e abstração e } \\
\text { velocidade percepto-motora }\end{array}$ & ---- \\
\hline $\begin{array}{l}\text { Rosseli e Ardila } \\
\text { (1996) }\end{array}$ & $61 / 63$ & 60 dias & $\mathrm{D}$ & $\begin{array}{c}\text { Memória, concentração, capacidade } \\
\text { de abstração e flexibilidade } \\
\text { cognitiva }\end{array}$ & --- \\
\hline $\begin{array}{l}\text { Hoff et al. } \\
\quad(1996)\end{array}$ & $38 / 54$ & 24,5 dias & $\mathrm{D}$ & $\begin{array}{c}\text { Resolução de problemas } \\
\text { complexos, memória espacial, } \\
\text { nomeação de objetos, velocidade } \\
\text { percepto-motora e flexibilidade } \\
\text { cognitiva. }\end{array}$ & $\begin{array}{c}\text { Formação de conceitos e } \\
\text { Fluência verbal }\end{array}$ \\
\hline $\begin{array}{c}\text { Mattos e Biscaia } \\
(1998)\end{array}$ & $21 / 38$ & 21 dias & $\mathrm{D}$ & $\begin{array}{l}\text { Recuperação de material visual } \\
\text { complexo (memória visual) }\end{array}$ & 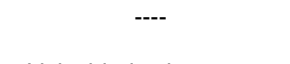 \\
\hline $\begin{array}{l}\text { Gillen et al. } \\
\text { (1998) }\end{array}$ & $19 / 16$ & 7 dias & D & $\begin{array}{c}\text { Tarefas de alto nível verbal, } \\
\text { sequenciamento de um material } \\
\text { visual complexo, memória visual } \\
\text { (tardia) e geração verbal de } \\
\text { palavras }\end{array}$ & Velocidade visomotora \\
\hline $\begin{array}{l}\text { Selby e Azrin } \\
\text { (1998) }\end{array}$ & $60 / 138$ & $\begin{array}{l}1080 \text { dias } \\
\text { (3 anos) }\end{array}$ & $A-D$ & ---- & ---- \\
\hline $\begin{array}{l}\text { Bolla et al. } \\
\text { (1999) }\end{array}$ & $30 / 21$ & 28 dias & A & $\begin{array}{c}\text { funções executivas, } \\
\text { visuopercepção, velocidade } \\
\text { psicomotora e destreza manual. }\end{array}$ & ---- \\
\hline $\begin{array}{l}\text { Cunha et al. } \\
\qquad(2001)\end{array}$ & $7 / 0$ & 31 dias & D & $\begin{array}{l}\text { atenção, memória visual, memória } \\
\text { verbal, funções executivas, } \\
\text { capacidade de aprendizagem e } \\
\text { coordenação visomotora }\end{array}$ & ---- \\
\hline $\begin{array}{l}\text { Toomey et al. } \\
\text { (2003) }\end{array}$ & $10 / 50$ & $\begin{array}{l}365 \text { dias } \\
(1 \text { ano })\end{array}$ & A & Atenção e funções motoras & Vigilância \\
\hline $\begin{array}{l}\text { Cunha et al. } \\
(2004)\end{array}$ & $15 / 15$ & 14 dias & $\mathrm{D}$ & $\begin{array}{l}\text { atenção, memória (visual e verbal), } \\
\text { capacidade de aprendizagem e } \\
\text { fluência verbal (fonológica) }\end{array}$ & ---- \\
\hline
\end{tabular}

\section{LEGENDA:}

* Estudo realizado com indivíduos esquizofrênicos, com e sem história de abuso de cocaína.

** Quanto ao padrão de uso: D=Dependentes; A=Abusadores; U=Usuários, sem especificação.

*** $O$ traço (----) significa que não foram encontradas alterações significativas. 
A maioria dos estudos que investigaram o funcionamento cognitivo em abusadores de cocaína relatou déficits neuropsicológicos. No entanto, o padrão de prejuízo descrito difere em cada estudo. Embora déficits de atenção, memória verbal e abstração sejam os mais freqüentemente observados, uma ampla faixa de déficits cognitivos têm sido vistos nesta população (Gillen et al., 1998). Há duas hipóteses para isso: ou realmente não se conseguiu ainda avaliar os reais déficits neuropsicológicos da droga, devido às dificuldades metodológicas, ou o abuso crônico da cocaína estaria mesmo relacionado a alterações cognitivas variáveis de um indivíduo para outro, como sugere o padrão multifocal de hipoperfusão cerebral encontrado nestes pacientes (Strickland et al., 1993; Nicastri et al., 2000).

Entre os problemas encontrados na avaliação de prejuízos cognitivos devido ao consumo crônico de substâncias estão o uso de múltiplas drogas pelos pacientes, exposição aos adulterantes e o impacto da via de administração (Carlin e O'Malley, 1996). Quantidade e duração do uso, tempo de abstinência, sensibilidade dos testes, falta de grupo controle, amostras pequenas, falta de controle da idade e nível de inteligência pré-mórbido também devem ser considerados nas pesquisas realizadas (Bolla et al. 1999), além da variedade de instrumentos e os diferentes métodos empregados para a interpretação dos resultados obtidos. Outro fator a ser considerado é a presença de sintomas relacionados ao TDAH na infância dos dependentes, principalmente porque este transtorno afeta cerca de $40 \%$ dos abusadores de 
cocaína (Rousanville et al., 1991), e, por si só, já seria suficiente para alterar o desempenho dos indivíduos em testes neuropsicológicos (Barkley, 1997; Toomey et al., 2003).

Diante dos dados apresentados, verifica-se que há a necessidade de um número maior de estudos metodologicamente controlados, para a verificação dos reais déficits neuropsicológicos decorrentes da dependência de cocaína. 


\section{OBJETIVOS}

O objetivo principal do presente estudo foi avaliar o desempenho neuropsicológico de sujeitos dependentes de cocaína durante a abstinência e comparar com um grupo controle sem diagnóstico atual ou prévio de abuso ou dependência de substâncias. Também foram examinadas correlações entre o desempenho dos sujeitos nos testes neuropsicológicos e o padrão de uso da droga, sintomas depressivos e ansiosos. 


\section{MÉTODOS}

\subsection{Casuística}

Todos os sujeitos que participaram da pesquisa concordaram em participar do estudo e assinaram um termo de consentimento livre e esclarecido, indicando a autorização e a compreensão de todos os aspectos da investigação, conforme a Resolução № 196/96 sobre a pesquisa envolvendo seres humanos do Conselho Nacional de Saúde (1996). Os detalhes da pesquisa foram explicados pelo mesmo profissional que ulteriormente aplicou a bateria de testes neuropsicológicos.

O grupo experimental (GE) foi composto por 30 dependentes de cocaína, do sexo masculino, sendo 20 pacientes do programa de tratamento realizado pelo Grupo Interdisciplinar de Estudos de Álcool e Drogas (GREA) do Instituto de Psiquiatria da Faculdade de Medicina da Universidade de São Paulo (IPq-HC-FMUSP) e mais 10 residentes da Associação Promocional Oração e Trabalho (APOT - Campinas/SP), uma comunidade terapêutica que oferece tratamento para dependência química, baseado no princípio dos 12 passos, em regime de internação voluntária. Todos os integrantes do GE preenchiam os critérios do DSM-IV (APA, 1994) para dependência de cocaína, que incluem a presença de um padrão mal-adaptativo de uso da substância, levando a comprometimento ou sofrimento clinicamente significativo, manifestado por três (ou mais) dos seguintes critérios: 
(1) tolerância (necessidade de quantidades cada vez maiores para obtenção do efeito desejado ou redução marcante do efeito com o uso continuado);

(2) abstinência (síndrome de abstinência característica ou a mesma substância é consumida para aliviar ou evitar sintomas da abstinência);

(3) a substância é consumida freqüentemente em maiores quantidades ou por um período mais longo do que o pretendido;

(4) desejo persistente ou esforços mal-sucedidos no sentido de reduzir ou controlar o uso;

(5) muito tempo é gasto em atividades necessárias para a obtenção da droga, utilização da substância ou na recuperação de seus efeitos;

(6) importantes atividades sociais, ocupacionais ou recreativas são abandonadas ou reduzidas em virtude do uso da substância;

(7) o uso da substância continua, apesar da consciência de ter um problema físico ou psicológico persistente ou recorrente que tende a ser causado ou exacerbado pela substância.

Os critérios de exclusão foram os seguintes:

(1) atraso no desenvolvimento neuropsicomotor (DNPM);

(2) relato de outros diagnósticos psiquiátricos do eixo I do DSM-IV (APA, 1994), tais como transtorno bipolar de humor e esquizofrenia;

(3) uso atual de medicamentos psicoativos; 
(4) história de traumatismo craniencefálico (TCE) ou outros distúrbios neurológicos;

(5) relato de problemas médicos que comprometam o sistema nervoso central (SNC), como hipertensão arterial e diabetes;

(6) história de distúrbio de aprendizagem, retardo mental ou freqüência em classes especiais;

O grupo controle (GC) foi constituído de 32 indivíduos, do sexo masculino, recrutados na comunidade. Os critérios de exclusão para esse grupo foram:

(1) dependência de qualquer substância psicoativa segundo os critérios do DSM-IV (APA, 1994);

(2) demais critérios do GE.

\subsection{Procedimentos}

Todos os sujeitos foram encaminhados para uma entrevista inicial, semi-dirigida, em que se buscou: 1) estabelecer bom contato com o sujeito; 2) esclarecer os principais aspectos da pesquisa; 3) convidar o indivíduo e obter o seu consentimento para a participação no estudo; 4) avaliar a história de cada um e os critérios de inclusão/exclusão do estudo; e 5) aplicar os seguintes questionários: Questionário de Triagem Psiquiátrica - SRQ-20 (Mari e Williams, 1986), Inventário de Depressão de Beck - IDB (Beck et al., 1982), Inventário de Ansiedade - Traço - Estado - IDATE (Gorenstein e Andrade, 1996), Escala de 
Intensidade da Dependência de Cocaína (Washton, 1989; Leite, 1999) e Perfil do Consumo de Cocaína (Washton, 1989; Leite, 1999)¹.

Questionário de Triagem Psiquiátrica - SRQ-20 (Mari e Williams, 1986), Escala de Ajustamento Social (Gorenstein et al., 2001), Critérios de Utah para avaliação do Déficit de Atenção em Adultos (Wender et al., 1981) e Escala de Wender-Utah para exame de sintomas de TDAH na infância (Ward et al., 1993; McCann et al., 2000); Auto ESA - Escala de Acompanhamento de Alcoolistas e Farmacodependentes (Andrade, 1991; Castel e Formigoni, 1999).

\subsection{Bateria Neuropsicológica}

Para elaboração da bateria neuropsicológica, procurou-se escolher testes com condições de avaliar um amplo espectro de capacidades cognitivas, no mais curto período de tempo possível. Ela teve a duração de aproximadamente três horas e a aplicação foi preferencialmente efetuada em um dia, buscando-se evitar o risco de desistência do sujeito no decorrer da testagem. A bateria foi aplicada por um profissional da área de Psicologia e autor do presente trabalho, com treinamento específico em avaliação neuropsicológica. Foram avaliadas as seguintes áreas do funcionamento cognitivo, com os seguintes instrumentos²:

Atenção e funções executivas: Trail Making Test (TMT), Stroop Color

\footnotetext{
${ }^{1}$ Essas duas últimas escalas serão aplicadas somente para os sujeitos do GE.

2 As folhas de respostas dos testes estão no Anexo 4.2. (pág. 86), enquanto uma descrição pormenorizada dos instrumentos se encontra no Apêndice. A maioria dos testes foram traduzidos e adaptados por Cândida H. P. Camargo, neuropsicóloga que na época exercia a função de Diretora do Serviço de Psicologia do IPq-HC-FMUSP.
} 
Word Test (Stroop) e Dígitos Diretos (DD) e Indiretos (DI) - Wechsler Memory Scale-Revised - WMS-R (Wechsler, 1987), Wisconsin Card Sorting Test (WCST) (Heaton et al., 1993) - versão reduzida, com 64 cartões (Haaland et al., 1987) e a versão adaptada da Bateria de Avaliação Frontal ${ }^{3}$ (Dubois et al., 2000; Cunha \& Novaes, 2004).

Memória: Memória Verbal: Memória Lógica (ML) - WMS-R (Wechsler, 1987); Memória Visual: Reprodução Visual (RV) - WMS-R (Wechsler, 1987) e Evocação Tardia (30 min) da Figura Complexa de Rey (ROCF) (Rey, 1999)

Processos de aprendizagem: Buschke Selective Reminding Test (BSRT).

Funções motoras: Desenhos alternados (Luria) e Códigos - WAIS-R (Wechsler, 1981)

Funções viso-espaciais (praxia construtiva): Cópia da ROCF (Rey, 1999) e Cubos - WAIS-R (Wechsler, 1981)

Linguagem: Vocabulário - WAIS-R (Wechsler, 1981), Controlled Oral Word Association Test (COWAT - Fluência verbal) e Boston Naming Test (BNT).

Tomada de Decisão: lowa Gambling Task ${ }^{4}$ (Bechara et al., 1994).

Além disso, alguns pacientes do GREA foram submetidos a exames de neuroimagem (SPECT), para verificação de possíveis correlações entre

\footnotetext{
${ }^{3}$ Teste novo, incluído pelas evidências recentes de envolvimento de problemas em áreas frontais na dependência química (Goldstein e Volkow, 2002) e por sua efetividade nos casos avaliados (Cunha e Nicastri, 2004).

${ }^{4}$ Outro instrumento recentemente desenvolvido, para avaliação pré-frontal, que tem sido importante na avaliação de problemas cognitivos em dependentes de substâncias (Grant et al., 2000; Bechara et al., 2001; Bolla et al., 2003).
} 
desempenho neuropsicológico e alterações de perfusão cerebral nestes indivíduos.

4.4. Forma de análise dos resultados

Foram então efetuados estudos e comparações entre as amostras estudadas, e a seqüência da análise foi a seguinte:

1) Análise de cada teste aplicado, comparando-se o GC com o GE.

2) Busca da relação entre a quantidade de droga utilizada e tempo de consumo com o desempenho dos sujeitos.

3) Estudo da relação entre sintomas depressivos e ansiosos encontrados e os resultados dos testes aplicados.

Quanto à análise estatística, as comparações entre os grupos de pacientes e controles foram feitas por meio de testes $t$ de Student para amostras independentes (no caso variáveis contínuas) ou pelo teste exato de Fisher (para variáveis categóricas).

Correlações entre resultados das aplicações das escalas foram avaliadas por meio do coeficiente de correlação de Spearman $\left(r_{s}\right)$. O nível de significância estatística adotado nesse estudo é de 0,05 e todos os testes estatísticos empregados eram bicaudais. As análises foram realizadas utilizando-se o programa SPSS, versão 10.0. 


\section{RESULTADOS}

No total, foram analisados os dados de 30 pacientes: destes, 20 eram provenientes do programa de tratamento oferecido pelo GREA (São Paulo, SP) e 10 da APOT (Campinas, SP). Para comparação, foram avaliados 32 voluntários pertencentes ao GC, os quais foram recrutados da comunidade.

\subsection{Dados sócio-demográficos}

Os dados referentes a informações sócio-demográficas e intelectuais de pacientes e controles encontram-se sumarizados nas tabelas 2 e 3 .

TABELA 2. IDADE, ESCOLARIDADE, RENDA FAMILIAR MENSAL E NÍVEL INTELECTUAL.

\begin{tabular}{|c|c|c|c|}
\hline & $\begin{array}{l}\text { Pacientes (GE) } \\
\text { Média (DP) } \\
(n=30)\end{array}$ & $\begin{array}{l}\text { Controles (GC) } \\
\text { Média (DP) } \\
(n=32)\end{array}$ & p* \\
\hline Idade (anos) & $27,17(7,64)$ & $26,75(5,55)$ & 0,808 \\
\hline Escolaridade (anos de estudo) & $9,93(2,74)$ & $10,78(2,20)$ & 0,186 \\
\hline Renda Familiar Mensal (R\$) & $2.452,66(1.918,37)$ & $2.135,00(1.711,40)$ & 0,495 \\
\hline Quociente Intelectual (QI) & $95,87(11,62)$ & $101,06(12,82)$ & 0,099 \\
\hline \multicolumn{4}{|c|}{$\begin{array}{l}\text { Notas: } \mathrm{DP}=\text { desvio padrão; } \mathrm{GE}=\text { Grupo Experimental; } \mathrm{GC}=\text { Grupo Controle } \\
* \text { teste t de Student para amostras independentes }\end{array}$} \\
\hline
\end{tabular}


TABELA 3. SEXO, ETNIA, NÍVEL SÓCIO-ECONÔMICO E LATERALIDADE

\begin{tabular}{lcccc}
\hline Variável & Categorias & $\begin{array}{c}\text { Pacientes (GE)* } \\
(\mathbf{n = 3 0 )}\end{array}$ & $\begin{array}{c}\text { Controles (GC)* } \\
(\mathbf{n = 3 2 )}\end{array}$ & p \\
\hline \multirow{2}{*}{ Etnia } & Branca & $27(90 \%)$ & $27(84,4 \%)$ & 0,709 \\
& Negra & $3(10 \%)$ & $5(15,6 \%)$ & \\
Nível sócio-econômico & Classes A e B & $10(33,3 \%)$ & $12(37,5 \%)$ & 0,795 \\
& Classes C e D & $20(66,7 \%)$ & $20(62,5 \%)$ & \\
Lateralidade & Destros & $28(93,3 \%)$ & $26(81,3 \%)$ & 0,258 \\
& Canhotos/Ambidestros & $2(6,7 \%)$ & $6(18,7 \%)$ & \\
& & &
\end{tabular}

Notas: * os números nas colunas Pacientes e Controles correspondem ao número de indivíduos em cada categoria e porcentagem (entre parênteses)

- Teste exato de Fisher.

$\mathrm{GE}=$ Grupo Experimental; GC = Grupo Controle

\# Não houve cálculo estatístico porque todos eram do sexo masculino.

Não houve diferenças significantes, sob o ponto de vista estatístico, para as variáveis gênero, etnia, nível sócio-econômico e lateralidade dos participantes (Tabela 3). 


\subsection{Sintomas Psiquiátricos}

Os indivíduos foram avaliados também através dos instrumentos SRQ20, IDB e IDATE, que foram aplicados a partir da segunda semana de abstinência para os pacientes do GE, e juntamente com a bateria neuropsicológica para os sujeitos do GC. As médias e desvios padrão do GE e GC obtidos na avaliação feita por meio de cada Inventário encontram-se na tabela abaixo (Tabela 4).

TABELA 4. SINTOMAS PSIQUIÁTRICOS

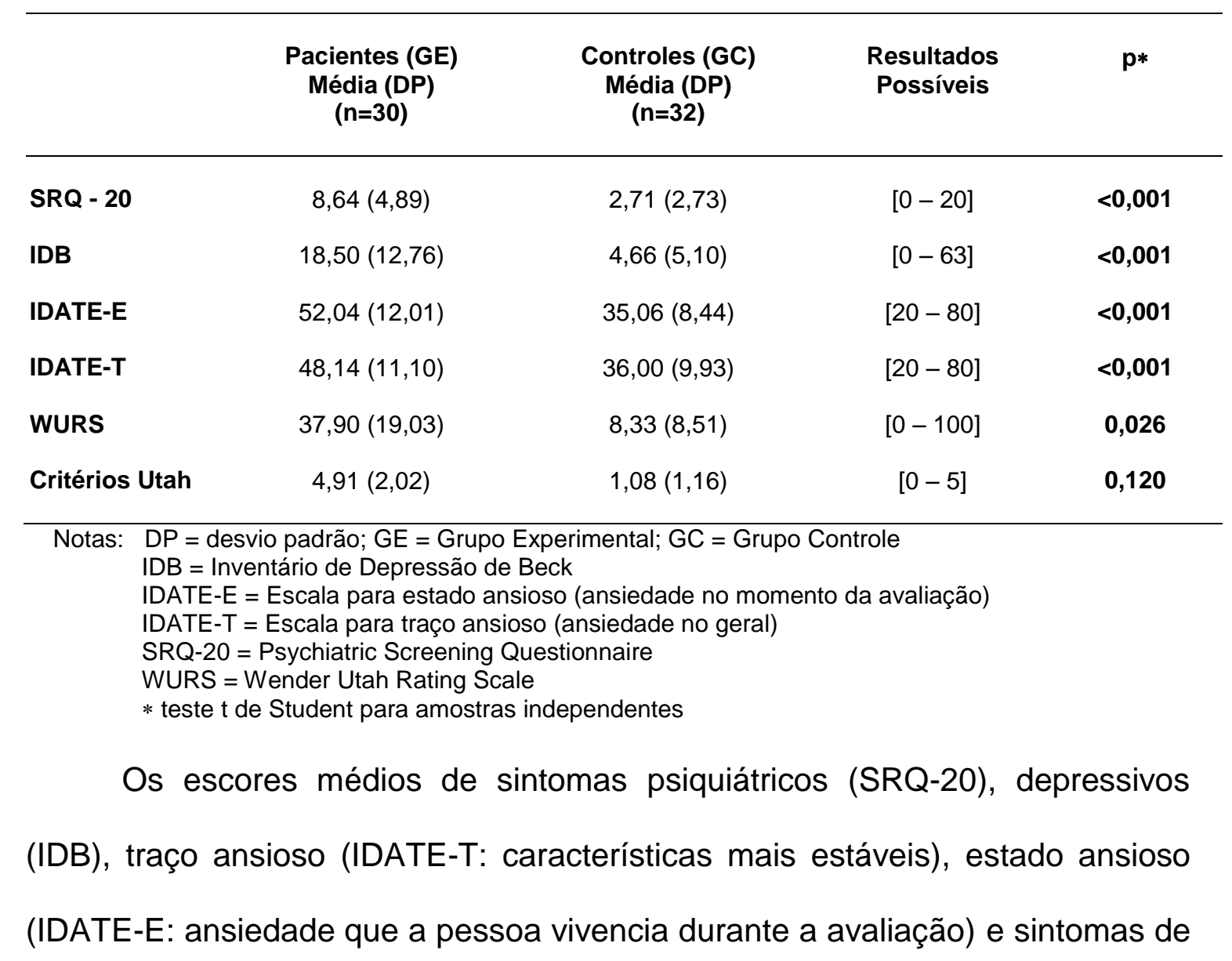


TDAH na infância (WURS) foram significativamente mais altos nos pacientes dependentes de cocaína do que nos indivíduos do grupo controle $(p<0,01)$. 
5.3. Perfil e Padrão de consumo de Cocaína e outras drogas pelo GE

O GE respondeu, também, aos seguintes instrumentos: Perfil do Consumo de Cocaína e Escala de Intensidade da Dependência de Cocaína, para a caracterização das informações a respeito do padrão de consumo de cocaína de cada paciente. Esses dados encontram-se sumarizados nas Tabelas 5 e 6.

TABELA 5. PADRÃO DE CONSUMO DE COCAÍNA PELO GE (1)

\begin{tabular}{|c|c|c|c|}
\hline CONSUMO DE COCAÍNA/CRACK & & $\mathbf{N}$ & $\%$ \\
\hline Via inicial da cocaína & $\begin{array}{l}\text { Cheirada (pó) } \\
\text { Fumada (crack) }\end{array}$ & $\begin{array}{c}25 \\
5\end{array}$ & $\begin{array}{l}83,3 \% \\
16,7 \%\end{array}$ \\
\hline Uso na vida de cocaína fumada (crack) & & 29 & $96,7 \%$ \\
\hline Uso na vida de cocaína injetável & & 8 & $26,7 \%$ \\
\hline \multirow{3}{*}{ Via(s) de Uso Atual } & Fumada ("Crack") & 16 & $53,3 \%$ \\
\hline & Ambas ("Crack" e "Pó") & 8 & $26,7 \%$ \\
\hline & Cheirada (“Pó”) & 6 & $20,0 \%$ \\
\hline Uso compulsivo ("binges") & & 19 & $63,3 \%$ \\
\hline \multirow[t]{4}{*}{ Período do dia* } & Noite (início) & 24 & $80,0 \%$ \\
\hline & Noite (madrugada) & 23 & $76,7 \%$ \\
\hline & Tarde & 16 & $53,3 \%$ \\
\hline & Manhã & 9 & $30,0 \%$ \\
\hline \multicolumn{4}{|l|}{ Situação de consumo* } \\
\hline \multirow[t]{4}{*}{ Companhia } & Com amigos & 21 & $70,0 \%$ \\
\hline & Sozinho & 20 & $66,7 \%$ \\
\hline & Com a esposa (cônjuge) & 6 & $20,0 \%$ \\
\hline & Outra(o) Parceira(o) Sexual & 2 & $6,7 \%$ \\
\hline \multirow[t]{2}{*}{ Local } & Em casa & 19 & $63,3 \%$ \\
\hline & $\begin{array}{l}\text { Nas festas } \\
\text { No trabalho }\end{array}$ & $\begin{array}{c}11 \\
5\end{array}$ & $\begin{array}{l}36,7 \% \\
16,7 \%\end{array}$ \\
\hline
\end{tabular}

Notas: nos itens marcados com (*) os pacientes poderiam fornecer mais de uma resposta $\mathrm{GE}=$ Grupo Experimental: dependentes de cocaína 
A grande maioria dos pacientes $(83,3 \%)$ iniciou o uso de cocaína pela via aspirada (pó), e quase todos experimentaram a via fumada, mais conhecida como crack $(96,7 \%)$. Cerca de um quarto dos pacientes chegou a usar cocaína na forma injetável $(26,7 \%)$, porém a via atual mais utilizada foi a fumada (53,3\%), ou o crack em combinação com a inalada (26,7\%). Apenas a parcela de $20 \%$ relatou preferência ao uso inalado da droga.

Quanto à maneira de uso, a maioria $(63,3 \%)$ revelou já ter feito padrão compulsivo de consumo, caracterizado pelo uso continuado e ininterrupto, até que a droga disponível acabe ("binges"). O uso de cocaína, na amostra avaliada, mostrou-se predominante no período noturno, tanto no início da noite (80\%), como na madrugada (76,7\%). Uma parcela significativa dos usuários costumava usar a droga no período da tarde $(53,3 \%)$ e $30 \%$ consumia cocaína logo pela manhã.

A maior parte dos dependentes de cocaína tinha o costume de usar a droga na própria casa $(63,3 \%)$, enquanto $36,7 \%$ usava nas festas, e $16,7 \%$, no trabalho.

Quanto às características de uso da droga e dados sócio-demográficos, não foram encontradas diferenças estatisticamente significantes entre os pacientes provenientes do GREA e da APOT. 
TABELA 6. CARACTERÍSTICAS DO CONSUMO DE COCAÍNA PELO GE (2)

\begin{tabular}{lccccc}
\hline CONSUMO DE COCAíNA/CRACK & Média & Mediana & DP & Mínimo & Máximo \\
\hline Idade do primeiro consumo & 18,93 & 17,00 & 5,64 & 13,00 & 34,00 \\
Progressão para uso regular (meses) & 23,20 & 24,00 & 25,25 & 0,00 & 108,00 \\
Tempo de uso (anos) & 8,23 & 7,50 & 5,27 & 1,00 & 23,00 \\
Gasto semanal (R\$) & 313,00 & 180,00 & 390,84 & 50,0 & $1.500,00$ \\
Gramas de cocaína/crack por semana & 18,73 & 10,00 & 14,94 & 3,00 & 60,00 \\
Dias de consumo por semana & 5,03 & 5,00 & 1,88 & 2,00 & 7,00 \\
Escore obtido na EIC & 25,52 & 25,00 & 6,66 & 11,00 & 36,00 \\
\hline
\end{tabular}

Notas: DP = desvio padrão; EIC = Escala de Intensidade da Dependência de Cocaína (consumo); resultados possíveis variam de 0 a 38 (quanto maior o número, pior a intensidade). $\mathrm{GE}=$ Grupo Experimental: dependentes de cocaína

A idade do primeiro consumo, dos pacientes avaliados, tanto do GREA como da APOT, foi em média 18,93 anos; a progressão para uso regular ocorreu em média 23,2 meses (cerca de dois anos) após o primeiro consumo. De acordo com os dados, os dependentes de cocaína utilizaram a substância por cerca de 8,23 anos $( \pm 7,5)$, e o consumo médio, por semana, era de 18,73 gramas, correspondendo a um dispêndio, em dinheiro, de $\mathrm{R} \$ 313,00$ durante este período. No mínimo, encontrou-se o gasto semanal de $\mathrm{R} \$ 50,00$, chegando até a $R \$ 1.500,00$, o que corresponderia a $R \$ 6.000,00$ por mês, direcionados para a compra da cocaína.

$\mathrm{Na}$ tabela 7 , pode-se observar o consumo de outras drogas pelos integrantes do GE. 
TABELA 7. PADRÃO DE CONSUMO DE ÁLCOOL, TABACO E OUTRAS DROGAS PELO GE* $(\mathrm{N}=28)$

\begin{tabular}{|c|c|c|c|}
\hline Substância & Padrão de Uso & $\mathbf{N}$ & $\%$ \\
\hline \multirow[t]{2}{*}{ Álcool } & $\begin{array}{l}\text { Não houve consumo } \\
\text { Consumo menor ou igual a duas doses por dia }\end{array}$ & $\begin{array}{c}9 \\
11\end{array}$ & $\begin{array}{l}32,1 \% \\
39,3 \%\end{array}$ \\
\hline & Consumo maior que duas doses por dia & 8 & $28,6 \%$ \\
\hline \multirow[t]{3}{*}{ Tabaco } & Não houve consumo & 8 & $28,6 \%$ \\
\hline & Menos que 20 cigarros por dia & 7 & $25,0 \%$ \\
\hline & De 20 a 40 cigarros por dia & 13 & $46,4 \%$ \\
\hline \multirow[t]{3}{*}{ Maconha } & Não houve consumo & 9 & $32,1 \%$ \\
\hline & Menos freqüente que diário & 9 & $32,1 \%$ \\
\hline & Consumo diário & 10 & $35,8 \%$ \\
\hline \multirow[t]{3}{*}{ Benzodiazepínicos } & Não houve consumo & 21 & $75 \%$ \\
\hline & Consumo esporádico (de um a cinco comprimidos no mês) & 5 & $14,3 \%$ \\
\hline & De um a dois comprimidos (por dia) & 3 & $10,7 \%$ \\
\hline \multirow[t]{2}{*}{ Anfetaminas } & Não houve consumo & 27 & $96,4 \%$ \\
\hline & Consumo esporádico (de um a dois comprimidos no mês) & 1 & $3,6 \%$ \\
\hline \multirow[t]{2}{*}{ LSD } & Não houve consumo & 27 & $96,4 \%$ \\
\hline & Consumo eventual (um "papel" no mês) & 1 & $3,6 \%$ \\
\hline Heroína & Não houve consumo & 28 & $100 \%$ \\
\hline
\end{tabular}

Notas: * Uso nos últimos 30 dias $(\mathrm{n}=28)$

- Cada dose $=12 \mathrm{~g}$ de álcool

$\mathrm{GE}=$ Grupo Experimental: dependentes de cocaína

De acordo com os dados, é possível perceber que a grande maioria dos pacientes avaliados esteve classificada entre os que não beberam ou que beberam em pouca quantidade, no mês precedente ao tratamento. No entanto, grande parte dos pacientes fazia uso de tabaco diariamente, e quase metade da amostra de pacientes costumava fumar mais que um maço de cigarros por dia. Quanto ao uso de maconha, é possível perceber que a maior parte dos pacientes do GE não consumia ou fumava cannabis menos que diariamente. Grande parte não usava ou consumiram poucos comprimidos de 
benzodiazepínicos, ninguém havia usado heroína e apenas um utilizou LSD e, outro, anfetamina no mês anterior à pesquisa (Tabela 7).

TABELA 8. TRATAMENTOS ANTERIORES E PERÍODO DE ABSTINÊNCIA ANTERIOR (GE).

\begin{tabular}{lccccc}
\hline Tratamentos Anteriores & Média & Mediana & DP & Mínimo & Máximo \\
\hline Quantidade de & & & & & \\
Tratamentos Anteriores em DQ & 2,19 & 1,50 & 2,74 & 0 & 13 \\
Período dos Tratamentos em DQ (Meses) & 9,33 & 4,00 & 11,69 & 0,50 & 50,73 \\
Maior período em abstinência (semanas) & 22,77 & 8,00 & 31,21 & 0,00 & 110,00 \\
\hline \multicolumn{2}{l}{ Notas: DP = desvio padrão; GE = Grupo Experimental: dependentes de cocaína } \\
\end{tabular}

$\mathrm{Na}$ amostra estudada (Tabela 8), estavam presentes desde pacientes que nunca haviam recebido tratamento anterior para a dependência química (DQ), até um que já havia passado por 13 programas de acompanhamento em DQ. A média foi 2,19 $( \pm 2,74)$ tratamentos para cada indivíduo do GE. Quanto ao período, dentre os que estiveram em tratamento, encontrou-se a média de 9,33 $( \pm 11,69)$ meses. O maior período em que se mantiveram em abstinência, prévio ao tratamento atual, independente de tratamentos anteriores, esteve na média de $22,77( \pm 31,21)$ semanas ou cinco meses e meio. 


\subsection{Bateria Neuropsicológica}

A tabela 9 resume os testes usados para se avaliar atenção, flexibilidade mental, funções motoras e praxia construtiva (raciocínio viso-espacial).

\section{TABELA 9. DESEMPENHO EM TESTES DE ATENÇÃO, FUNÇÕES EXECUTIVAS, MOTORAS E PRAXIA CONSTRUTIVA}

\begin{tabular}{|c|c|c|c|c|c|}
\hline \multirow{3}{*}{$\begin{array}{l}\text { Função Testada } \\
\text { Atenção e } \\
\text { Funços Executivas }\end{array}$} & \multicolumn{2}{|l|}{ Testes Aplicados } & \multirow{2}{*}{$\begin{array}{c}\begin{array}{c}\text { Pacientes (GE) } \\
\text { Média (DP) } \\
(\mathbf{n}=30)\end{array} \\
5,30(2,09)\end{array}$} & \multirow{2}{*}{$\begin{array}{c}\begin{array}{c}\text { Controles (GC) } \\
\text { Média (DP) } \\
(\mathbf{n}=32)\end{array} \\
6,63(2,51)\end{array}$} & \multirow{2}{*}{$\begin{array}{c}\mathbf{p}^{*} \\
0,02\end{array}$} \\
\hline & Dígitos (WMS-R) & Diretos & & & \\
\hline & & Indiretos & $4,60(1,90)$ & $6,25(2,36)$ & $<0,01$ \\
\hline & TMT (Trail) & parte $\mathrm{A}$ & $34,00(15,89)$ & $29,35(11,58)$ & 0,19 \\
\hline & & parte B & $87,20(40,31)$ & $73,40(43,59)$ & 0,20 \\
\hline & SCWT (Stroop) & parte 1 & $16,06(9,09)$ & $14,58(4,22)$ & 0,42 \\
\hline & & parte 2 & $19,40(6,10)$ & $17,29(4,71)$ & 0,13 \\
\hline & & parte 3 & $29,46(9,69)$ & $26,08(8,88)$ & 0,15 \\
\hline & $\mathrm{FAB}$ & total & $15,07(1,41)$ & $16,65(1,25)$ & 0,01 \\
\hline & WCST & Corretas & $44,03(7,73)$ & $43,84(9,15)$ & 0,93 \\
\hline & & Erros & $19,83(7,90)$ & $19,78(9,10)$ & 0,98 \\
\hline & & $\begin{array}{l}\text { Erros } \\
\text { Perseverativos }\end{array}$ & $10,03(4,96)$ & $10,22(5,57)$ & 0,89 \\
\hline & & Perdas de set & $0,73(0,87)$ & $0,63(0,79)$ & 0,61 \\
\hline & & Categorias & $2,63(1,25)$ & $2,72(1,30)$ & 0,79 \\
\hline & IGT & Net score & $-7,33(15,76)$ & $8,83(19,70)$ & 0,04 \\
\hline \multirow[t]{2}{*}{ Funções Motoras } & $\mathrm{DA}$ & Corretos & $2,62(0,49)$ & $2,78(0,49)$ & 0,20 \\
\hline & Códigos (WAIS-R) & & $41,28(9,90)$ & $48,88(12,43)$ & 0,01 \\
\hline \multirow[t]{2}{*}{ Praxia Construtiva } & Figura de Rey & Cópia & $32,63(4,15)$ & $34,20(2,06)$ & 0,06 \\
\hline & Cubos (WAIS-R) & & $29,07(8,00)$ & $33,06(11,30)$ & 0,11 \\
\hline
\end{tabular}

Notas: DP = desvio padrão; GE = Grupo Experimental; GC = Grupo Controle; WMS-R = Wechsler Memory Scale-Revised; TMT = Trail Making Test; SCWT = Stroop Color Word Test; FAB = Frontal Assessment Battery; WCST = Wisconsin Card Sorting Test; IGT = lowa Gambling Task; $\mathrm{DA}=$ Desenhos Alternados (Luria); WAIS-R = Wechsler Intelligence Scale for Adults-Revised * teste $\mathrm{t}$ de Student para amostras independentes (os números em negrito representam significação estatística). 
Foram observadas diferenças estatisticamente significantes $(p<0.05)$ em testes de atenção e coordenação psicomotora, incluindo dígitos diretos $(p<0.01)$, indiretos (WMS-R), funções executivas $(F A B)$, tomada de decisões (IGT) e códigos (WAIS-R).

Os resultados dos testes aplicados para a testagem de memória (verbal e visual) e aprendizagem encontram-se sumarizados na tabela 10.

TABELA 10. DESEMPENHO EM TESTES DE MEMÓRIA E APRENDIZAGEM (VERBAL E VISUAL)

\begin{tabular}{|c|c|c|c|c|c|c|c|}
\hline \multirow{2}{*}{$\begin{array}{l}\text { Função Testada } \\
\text { Memória e } \\
\text { Aprendizagem }\end{array}$} & \multicolumn{2}{|c|}{ Testes Aplicados } & \multicolumn{2}{|c|}{$\begin{array}{c}\text { Pacientes (GE) } \\
\text { Média (DP) } \\
(n=30)\end{array}$} & \multicolumn{2}{|c|}{$\begin{array}{l}\text { Controles (GC) } \\
\text { Média (DP) } \\
(\mathrm{n}=32)\end{array}$} & \multirow{2}{*}{\begin{tabular}{r}
\multicolumn{1}{c}{$\mathbf{p}^{\star}$} \\
$<0,01$ \\
$<0,01$
\end{tabular}} \\
\hline & ML (WMS-R) & $\begin{array}{l}\text { parte } 1 \\
\text { parte } 2\end{array}$ & \multicolumn{2}{|c|}{$\begin{array}{ll}22,83 & (6,04) \\
17,83 & (5,09)\end{array}$} & \multicolumn{2}{|c|}{$\begin{array}{ll}27,28 & (5,98) \\
23,38 & (6,26)\end{array}$} & \\
\hline & RV (WMS-R) & parte 1 & 31,57 & $(7,04)$ & 35,97 & $(5,63)$ & $<0,01$ \\
\hline & & parte 2 & 23,73 & $(8,94)$ & 31,94 & $(9,35)$ & $<0,01$ \\
\hline & Figura de Rey & & 16,81 & $(7,18)$ & 21,62 & $(6,03)$ & $<0,01$ \\
\hline & SRT & Recuperação & 110,59 & $(14,95)$ & 123,16 & $(11,43)$ & $<0,01$ \\
\hline & & LTR & 101,52 & $(21,49)$ & 118,16 & $(13,78)$ & $<0,01$ \\
\hline & & STR & 9,00 & $(7,79)$ & 5,34 & $(3,37)$ & 0,01 \\
\hline & & LTS & 112,38 & $(19,84)$ & 124,13 & $(9,14)$ & $<0,01$ \\
\hline & & CLTR & 69,07 & $(28,90)$ & 101,63 & $(27,01)$ & $<0,01$ \\
\hline & & RLTR & 32,66 & $(16,21)$ & 16,19 & $(14,20)$ & $<0,01$ \\
\hline & & REMINDER & 33,28 & $(15,10)$ & 20,00 & $(11,19)$ & $<0,01$ \\
\hline & & Após Distração & 9,69 & $(2,35)$ & 11,16 & $(1,08)$ & $<0,01$ \\
\hline & & Reconhecimento & 11,97 & $(0,19)$ & 12,00 & $(0,00)$ & 0,29 \\
\hline & & Intrusões & 2,03 & $(2,18)$ & 1,66 & $(1,75)$ & 0,45 \\
\hline
\end{tabular}

Notas: DP = desvio padrão; GE = Grupo Experimental; GC = Grupo Controle; ML = Memória Lógica; RV = Reprodução Visual; WMS-R = Wechsler Memory Scale-Revised; SRT = Selective Reminding Test; LTR = Long Term Retrieval; STR = Short Term Retrieval; LTS = Long Term Storage; CLTR = Consistent Long Term Retrieval; RLTR = Randomic Long Term Retrieval;

* teste $\mathrm{t}$ de Student para amostras independentes (os números em negrito representam significação estatística). 
Obs: importante ressaltar que nos itens STR, RLTR, REMINDER e Intrusões do SRT, quanto menor o número, melhor o desempenho dos indivíduos testados.

Quanto à memória, o desempenho do GE esteve significativamente rebaixado quando comparado ao $\mathrm{GC}$, tanto no campo verbal como visual (ML I e II, RV I e II, Recuperação da Figura de Rey e SRT).

TABELA 11. DESEMPENHO NOS TESTES DE LINGÜAGEM

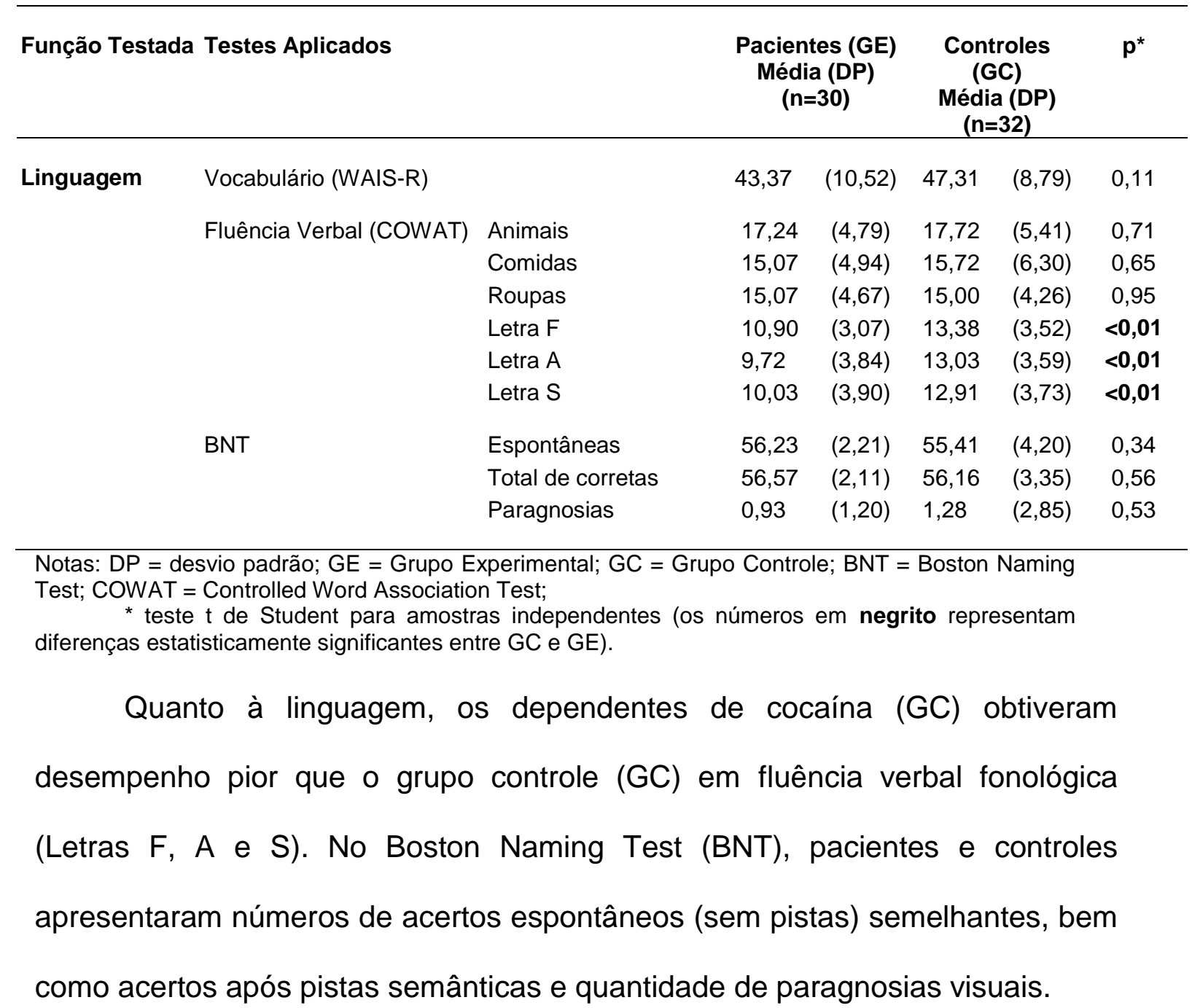


5.5. Correlações entre desempenho cognitivo e sintomas depressivos e ansiosos

Todos os testes neuropsicológicos foram correlacionados com os resultados das escalas utilizadas para a avaliação de sintomas depressivos e ansiosos. Na tabela 12, está representada a análise de correlação entre resultados de testes neuropsicológicos e escores para depressão e ansiedade $(p<0,05)$.

TABELA 12. CORRELAÇÃO ENTRE DESEMPENHO NEUROPSICOLÓGICO E SINTOMAS DEPRESSIVOS, ANSIOSOS E DE TDAH DOS PACIENTES (GE)

\begin{tabular}{|c|c|c|c|c|c|}
\hline \multirow{3}{*}{$\begin{array}{l}\text { Função Testada } \\
\begin{array}{l}\text { Atenção/Concentração } \\
\text { Praxia Construtiva }\end{array}\end{array}$} & \multicolumn{2}{|c|}{ Testes Aplicados } & \multirow{3}{*}{$\begin{array}{c}\text { IDB } \\
\text { Sintomas } \\
\text { Depressivos } \\
\\
-0,427 \\
-0,405\end{array}$} & \multirow{2}{*}{$\begin{array}{l}\text { IDATE-T } \\
\text { Traço } \\
\text { Ansioso }\end{array}$} & \multirow{2}{*}{$\begin{array}{l}\text { TDAH } \\
\text { (Utah) }\end{array}$} \\
\hline & Dígitos (WMS-R) & Diretos (DD) & & & \\
\hline & Figura de Rey & Cópia & & & \\
\hline & Cubos (WAIS-R) & & $-0,495$ & & \\
\hline Memória e Aprendizagem & ML (WMS-R) & parte 2 & $-0,439$ & & \\
\hline \multirow[t]{4}{*}{ Linguagem } & Vocabulário & (WAIS-R) & $-0,470$ & & \\
\hline & Fluência Verbal & Comidas & & $-0,399$ & \\
\hline & & Roupas & $-0,402$ & & \\
\hline & BNT & Espontâneas & $-0,378$ & & \\
\hline Tomada de decisão & IGT & Net score & & & $-0,606$ \\
\hline $\begin{array}{l}\text { Notas: O corpo da tabe } \\
\text { ilustradas apenas as cor } \\
\text { (IDATE-E) não mostr } \\
\text { neuropsicológicos. } \\
\text { GE = Grupo Experiment } \\
\mathrm{ML}=\text { Memória Lógica } \\
\text { Intelligence Scale - Revis }\end{array}$ & $\begin{array}{l}\text { representa valor } \\
\text { ações estatisticar } \\
\text { Im correlação } \\
\text { IDB }=\text { Inventário } \\
\text { VMS-R = Wech }\end{array}$ & $\begin{array}{l}\text { de coeficiente } \\
\text { te significante } \\
\text { atisticamente } \\
\text { Depressão de } \\
\text { Memory Sc }\end{array}$ & $\begin{array}{l}\text { e correlaçã } \\
\text { gnificante } \\
\text { gnifinte } \\
\text { k; IDATE-T } \\
\text { - Revised; }\end{array}$ & $\begin{array}{l}\text { Spearn } \\
\text { res par } \\
\text { nenhl }\end{array}$ & $\begin{array}{l}\text { is). Foram } \\
\text { do ansioso } \\
\text { os testes }\end{array}$ \\
\hline
\end{tabular}

Observa-se, através da tabela, que dentre os sintomas analisados, não houve correlações fortes ( $R_{s}>0,7$ ou $R_{s<-0,7)}$ dos sintomas depressivos e 
ansiosos com o desempenho neuropsicológico dos pacientes (GE). No entanto, os dados indicam baixa probabilidade de algumas correlações serem nulas, como, por exemplo, entre sintomas depressivos e DD (WMS-R), Cópia da Figura de Rey, Cubos (WAIS-R), ML Parte 2 (WMS-R), Vocabulário (WAIS-R), Fluência Verbal (roupas) e BNT (acertos espontâneos). Para os sintomas que indicavam estado ansioso (IDATE-E), não foram encontradas correlações estatisticamente significantes, mas para traço ansioso (IDATE-T), encontrou-se correlação significante, sob o ponto de vista estatístico, destes sintomas e Fluência Verbal (Comida). Os sintomas de TDAH atuais (critérios de Utah) também estiveram correlacionados com o desempenho no lowa Gambling Task, um instrumento de exame da tomada de decisão. Em todos os casos, foram encontradas correlações negativas, ou seja, na medida em que os sintomas depressivos, ansiosos ou de TDAH aumentam, observa-se um decréscimo nas funções cognitivas dos indivíduos do GE.

5.6. Correlações entre desempenho cognitivo e padrão de consumo de cocaína

$\mathrm{Na}$ tabela 13, estão agrupadas as variáveis referentes ao consumo de cocaína, levando em conta a quantidade consumida por semana (gramas), tempo de uso na vida (em anos) e tempo de abstinência em que se encontravam os dependentes de cocaína (em dias). 
TABELA 13. CORRELAÇÃO ENTRE DESEMPENHO NEUROPSICOLÓGICO E O PADRÃO DE CONSUMO DE COCAÍNA DOS PACIENTES (GE)

\begin{tabular}{|c|c|c|c|c|c|}
\hline \multirow{2}{*}{$\begin{array}{l}\text { Função Testada } \\
\begin{array}{l}\text { Atenção/Concentração } \\
\text { Praxia Construtiva }\end{array}\end{array}$} & \multicolumn{2}{|c|}{ Testes Aplicados } & \multirow{2}{*}{ 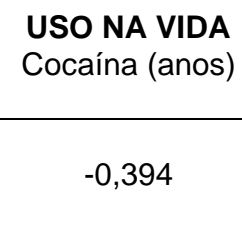 } & \multirow{2}{*}{$\begin{array}{l}\text { QUANTIDADE } \\
\text { Gramas por } \\
\text { Semana }\end{array}$} & \multirow{2}{*}{$\begin{array}{c}\text { ABSTINÊNCIA } \\
\text { Tempo (Dias) } \\
0,469 \\
0,408\end{array}$} \\
\hline & $\begin{array}{l}\text { Dígitos (WMS-R) } \\
\text { Cubos (WAIS-R) }\end{array}$ & Indiretos (DI) & & & \\
\hline Memória e & RV (WMS-R) & parte 1 & & & 0,377 \\
\hline \multirow[t]{3}{*}{ Aprendizagem } & SRT & Recuperação & $-0,479$ & & 0,373 \\
\hline & & REMINDER & 0,494 & & $-0,385$ \\
\hline & & $\begin{array}{l}\text { Após } \\
\text { Distração } \\
\text { Intrusões }\end{array}$ & $\begin{array}{l}-0,458 \\
0,472\end{array}$ & & \\
\hline Linguagem & Fluência Verbal & Animais & & 0,386 & \\
\hline
\end{tabular}

Notas: O corpo da tabela representa valores de coeficientes de correlação de Spearman $\left(\mathrm{R}_{\underline{s}}\right)$. Foram ilustradas apenas as correlações estatisticamente significantes $(p<0,05)$.

$\mathrm{GE}=$ Grupo Experimental; RV = Reprodução Visual; WMS-R = Wechsler Memory Scale - Revised; WAIS$\mathrm{R}=$ Wechsler Adult Intelligence Scale - Revised; SRT = Selective Reminding Test.

Constata-se, a partir da tabela 13, que não foram encontradas correlações fortes (Rs>0,7 ou Rs<-0,7) entre o padrão de uso de cocaína e o desempenho neuropsicológico dos pacientes. A despeito disso, algumas correlações encontradas foram estatisticamente significantes $(p<0,05)$. $O$ uso na vida de cocaína (em anos), por exemplo, parece exercer impacto negativo nos resultados em DI (WMS-R), Recuperação de Palavras (SRT) e Acertos após a distração (correlação negativa: quanto maior o uso, pior o desempenho). O tempo de uso esteve ainda correlacionado, positivamente, com os fatores Reminder (SRT) e Intrusões, o que significa que, quanto mais pesado o uso da droga, mais ajuda o paciente precisava do examinador (REMINDER) e mais palavras eram inventadas para tentar descobrir quais as palavras da lista (Intrusões). Já o consumo de drogas (gramas por semana) esteve levemente 
correlacionado ao número de palavras referentes a tipos de animais (fluência verbal), o que indicaria que quanto maior o uso, mais palavras foram verbalizadas pelos pacientes. O tempo de abstinência dos dependentes de cocaína, por sua vez, correlacionado positivamente a DI, Cubos (WAIS-R), RV I (WMS-R) e Recuperação de palavras (SRT), demonstra que quanto maior o tempo que o indivíduo fica sem a droga, melhor o desempenho obtido nos testes e ainda menores as chances de o paciente precisar de ajuda do examinador para a lembrança das palavras (correlação negativa entre tempo de uso e Reminder - SRT).

5.7. Resultados dos exames de SPECT dos pacientes dependentes de cocaína

Dentre os pacientes avaliados pelo GREA, que se encontravam internados no IPq-HC-FMUSP, foi possível a realização de exame de SPECT cerebral em seis deles. Destes, dois se encontravam alterados, e os outros quatro, não. Em um deles (Paciente 14), constatou-se irregularidade cortical difusa, não se observando déficit focal de perfusão cortical. No outro (Paciente 28), foi observada irregularidade perfusional cortical difusa, com déficit mais evidente na transição fronto-têmporo-parietal direita e na região têmporooccipital direita. 
5.8. Correlação entre os resultados de SPECT e desempenho neuropsicológico

Esta etapa da pesquisa demandou análises com refinamento estatístico mais detalhado quanto ao desempenho cognitivo de cada um dos dependentes de cocaína, visando a obtenção do $Z$ score para análise dos resultados. $O Z$ score é uma medida que leva em conta a média e o desvio padrão de uma amostra de referência, e representa o quanto um dado valor se distancia (em unidades de desvio-padrão) da média esperada.

Utilizou-se então a amostra do grupo controle como referência, e buscou-se calcular o Z score para cada paciente e teste realizado (Quadro 1).

Quadro 1. Z score

$$
\begin{aligned}
& \text { Z score }=(\mathrm{R}-\mathrm{M}) / \mathrm{DP} \\
& \begin{array}{l}
\text { Notas: } \mathrm{R}=\text { Resultado obtido pelo paciente }(\mathrm{GE}) \\
M=\text { Média do } \mathrm{GC} \\
\mathrm{DP}=\text { Desvio-padrão do GC }
\end{array}
\end{aligned}
$$

No Gráfico 1, podem-se observar os resultados dos Z scores para os testes cujas médias apresentaram diferenças estatisticamente significantes nas comparações entre GC e GE. 
Gráfico 1. Relação entre as alterações dos exames de SPECT dos pacientes com os testes de atenção, working memory, funções viso-motoras e fluência verbal

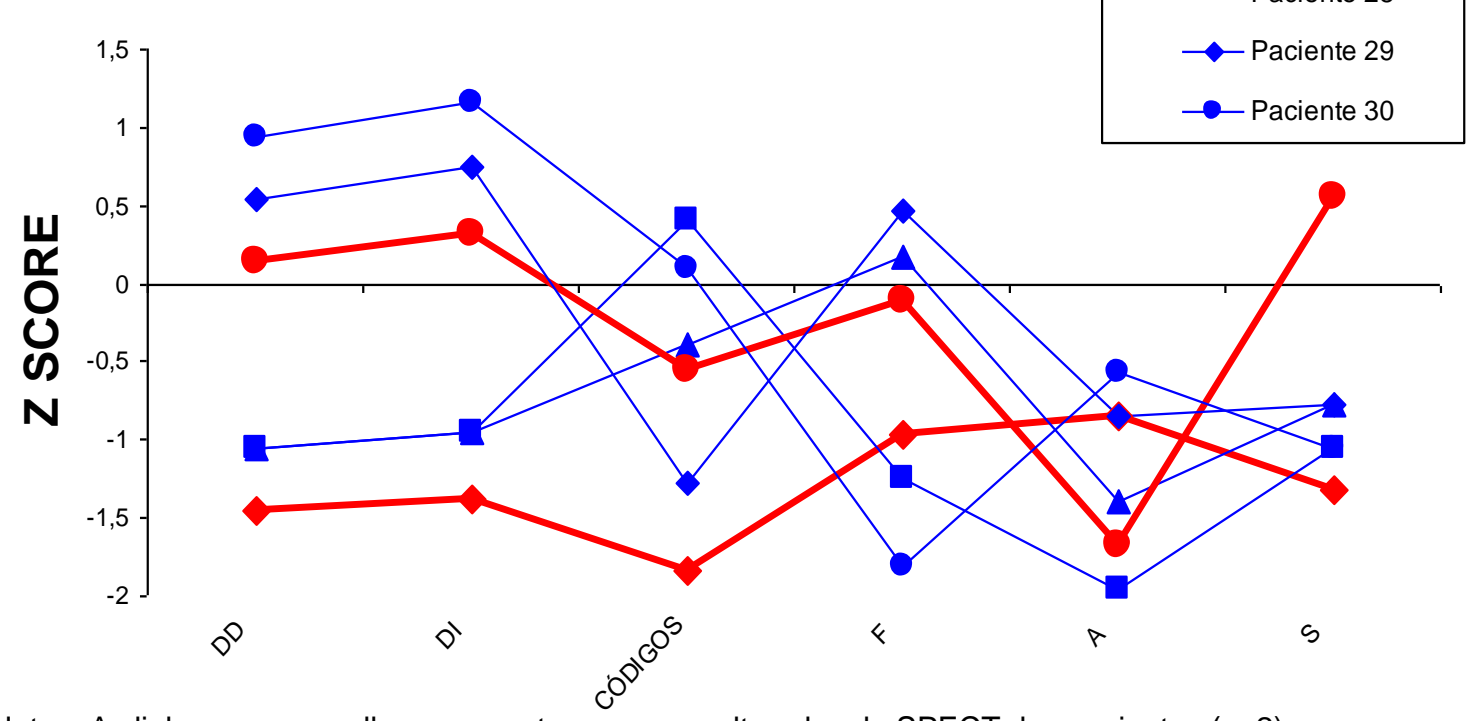

Notas: As linhas em vermelho representam exames alterados de SPECT dos pacientes $(n=2)$;

Paciente 14: irregularidade cortical difusa;

Paciente 28: irregularidade perfusional cortical difusa, com déficit mais evidente na transição frontotêmporo-parietal direita e na região têmporo-occipital direita.

A cor azul representa aqueles pacientes cujos exames não demonstraram anormalidades $(n=4)$. $\mathrm{DD}$ = Dígitos Diretos (WMS-R)

DI = Dígitos Indiretos (WMS-R)

WMS-R $=$ Wechsler Memory Scale-Revised

$\mathrm{F}, \mathrm{A}$ e $\mathrm{S}=$ Controlled Oral Word Association Test (COWAT): Fluência verbal

No gráfico acima, pode-se observar que não parece ter havido associação entre irregularidade cortical e o desempenho dos pacientes nos testes envolvendo dígitos (DD e DI), e fluência verbal (letras F, A e S). Já no teste de Códigos (WAIS-R), é provável que haja alguma correlação, mas apenas estudos mais amplos poderiam investigar melhor esta hipótese. 
No próximo gráfico (Gráfico 2) estão dispostos os $Z$ scores para outro teste neuropsicológico (SRT), cujas médias apresentaram anormalidades nas comparações finais entre $G C$ e $G E(p<0,05)$. Foram inseridos ainda outros instrumentos de avaliação neuropsicológica, que de acordo com a literatura, têm se mostrado sensíveis a alterações cerebrais associadas à dependência de cocaína (Trail Making Test, Stroop Test, Wisconsin Card Sorting Test e Figura de Rey).

Gráfico 2. Relação entre as alterações dos exames de SPECT dos pacientes com os testes de atenção dividida, controle inibitório, funções executivas, memória e funções viso-espaciais

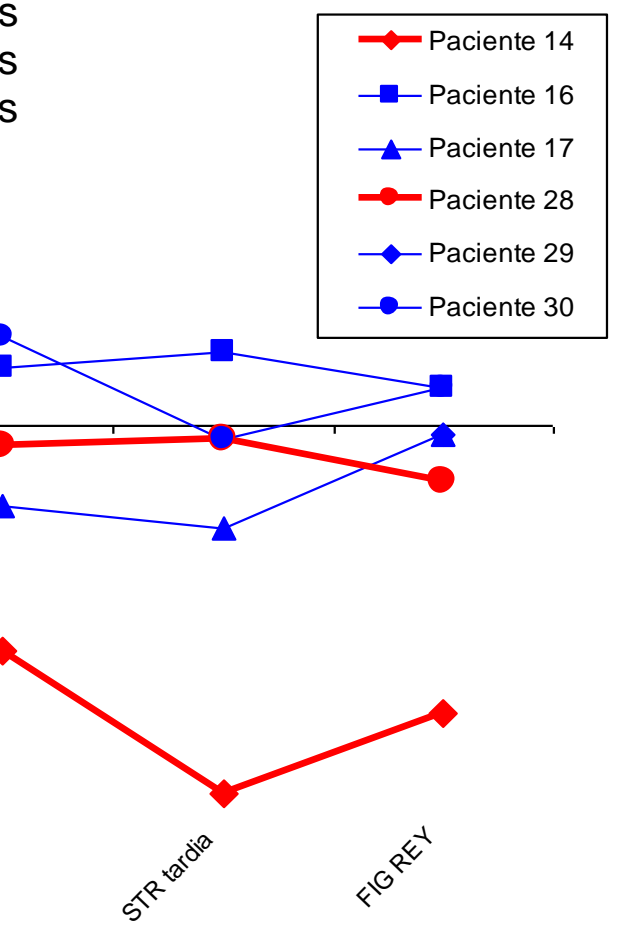

Notas: As linhas em vermelho representam exames alterados de SPECT dos pacientes $(n=2)$;

Paciente 14: irregularidade cortical difusa;

Paciente 28: irregularidade perfusional cortical difusa, com déficit mais evidente na transição frontotêmporo-parietal direita e na região têmporo-occipital direita.

A cor azul representa aqueles pacientes cujos exames não demonstraram anormalidades $(n=4)$.

Trail B = Trail Making Test, Parte B

WCST EP $=$ Erros Perseverativos do Wisconsin Card Sorting Test (WCST)

SRT cltr = Controlled Long-Term Retrieval (CLTR), do Selective Reminding Test (SRT)

SRT tardia = Recuperação tardia (após 15 minutos) no Selective Reminding Test (SRT)

FIG REY = Cópia da Figura de Rey 
Obs: O Paciente 29 desistiu no meio do SRT, e por isto seus resultados (SRT cltr e SRT tardia) não foram incluídos no gráfico.

No gráfico anterior, pode-se observar a correlação entre alguns testes neuropsicológicos e a perfusão cerebral dos dependentes de cocaína. Os testes Trail B e Stroop 2, por exemplo, estiveram bastante prejudicados ( $Z$ score negativo) apenas naqueles pacientes cujos exames de SPECT apresentaram anormalidades. Da mesma forma, a cópia da Figura de Rey mostrou-se suscetível a problema de perfusão cerebral em dependentes de cocaína. Parece ter havido, ainda, uma tendência de correlação entre as funções de memória/aprendizagem (SRT), funções executivas (Erros Perseverativos, WCST) e a circulação sanguínea irregular no cérebro destes pacientes. 


\section{DISCUSSÃO}

O presente estudo foi realizado comparando-se dois grupos de indivíduos, um formado por dependentes de cocaína $(n=30)$ e outro por controles normais $(n=32)$, pareados em idade, gênero, escolaridade, lateralidade e nível sócio-econômico. O tempo de abstinência para a avaliação dos dependentes de cocaína foi padronizado, bem como houve análise de sintomas depressivos, ansiosos e o modo de consumo da droga (tempo, freqüência e quantidade).

\subsection{Desempenho Neuropsicológico}

A avaliação da capacidade de atenção e funções executivas dos sujeitos da pesquisa evidenciou prejuízos nos dependentes de cocaína, alteração neuropsicológica freqüentemente observada em outros estudos (Ardila et al., 1991; O'Malley et al., 1992; Berry et al., 1993; Strickland et al., 1993; Beatty et al., 1995; Rosseli \& Ardila, 1996; Cunha et al., 2001; Toomey et al., 2003; Cunha et al., 2004). Bolla et al. (1999) verificou, por exemplo, que quanto maior a dose de cocaína utilizada durante a semana, piores eram os prejuízos de atenção dos dependentes, apesar de ainda haver controvérsias sobre o assunto (Horner, 1999). Nosso estudo demonstrou, por exemplo, que o tempo de uso de cocaína (em anos) pode influenciar negativamente os resultados nos testes. É importante a realização de mais estudos na área, para estudo pormenorizado 
da existência, natureza e severidade dos déficits atencionais e executivos associados à dependência de cocaína (Horner, 1999), principalmente controlando pela variável de sintomas de déficits de atenção/hiperatividade precedentes à dependência de cocaína (Cunha et al., 2004) uma vez que eles têm implicação clínica direta no tratamento destes pacientes, que geralmente envolvem uma ênfase cognitiva (Rogers, 2001; Aharonovich et al., 2003).

Da mesma forma, foram encontrados déficits de memória verbal e visual, tanto imediata quanto tardia, pelos subtestes da escala Wechsler de Memória (Reprodução Visual I e II; Memória Lógica I e II), na evocação (recuperação) tardia da Figura de Rey e nos itens do Selective Reminding Test (SRT). Esta tarefa evidenciou falhas significativas na consistência da recuperação de memória e aprendizado verbal nos dependentes de cocaína, sugerindo que estes pacientes apresentam dificuldades para armazenar novas informações verbais, possivelmente associadas a alterações funcionais de lobo temporal dominante (Spreen \& Strauss, 1998). A diminuição na disponibilidade de dopamina e serotonina durante a abstinência nestas áreas tem sido associada especificamente com déficits de aprendizado e memória (Mattos e Biscaia, 1998; Serper et al., 2000), e resultados semelhantes quanto aos déficits de memória e aprendizagem verbal já foram descritos na literatura internacional (Sevy et al., 1990; Ardila et al., 1991; Strickland et al., 1993; Beatty et al., 1995; van Gorp et al., 1999 e Serper et al., 2000). Tais prejuízos cognitivos vistos em dependentes de cocaína assemelham-se àqueles observados em portadores de 
esquizofrenia (Serper et al., 2000), e podem prejudicar significativamente a capacidade do paciente memorizar e incorporar estratégias específicas necessárias para a prevenção de recaídas (Strickland et al., 1993).

Os resultados do presente estudo revelaram significação estatística na avaliação de desempenho entre GE e GC nos testes de fluência verbal fonológica (Letras F, A e S). Isto representa forte evidência para a presença de déficits neurocognitivos nos pacientes dependentes de cocaína, detectados em fluência verbal fonológica, mas não na área de verbalização semântica (ex: animais, comidas e roupas). Aliás, trabalhos recentemente publicados na literatura internacional não mostraram um padrão específico e invariável de acometimento da fluência verbal relacionado ao abuso de cocaína. Enquanto Strickland et al. (1993) e Gillen et al. (1998) observaram pior fluência verbal nos dependentes de cocaína, O'Malley et al. (1992) e Hoff et al. (1996) encontraram uma fluência verbal melhor nos dependentes de cocaína, em relação aos controles. É necessário, portanto, que se estude melhor o funcionamento verbal desses pacientes, uma vez que praticamente todo o processo de tratamento se baseia na comunicação e assimilação de estratégias verbais para prevenção de recaídas (Teichner et al., 2001).

6.2. Relação dos Déficits Cognitivos com os Sintomas Depressivos e Ansiosos

Apesar de não ter havido correlações fortes para quaisquer das variáveis 
analisadas (sintomas ansiosos e depressivos), foram observados indícios de que, muitas delas provavelmente existam, como foi o caso de sintomas depressivos associados a uma piora em atenção (DD), problemas de planejamento viso-espacial (Cópia da Figura de Rey e Cubos, WAIS-R), falhas de memória (ML II, WMS-R), vocabulário (WAIS-R), fluência verbal (COWAT: roupas) e capacidade de nomeação espontânea (BNT). Quanto à ansiedade, apenas em fluência verbal foi encontrada uma probabilidade significante de haver correlação com o traço ansioso. De fato, sabe-se que sintomas depressivos e ansiosos fazem parte do quadro de abstinência à cocaína, como já demonstraram alguns estudos da área (Gawin \& Kleber, 1986), e tendem a afetar algumas funções neuropsicológicas (Lezak, 1995). Entretanto, há pouca evidência de que os sintomas seriam os responsáveis, por si só, pelas alterações neurocognitivas observadas nos pacientes, uma vez que os déficits cognitivos não são o sintoma proeminente (Austin, 2001; Carpenter \& Hittner, 1997).

6.3. Relação dos déficits cognitivos com o padrão de consumo de cocaína e tempo de abstinência

De acordo com os dados analisados, foram encontradas correlações significantes $(p<0,05)$ entre consumo na vida de cocaína (em anos) e funções neuropsicológicas. Quanto maior o tempo de uso de cocaína (em anos), piores os prejuízos de atenção, memória de trabalho ou working memory (DI, WMS-R), 
memória/aprendizagem verbal (SRT) e concentração (Intrusões, SRT). Já a quantidade de cocaína usada na semana (em gramas) esteve ligeiramente correlacionada positivamente com a fluência verbal semântica, ou seja, quanto maior a quantidade utilizada, melhor ficaria a fluência verbal dos pacientes. Há algumas explicações possíveis para o fato, como a possibilidade de este ter sido um achado ao acaso, uma vez que, se realmente a cocaína levasse a um melhor desempenho na tarefa, possivelmente também acarretaria em melhorias para a verbalização das outras categorias de fluência verbal semântica, como "comidas" e "roupas", uma vez que estas tarefas parecem envolver os mesmos circuitos neurais. Por outro lado, conforme exposto no item anterior, a literatura na área ainda não chegou a um consenso com relação a isso, havendo trabalhos que mostraram déficits na fluência verbal dos dependentes (Strickland et al., 1993; Gillen et al., 1998), ou que observaram o contrário (O’Malley et al., 1992; Hoff et al., 1996).

Outro fator importante a ser analisado, ainda com relação ao consumo da droga, foi a abstinência dos dependentes de cocaína. Apesar da variabilidade do tempo de abstinência ter sido bem pequena, houve a ligeira possibilidade de correlação entre tempo sem usar a droga e as funções de working memory (DI, WMS-R), funções viso-espaciais (Cubos, WAIS-R), Memória Visual Imediata (RV I, WMS-R), e Memória/Aprendizagem Verbal (SRT). Há indícios de que ocorra realmente recuperação cognitiva com a abstinência (Selby e Azrin, 1998; Bartzokis et al., 2000), relacionadas a 
melhorias no funcionamento cerebral, que inclusive repercutem no tratamento (Gottschalk et al., 2001), mas sabe-se também que algumas alterações cognitivas são mais duradouras, mesmo após seis meses (Strickland et al., 1993; Di Sclafani et al., 2002) ou um ano de abstinência (Toomey et al., 2003).

6.4. Relação dos Déficits Cognitivos com os Exames de Neuroimagem (SPECT)

As análises das imagens cerebrais revelaram alterações de perfusão em um terço dos pacientes avaliados. Embora não se devam tirar muitas conclusões de um número tão baixo de observações, essa é uma proporção que pode ser considerada baixa em comparação com estudos já publicados (Nicastri et al., 2000). Hipoperfusão difusa ou déficits focais foram encontrados nestes indivíduos, que em alguns dos testes neuropsicológicos acabaram obtendo piores escores de desempenho cognitivo. Não foi observado um padrão fixo de alterações, até porque é possível que cada dependente de cocaína apresente problemas em regiões cerebrais difusas (Idem). Nossos dados sugerem um desempenho pior dos pacientes com exames de SPECT alterados em algumas funções cognitivas, como em atenção dividida (Trail B), controle inibitório (Stroop 2), memória/aprendizagem (SRT), funções visoespaciais (Figura de Rey), viso-motoras (Códigos, WAIS-R) e funções executivas (Erros Perseverativos, WCST).

Alterações cognitivas no desempenho de dependentes de cocaína no 
Trail Making Test (TMT), Parte B, por exemplo, já foram descritos na literatura, sendo que um dos principais estudos na área chegou a detectar um efeito diretamente relacionado à dose diária da droga (Bolla et al., 1999). O estudo de Bolla et al. (2004) observou um padrão alterado de ativação em regiões do córtex cingulado anterior e córtex lateral pré-frontal durante a realização de uma versão modificada do teste de Stroop, embora os resultados quantitativos dos pacientes avaliados pelos pesquisadores não tenham diferido significativamente dos controles. Outro fato interessante em nossos resultados foi a correlação entre a quantidade de erros perseverativos (WCST) e alterações de neuroimagem dos pacientes. A presença de erros perseverativos indica dificuldade de o paciente obter benefício das regras e normas ambientais, para a mudança efetiva e adaptação de seu comportamento. Esta habilidade é conhecida como flexibilidade cognitiva e faz parte das funções executivas, estando relacionada também à possibilidade de a pessoa se beneficiar de técnicas psicossociais de intervenção, como a terapia cognitivo-comportamental (Gottschalk et al., 2001). É por isso que a avaliação neuropsicológica, quando bem empregada para avaliação dos dependentes químicos em recuperação, pode indicar as estratégias específicas de abordagem dos pacientes e auxiliar na escolha quanto à graduação da intensidade do tratamento, podendo ser de grande valia para diminuir a probabilidade de ocorrência de desistências e abandonos do tratamento (Teichner et al., 2002). 


\section{CONCLUSÕES}

O presente estudo observou alterações neurocognitivas em dependentes de cocaína, quando comparados com um grupo controle adequado, pareado em diversas variáveis que poderiam influenciar o desempenho. A pesquisa demonstrou, nos pacientes, déficits neuropsicológicos significativos em várias funções, como atenção, memória verbal, memória visual, memória de trabalho (working memory), aprendizagem, funções viso-motoras e funções executivas (tomada de decisão). De acordo com os exames de SPECT realizados nos pacientes, estas alterações estão potencialmente relacionadas a alterações difusas de perfusão cerebral.

Embora alguns sintomas depressivos e de atenção prévios (ex: TDAH) pareçam ter alguma influência nos déficits cognitivos, não explicariam totalmente o desempenho rebaixado dos dependentes de cocaína. Houve correlação negativa (quanto maior tempo, pior o desempenho) ainda entre o tempo de abuso de cocaína (em anos) com medidas envolvendo atenção, memória de trabalho (working memory) e capacidade de memória/aprendizagem, sugerindo um efeito cumulativo da droga no cérebro. Entretanto, há indícios de que estas alterações neurocognitivas possam melhorar levemente, mesmo dentro do primeiro mês de abstinência, denotando necessidade de se considerar tais déficits desde os primeiros dias de tratamento para os dependentes de cocaína, uma vez que freqüentemente 
estão relacionadas a piores prognósticos e problemas na manutenção da abstinência (Aharonovich et al., 2003). De acordo com a literatura, déficits de atenção, working memory, fluência verbal e memória podem prejudicar o acompanhamento, uma vez que praticamente todo o processo de recuperação se baseia na comunicação e assimilação de estratégias verbais para prevenção de recaídas. 


\section{REFERÊNCIAS}

1. AHARONOVICH, E.; NUNES, E.; HASIN, D. Cognitive Impairment, retention and abstinence among cocaine abusers in cognitive-behavioral treatment. Drug and Alcohol Dependence 71, 207-211, 2003.

2. AMERICAN PSYCHIATRIC ASSOCIATION (APA). Diagnostic and Statistical Manual of Mental Disorders, Fourth Edition. Washington, DC: APA, 1994.

3. ANDRADE, A.G. Avaliação da Eficácia Terapêutica no Alcoolismo. São Paulo. Tese (Doutorado) Faculdade de Medicina, Universidade de São Paulo, 142p, 1991.

4. ARDILA, A.; ROSSELI, M.; STRUMWASSER, S. Neuropsychological Deficits in Chronic Cocaine Abusers. International Journal of Neuroscience 57, 73-79, 1991.

5. AUSTIN, M. P. Cognitive deficits in depression. The British Journal of Psychiatry 178, 200-206, 2001.

6. BARKLEY, R. A. Behavioral Inhibition, Sustained Attention, and Executive Functions: Constructing a Unifying Theory of ADHD. Psychological Bulletin 121 (1), 65-94, 1997.

7. BARTZOKIS, G.; LU, P.H.; BECKSON, M.; RAPOPORT, R.; GRANT, S.; WISEMAN, E.J.; LONDON, E.D. Abstinence from Cocaine Reduces High-Risk Responses on a Gambling Task. Neuropsychopharmacology 
22, 102-103, 2000.

8. BEATTY, W. W.; KATZUNG V. M.; MORELAND, V. J.; NIXON, S. J. Neuropsychological performance of recently abstinent alcoholics and cocaine abusers. Drug and Alcohol Dependence 37, 247-253, 1995.

9. BECHARA, A.; DAMASIO, A.R.; DAMASIO, H.; ANDERSON, S. Insensitivity to future consequences following damage to human prefrontal cortex. Cognition 50, 7-15, 1994.

10. BECHARA, A.; DOLAN, S.; DENBURG, N.; HINDES, A.; ANDERSON, S.W.; NATHAN, P.E. Decision-making deficits, linked to a dysfunctional ventromedial prefrontal cortex, revealed in alcohol and stimulant abusers. Neuropsychologia 39, 376-389, 2001.

11. BECK, A. T.; RUSH, A. J.; SHAW, B. F.; EMERY, G. Terapia Cognitiva da Depressão. Rio de Janeiro: Zahar, 1982.

12. BERRY, J.; GORP, W. G. V.; HERZBERG, D. S.; HINKIN, C; BOONE, K; STEINMAN, L.; WILKINS, J. N. Neuropsychological deficits in abstinent cocaine abusers: preliminary findings after two weeks of abstinence. Drug and Alcohol Dependence 32, 231-237, 1993.

13. BOLLA, K.; ERNST, M.; KIEHL, K.; MOURATIDIS, M.; ELDRETH, D.; CANTOREGGI, C.; MATOCHIK, J.; KURIAN, V.; CADET, J.; KIMES, A.; FUNDERBURK, F.; LONDON E. Prefrontal Cortical Dysfunction in Abstinent Cocaine Abusers. The Journal of Neuropsychiatry and Clinical Neurosciences 16, 456-464, 2004. 
14. BOLLA, K. I.; ROTHMAN, R.; CADET, J. L. Dose-Related Neurobehavioral Effects of Chronic Cocaine Use. The Journal of Neuropsychiatry and Clinical Neurosciences 11, 361-369, 1999.

15. BOLLA, K. I.; FUNDERBURCK, F. R.; CADET, J. L. Differential effects of cognitive and cocaine + alcohol on neurocognitive performance. Neurology 54, 2285-2292, 2000.

16. BOLLA, K.I.; ELDRETH, D.A.; LONDON E.D.; KIEHL, K.A.; MOURATIDIS, M.; CANTOREGGI, C.; MATOCHIK, J.A.; KURIAN, V.; CADET, J.L.; KIMES, A.S.; FUNDERBURK, F.R.; ERNST, M. Orbitofrontal cortex dysfunction in abstinent cocaine abusers performing a decision-making task. Neurolmage 19, 1085-1094, 2003.

17. CARLIN, A. S.; O'MALLEY, S. Neuropsychological Consequences of Drug Abuse. In Neuropsychological Assessment of Neuropsychiatric Disorders. New York: Oxford University Press, 1996. p. 486-503.

18. CARLINI, E. A.; GALDURÓZ, J. C. F.; NOTO, A. R.; NAPO, S. A. I Levantamento Domiciliar sobre o uso de drogas Psicotrópicas no Brasil. São Paulo: [CEBRID] Centro Brasileiro de Informações sobre Drogas Psicotrópicas, Departamento de Psicobiologia, Escola Paulista de Medicina, Universidade Federal Paulista; 2001.

19. CARPENTER, K. M.; HITTNER, J. B. Cognitive impairment among the dually-diagnosed: substance use history and depressive symptons correlates. Addiction 92 (6), 747-759, 1997. 
20. CASTEL, S.; FORMIGONI, M. L. O. S. Escalas de avaliação de dependência de drogas: aspectos gerais. Revista de Psiquiatria Clínica $26(1), 1999$.

21. CONSELHO NACIONAL DE SAÚDE (CNS) - Ministério da Saúde. Resolução № 196/96 sobre pesquisa envolvendo seres humanos. Brasília: CNS, 1996.

22. Cleaveland, B. L.; DENIER, C. A. Recommendations for Health Care Professionals to Improve Compliance and Treatment Outcome among Patients with Cognitive Deficits. Issues on Mental Health Nursing 19, 113-124, 1998.

23. CUNHA, P. J.; CAMARGO, C. H. P.; NICASTRI, S. Déficits Neuropsicológicos e Cocaína: um estudo-piloto. Jornal Brasileiro de Dependências Químicas 1 (1), 31-37, 2001.

24. CUNHA, P. J.; NICASTRI, S.; GOMES, L. P.; MOINO, R. M.; PELUSO, M. A. Neuropsychological Impairments In Crack Cocaine-Dependent Inpatients: Preliminary Findings. Revista Brasileira de Psiquiatria 26 (2): 103-106, 2004.

25. CUNHA, P. J.; NICASTRI, N. Findings about the long-term neurocognitive deficits associated to cocaine use. Proceeding of the Society for Neuroscience (SfN) 34th Annual Meeting, October 23-27, San Diego, CA, USA, 2004.

26. CUNHA, P. J.; NOVAES, M. A. Neurocognitive assessment in alcohol abuse 
and dependence: implications for treatment. Revista Brasileira de Psiquiatria 26 (supl. I): 23-27, 2004.

27. DI SCLAFANI, V.; TOLOU-ShAMS, M.; PRICE, L. J.; FEIN, G. Neuropsychological performance of individuals dependent on crackcocaine, or crack-cocaine and alcohol, at 6 weeks and 6 months of abstinence. Drug and Alcohol Dependence 66 (2), 161-71, 2002.

28. DUBOIS, B.; SLACHEVSKY, A.; LITVAN, I.; PILLON, B. The FAB: A frontal assessment battery at bedside. Neurology 55, 1621-1626, 2000.

29. FEIN, G.; DI SCLAFANI, V.; MEYERHOFF, D. J. Prefrontal cortical volume reduction associated with frontal cortex function deficit in 6-week abstinent crack-cocaine dependent men. Drug and Alcohol Dependence 68, 87- 93, 2002.

30. FERRI, C. P.; DUNN, J.; GOSSOP, M.; LARANJEIRA, R. Factors associated with adverse reactions to cocaine among a sample of longterm, high-dose users in São Paulo, Brazil. Addictive Behaviors 29, 365-374, 2004.

31. GALDURÓZ, J. C. F.; D'ALMEIDA, V.; CARVALHO, V.; CARLINI, E. A. III Levantamento sobre o Uso de Drogas entre Estudantes de $1^{\circ}$ e $2^{\circ}$ graus em 10 Capitais Brasileiras-1993. São Paulo: Centro Brasileiro de Drogas Psicotrópicas (Cebrid), 1994.

32. GALDURÓZ, J. C. F.; NOTO, A. R.; CARLINI, E. A. IV Levantamento sobre o Uso de Drogas entre Estudantes de $1^{\circ}$ e $2^{\circ}$ graus em 10 Capitais 
Brasileiras-1997. São Paulo: Cebrid, 1997.

33. GAWIN, F. H.; KLEBER, H. D. Abstinence Symptomatology and Psychiatric Diagnosis in Cocaine Abusers. Archives of General Psychiatry 43, 107113, 1986.

34. GILLEN, R. W.; KRANZLER, H. R.; BAUER, L. O.; BURLESON, J. A.; SAMAREL, D.; MORRISON, D. J. Neuropsychologic Findings in Cocaine-Dependent Outpatients. Prog. Neuro-Psychofarmacol. \& Biol. Psychiat. 22, 1061-1076, 1998.

35. GOLDSTEIN, R. Z.; VOLKOW, N. D. Drug Addiction and its Underlying Neurobiological Basis: Neuroimaging Evidence for the Involvement of the Frontal Cortex. American Journal of Psychiatry 159, 1642-1652, 2002.

36. GORENSTEIN, C.; ANDRADE, L. Validation of a Portuguese version of the Beck Depression Inventory and the State-Trait Anxiety Inventory in Brazilian subjects. Brazilian Journal of Medical and Biological Research 29 (4), 453-457, 1996.

37. GORENSTEIN, C.; MORENO, R. A.; BERNIK, M. A.; CARVALHO, S. C.; NICASTRI, S.; CORDAS, T.; CAMARGO, A. P. P.; ARTES, R.; ANDRADE, L. Validation of the Portuguese version of the Social Adjustment Scale on Brazilian samples. Journal of Affective Disorders 69 (1-3), 167-75, 2002.

38. GOTTSCHALK, C.; BEAUVAIS, J.; HART, R.; KOSTEN, T. Cognitive 
Function and Cerebral Perfusion During Cocaine Abstinence. American Journal of Psychiatry 158, 540-545, 2001.

39. GRANT, S.; CONTOREGGI, C.; LONDON, E. D. Drug abusers show impaired performance in a laboratory test of decision making. Neuropsychologia, 38, 1180-1187, 2000.

40. HAALAND, K. Y.; VRANES, L. F.; GOODWIN, J. S.; GARRY, P. J. Wisconsin Card Sort Test Performance in a Healthy Elderly Population. Journal of Gerontology 42 (3), 345-346, 1987.

41. HEATON, R. K.; CHELUNE, G. J.; TALLEY, J. L.; KAY, G. G.; CURTISS, G. Wisconsin Card Sorting Test Manual-Revised and Expanded. Psychological Assessment Resources (PAR), 1993.

42. HOFF, A. H.; RIORDAN, H.; MORRIS, L. CESTARO, V.; WIENEKE, M.; ALPERT, R.; WANG, G. J.; VOLKOW, N. Effects of Crack cocaine on neurocognitive function. Psychiatry Research 60, 167-176, 1996.

43. HORNER, M. D. Attentional functioning in abstinent cocaine abusers - Drug and Alcohol Dependence, 54, 19-33, 1999.

44. LACAYO, A. Neurologic and Psychiatric Complications of Cocaine Abuse. Neuropsychiatry, Neuropsychology, and Behavioral Neurology 8 (1), 5360, 1995.

45. LARANJEIRA, R.; SILVEIRA, D. X.; FORMIGONI, M. L.; FERRI, C. P.; DUNN, J. Crack cocaine: an increase in use among patients attending clinics in São Paulo: 1990-1993. Substance Use and Misuse 31, 519- 
$527,1996$.

46. LARANJEIRA, R. R.; JUNGERMAN, F.; DUNN, J. Drogas: Maconha, Cocaína e Crack. São Paulo: Contexto, 1998.

47. LEITE, M. C. Abuso e Dependência da Cocaína: Conceitos. In LEITE, M. C.; ANDRADE, A. G. Cocaína e crack: dos fundamentos ao tratamento. Porto Alegre: Editora Artes Médicas Sul Ltda, 1999. p. 25-41.

48. LelTE, M. C.; SEGAL, A.; CABRAL, A. C. J. Complicações Médicas do Consumo de Cocaína. In LEITE, M. C.; ANDRADE, A. G. Cocaína e crack: dos fundamentos ao tratamento. Porto Alegre: Editora Artes Médicas Sul Ltda, 1999. p. 98-110.

49. LEZAK, M. Neuropsychological Assessment. New York: Oxford University Press, 1995.

50. MARI, J. J.; WILLIAMS, P. A Validity Study of a Psychiatric Screening Questionnaire (SRQ-20) in Primary Care in the city of Sao Paulo. British Journal of Psychiatry 148, 23-26, 1986.

51. MATOCHIK, J. A.; LONDON, E. D.; ELDRETH, D. A.; CADET, J. L.; BOLLA, K. I. Frontal cortical tissue composition in abstinent cocaine abusers: a magnetic resonance imaging study. Neuroimage 19, 10951102, 2003.

52. MATOS, P.; BISCAIA, M. Déficits Cognitivos e Cocaína. Jornal Brasileiro de Psiquiatria 47 (8), 397-400, 1998.

53. McCANN, B. S.; SCHEELE, L.; NICHOLAS, W.; ROY-BYRNE, P. 
Discriminant Validity of the Wender Utah Rating Scale for AttentionDeficit/Hyperactivity Disorder in Adults. Journal of Neuropsychiatry and Clinical Neurosciences, 12 (2), 240-45, 2000.

54. NAPPO, S. A.; GALDURÓZ, J. C. F.; NOTO, A. R. Uso do "crack" em São Paulo: fenômeno emergente? Revista ABP-APAL 16 (2): 75-83, 1994.

55. NOTO, A. R.; NAPPO, S.; GALDURÓZ, J. C. F.; MATTEI, R.; CARLINI, E. A. III Levantamento sobre o Uso de Drogas entre Meninos e Meninas em Situação de Rua de Cinco Capitais Brasileiras-1993. São Paulo: Cebrid, 1994.

56. NICASTRI, S.; BUCHPIGUEL, C. A.; ANDRADE, A. G. Anormalidades de fluxo sangüíneo cerebral em indivíduos dependentes de cocaína. Revista Brasileira de Psiquiatria 22 (2): 42-50, 2000.

57. ODO, A. S. Avaliação da confiabilidade do relato do uso de cocaína em pacientes sob tratamento ambulatorial através da analisa toxicológica da urina por imunofluorescência polarizada. Dissertação para a obtenção de grau de Mestre, apresentada à Faculdade de Ciências Farmacêuticas da Universidade de São Paulo, 1999.

58. O'MALLeY, S; ADAMSE, M.; HEATON, R. K.; GAWIN, F. H. Neuropsychological Impairment in Chronic Cocaine Abusers. American Journal of Drug and Alcohol Abuse 18 (2), 131-144, 1992.

59. REY, A. Teste de cópia e de reprodução de memória de figuras geométricas complexas: manual e adaptação brasileira (coord. Oliveira, 
M. S.) São Paulo: Casa do Psicólogo, 1999.

60. ROGERS, R. D.; ROBINS, T. W. Investigating the neurocognitive functioning in drug abusers. Drug and Alcohol Dependence 50 (1), 39 45, 2001.

61. ROSSELI, M.; ARDILA, A. Cognitive Effects of Cocaine and Polydrug Abuse. Journal of Clinical and Experimental Neuropsychology 18 (1), 122-135, 1996.

62. ROUSANVILLE, B. J.; ANTON, S. F.; CARROLL, K.; BUDDE, D.; PRUSOFF, B. A.; GAWIN, F. Psychiatric Diagnoses of TreatmentSeeking Cocaine Abusers. Archives of General Psychiatry 48, 43-51, 1991.

63. SELBY, M. J.; AZRIN, R. L. Neuropsychological functioning in drug abusers. Drug and Alcohol Dependence 50, 39-45, 1998.

64. SERPER, M. R.; COPERSINO, M. L.; RICHARME, D.; VADHAN, N.; CANCRO, R. Neurocognitive functioning in recently abstinent, cocaineabusing schizophrenic patients. Journal of Substance Abuse 11 (2), 205-213, 2000.

65. SEVY, S.; KAY, S. R.; OPLER, L. A.; VAN PRAAG, H. M. Significance of Cocaine History in Schizophrenia. The Journal of Nervous and Mental Disease 178 (10), 642-648, 1990.

66. SMITH, D. A.; BROWNING, M.; DUNWIDDIE, T. V. Cocaine inhibits hippocampal long-term potentiation. Brain Research 1993; 608: 259- 
265.

67. SPREEN, O., STRAUSS, E. A Compendium of Neuropsychological TestsAdministration, Norms and Commentary. New York: Oxford University Press, 1998.

68. STRICKLAND, T. L.; MENA, I.; VILLANUEVA-MEYER, J.; MILLER, B. L.; CUMMINGS, J.; MEHRINGER, C. M.; SATZ, P.; MYERS, H. Cerebral Perfusion and neuropsychological consequences of chronic cocaine use. The Journal of Neuropsychiatry and Clinical Neurosciences 5, 410427, 1993.

69. TEICHNER, G.; HORNER, M. D.; HARVEY, R. T. Neuropsychological predictors of the attainment of treatment objectives in substance abuse patients. International Journal of Neuroscience 106, 253-63, 2001.

70. TEICHNER, G.; HORNER, M. D.; ROITZSCH, J. C.; HERRON, J.; THEVOS, A. Substance abuse treatment outcomes for cognitively impaired and intact outpatients. Addictive Behaviors 27, 751-763, 2002.

71. TOOMEY, R.; LYONS, M. J..; EISEN, S. A.; XIAN, H.; CHANTARUJIKAPONG, S.; SEIDMAN, L., FARAONE, S. V..; TSUANG, M. T. A Twin Study of the Neuropsychological Consequences of Stimulant Abuse. Archives of General Psychiatry 60, 303-310, 2003.

72. UNITED NATIONS OFFICE FOR DRUG CONTROL AND CRIME PREVENTION (UNODCCP). Global illicit drug trends 2002 [online]. New York: UNODCCP, 2002. Available from: URL: 
http://www.undcp.org/pdf/report 2002-06-26 1/report 2002-06-

26 1.pdf.

73. VAN GORP, W. G.; WILKINS, J. N.; HINKIN, C. H.; MOORE, L. H.; HULL, J.; HORNER, M. D.; PLOTKIN, D. Declarative and procedural memory functioning in abstinent cocaine abusers. Archives of General Psychiatry 56 (1), 85-89, 1999.

74. VOLKOW, N.D., HITZEMANN, R., WANG, G., FOWLER, J.S., WOLF, A.P., DEWEY, S., HANDELSMAN, L. Long-term frontal brain metabolic changes in cocaine abusers. Synapse 11, 184-190, 1992.

75. WARD, M. F.; WENDER, P. H.; REIMHERR, F. W. The Wender Utah Rating Scale: An Aid in the Retrospective Diagnosis of Childhood Attention Deficit Hyperactivity Disorder. American Journal of Psychiatry 150 (6), 885-890, 1993.

76. WASHTON, A. M. Cocaine Addiction: treatment, recovery and relapse prevention. New York: W. W. Norton \& Company, 1989.

77. WASHTON, A. M.; GOLD, M. S.; POTTASH, A. L. C. Survey of 500 callers to a national cocaine helpline. Psychosomatics 25, 771-775, 1984.

78. WECHSLER, D. Wechsler Intelligence Scale for Adults-Revised. New York: The Psychological Corporation, 1981.

79. WECHSLER, D. Wechsler Memory Scale-Revised. New York: The Psychological Corporation, 1987.

80. WEISSMAN, M. M.; BOTHWELL, S. Assessment of social adjustment by 
patient self-report. Archives of General Psychiatry 33 (9), 1111-1115, 1976.

81. WENDER, P. H.; REIMHERR, F. W.; WOOD, D. R. Attention Deficit Disorder ('Minimal Brain Dysfunction') in Adults. Archives of General Psychiatry 38, 449-456, 1981. 


\section{APÊNDICES}

\section{Escalas e Inventários}




\section{SRQ-20 - Psychiatric Screening Questionnaire (Mari \& Williams, 1986)}

Por favor, responda às seguintes perguntas a respeito da sua saúde. Assinale a resposta correta marcando-a com um "X"

\begin{tabular}{|c|c|c|}
\hline PERGUNTAS & SIM & NÃO \\
\hline 1. Tem dores de cabeça freqüentes? & & \\
\hline 2. Tem falta de apetite? & & \\
\hline 3. Dorme mal? & & \\
\hline 4. Assusta-se com facilidade? & & \\
\hline 5. Tem tremores nas mãos? & & \\
\hline 6. Sente-se nervoso(a), tenso(a) ou preocupado(a)? & & \\
\hline 7. Tem má digestão? & & \\
\hline 8. Tem dificuldade de pensar com clareza? & & \\
\hline 9. Tem se sentido triste ultimamente? & & \\
\hline 10. Tem chorado mais que de costume? & & \\
\hline $\begin{array}{l}\text { 11. Encontra dificuldades para realizar com satisfação suas atividades } \\
\text { diárias? }\end{array}$ & & \\
\hline 12. Tem dificuldades para tomar decisões? & & \\
\hline $\begin{array}{l}\text { 13. Tem dificuldades no serviço (seu trabalho é penoso, Ihe causa } \\
\text { sofrimento)? }\end{array}$ & & \\
\hline 14. É incapaz de desempenhar um papel útil em sua vida? & & \\
\hline 15. Tem perdido o interesse pelas coisas? & & \\
\hline 16. Você se sente uma pessoa inútil, sem-préstimo? & & \\
\hline 17. Tem tido a idéia de acabar com a vida? & & \\
\hline 18. Sente-se cansado(a) o tempo todo? & & \\
\hline 19. Tem sensações desagradáveis no estômago? & & \\
\hline 20. Você se cansa com facilidade? & & \\
\hline 21. Sente que alguém quer lhe fazer mal? & & \\
\hline $\begin{array}{l}\text { 22. Você é alguém muito mais importante do que a maioria das pessoas } \\
\text { pensam? }\end{array}$ & & \\
\hline $\begin{array}{l}\text { 23. Tem notado alguma interferência ou problema estranho com seu } \\
\text { pensamento? }\end{array}$ & & \\
\hline
\end{tabular}




\begin{tabular}{|c|c|}
\hline $\begin{array}{l}\text { 24. Ouve vozes que não sabe de onde vêm, ou que outras pessoas não } \\
\text { podem ouvir? }\end{array}$ & \\
\hline $\begin{array}{l}\text { 25. Sente-se chateado(a) consigo mesmo(a) pela maneira com que costuma } \\
\text { beber? }\end{array}$ & \\
\hline 26. Costuma beber pela manhã para diminuir o nervosismo ou ressaca? & \\
\hline 27. As pessoas o(a) aborrecem porque criticam seu modo de beber? & \\
\hline $\begin{array}{l}\text { 28. Alguma vez sentiu que deveria diminuir a quantidade de bebida ou parar } \\
\text { de beber? }\end{array}$ & \\
\hline
\end{tabular}




\section{INVENTÁRIO DE DEPRESSÃO DE BECK}

Nome:

Data: /

Neste questionário existem grupos de alternativas. Por favor, leia cada uma delas e selecione a afirmativa que melhor descreve como você se sentiu NA SEMANA QUE PASSOU, INCLUINDO O DIA DE HOJE. Desenhe um círculo ao lado da afirmativa que tiver selecionado. Se várias afirmativas do grupo parecem aplicar-se igualmente bem, circule cada uma delas. Certifique-se de ter lido todas as afirmativas antes de fazer sua escolha.

1) 0 - Não me sinto triste.

1 - Sinto-me triste.

2 - Sinto-me triste o tempo todo e não consigo sair disso.

3 - Estou tão triste e infeliz que não posso agüentar.

2) 0 - Não estou particularmente desencorajado quanto ao futuro.

1 - Sinto-me desencorajado quanto ao futuro.

2 - Sinto que não tenho nada por que esperar.

3 - Sinto que o futuro é sem esperança e que as coisas não podem melhorar.

3) 0 - Não me sinto fracassado.

1 - Sinto que falhei mais do que um indivíduo médio.

2 - Quando olho para trás em minha vida, tudo que vejo é uma porção de fracassos.

3 - Sinto que sou um fracasso completo como pessoa.

4) 0 - Obtenho tanta satisfação com as coisas como costumava fazer.

1 - Não gosto das coisas da maneira como costumava gostar.

2 - Não consigo mais sentir satisfação real com coisa alguma.

3 - Estou insatisfeito ou entediado com tudo.

5) 0 - Não me sinto particularmente culpado.

1 - Sinto-me culpado boa parte do tempo.

2 - Sinto-me muito culpado a maior parte do tempo.

3 - Sinto-me culpado o tempo todo.

6) 0 - Não sinto que esteja sendo punido.

1 - Sinto que posso ser punido.

2 - Sinto que estou sendo punido.

3 - Sinto que preciso ser punido.

7) 0 - Não me sinto desapontado comigo mesmo.

1 - Sinto-me desapontado comigo mesmo.

2 - Sinto-me aborrecido comigo mesmo

3 - Eu me odeio.

8) 0 - Não sinto que seja pior que qualquer outra pessoa.

1 - Critico minhas fraquezas ou erros.

2 - Responsabilizo-me o tempo todo por minhas falhas.

3 - Culpo-me por todas as coisas ruins que acontecem.

9) 0 - Não tenho nenhum pensamento a respeito de me matar.

1 - Tenho pensamentos sobre me matar mas não os levaria adiante.

2 - Gostaria de me matar.

3 - Eu me mataria se tivesse uma oportunidade. 
10) 0 - Não costumo chorar mais que o habitual.

1 - Choro mais agora do que costumava fazer.

2 - Atualmente choro o tempo todo.

3 - Sinto-me culpado o tempo todo.

11) 0 - Não me irrito mais agora do que em qualquer época.

1 - Fico molestado ou irritado mais facilmente do que costumava.

2 - Atualmente sinto-me muito irritado o tempo todo.

3 - Absolutamente me irrito com todas as coisas que costumavam irritar-me.

12) 0 - Não perdi o interesse nas outras pessoas.

1 - Interesso-me menos do que costumava pelas outras pessoas.

2 - Perdi a maior parte do meu interesse nas outras pessoas.

3 - Perdi todo o meu interesse nas outras pessoas.

13) 0 - Tomo decisões mais ou menos tão bem como em qualquer outra época.

1 - Adio minhas decisões mais do que costumava.

2 - Tenho maior dificuldade em tomar decisões do que antes.

3 - Não consigo mais tomar decisões.

14) 0 - Não sinto que minha aparência seja pior do que costumava ser.

1 - Preocupo-me por estar parecendo velho ou sem atrativos.

2 - Sinto que há mudanças permanentes em minha aparência que me fazem parecer sem atrativos.

3 - Considero-me feio.

15) 0 - Posso trabalhar mais ou menos tão bem quanto antes.

1 - Preciso de um esforço extra para começar qualquer coisa.

2 - Tenho que me forçar muito até fazer qualquer coisa.

3 - Não consigo fazer nenhum trabalho.

16) 0 - Durmo tão bem quanto de hábito.

1 - Não durmo tão bem quanto costumava.

2 - Acordo 1 ou 2 horas mais cedo do que de hábito e tenho dificuldade de voltar a dormir.

3 - Acordo várias horas mais cedo do que costumava e tenho dificuldades de voltar a dormir.

17) 0 - Não fico mais cansado que de hábito.

1 - Fico cansado com mais facilidade do que costumava.

2 - Sinto-me cansado ao fazer quase qualquer coisa.

3 - Estou cansado demais para fazer qualquer coisa.

18) 0 - Meu apetite está pior do que de hábito.

1 - Meu apetite não é tão bom como costumava ser

2 - Meu apetite está muito pior agora.

3 - Não tenho mais nenhum apetite.

19) 0 - Não perdi muito peso se é que perdi algum ultimamente.

1 - Perdi mais de $2,5 \mathrm{Kg}$.

2 - Perdi mais de $5,0 \mathrm{Kg}$.

3 - Perdi mais de 7,5 Kg.

Estou tentando perder peso, comendo menos:

$\operatorname{SIM}(\quad)$

NÃO ( )

20) 0 - Não me preocupo mais do que de hábito com minha saúde.

1 - Preocupo-me com problemas físicos, como dores e aflições, ou perturbações no estômago ou prisões de ventre. 
2 - Estou muito preocupado com problemas físicos e é difícil pensar em muito mais que isso.

3 - Estou tão preocupado com meus problemas físicos que não consigo pensar em outra coisa.

21) 0 - Não tenho observado qualquer mudança recente em meu interesse sexual.

1 - Estou menos interessado por sexo do que costumava.

2 - Estou bem menos interessado em sexo atualmente.

3 - Perdi completamente o interesse por sexo. 


\section{IDATE - INVENTÁRIO DE ANSIEDADE}

Nome:

Data:

\section{Parte 1}

Leia cada pergunta e faça um círculo ao redor do número à direita da afirmação que melhor indicar como você se sente agora, neste momento.

Não gaste muito tempo numa única afirmação, mas tente dar uma resposta que mais se aproxima de como você se sente neste momento.

\section{AVALIAÇÃO}

Muitíssimo.............4

Um Pouco............................2

Bastante................3

Absolutamente não...............1

1. Sinto-me calmo (a)

2. Sinto-me seguro (a)

)

3. Estou tenso (a)

4. Estou arrependido (a)

5. Sinto-me à vontade

6. Sinto-me perturbado (a)

7. Estou preocupado (a) com possíveis infortúnios

8. Sinto-me descansado (a)

9. Sinto-me ansioso (a)

10. Sinto-me "em casa" (a)

11. Sinto-me confiante (a)

12. Sinto-me nervoso (a)

13. Estou agitado (a)

14. Sinto-me uma pilha de nervos (a)

15. Estou descontraído (a)

16. Sinto-me satisfeito (a)

17. Estou preocupado (a)

(a) ………………………………......

18. Sinto-me super

excitado

$\begin{array}{lll}\text { (a) } \mathrm{e} \text { confuso } & \text { (a) } 1\end{array}$

12

3

3

123

123

123

123

123

123

$\begin{array}{lll}1 & 2 & 3 \\ & 2 & 3\end{array}$

123

$\begin{array}{lll}1 & 2 & 3 \\ 1 & 2 & 3\end{array}$

$\begin{array}{lll}1 & 2 & 3\end{array}$




\section{Parte II}

Leia cada pergunta e faça um círculo em redor do número à direita que melhor indicar como você geralmente se sente.

Não gaste muito tempo numa única afirmação, mas tente dar a resposta que mais se aproximar de como você se sente geralmente.

\section{AVALIAÇÃO}

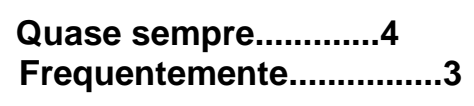

Às vezes...........................

Quase nunca..............1

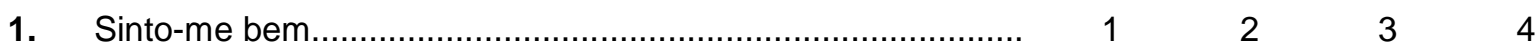

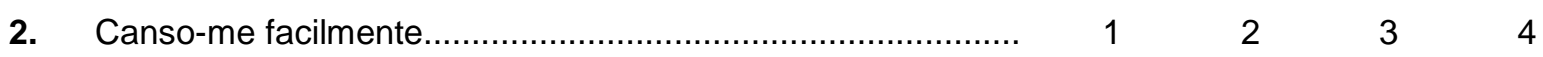

3. Tenho vontade de chorar................................................ 1124

4. Gostaria de ser tão feliz quanto os outros parecem

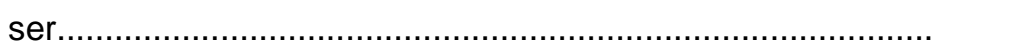

5. Perco oportunidades porque não consigo tomar decisões $\begin{array}{lllll}1 & 2 & 3 & 4\end{array}$ rapidamente.

6. Sinto-me descansado (a)

7. Estou calmo (a), ponderado (a) e senhor de mim mesmo......

$\begin{array}{llll}1 & 2 & 3 & 4\end{array}$

8. Sinto que as dificuldades que estão se acumulando de tal forma que não as consigo resolver.

$\begin{array}{llll}1 & 2 & 3 & 4\end{array}$

9. Preocupo-me demais com coisas sem importância.................

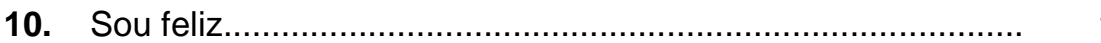

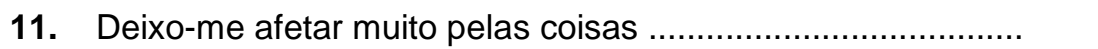

12. Não tenho muita confiança em mim mesmo (a) ....................

13. Sinto-me seguro (a)

14. Evito ter que enfrentar crises ou problemas...........................

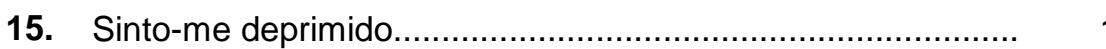

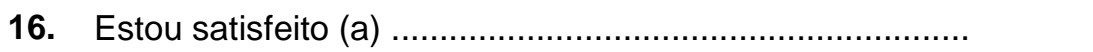

17. Às vezes, idéias sem importância me entram na cabeça e ficam me preocupando.

18. Levo os desapontamentos tão a sério que não consigo tirá-

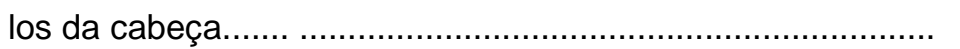

19. Sou uma pessoa estável

$\begin{array}{llll}1 & 2 & 3 & 4 \\ 1 & 2 & 3 & 4\end{array}$

20. Fico tenso (a) e perturbado quando penso em meus problemas do momento

123




\section{ESCALA DE AJUSTAMENTO SOCIAL}

Nome:

Data:

Aval $n^{\circ}$ :

\section{RgHC:}

Gostariamos de saber como você se sentiu no seu trabalho, lazer $\mathrm{c}$ vida familiar nas DUAS ÚLTIMAS SEMANAS. Não existem respostas certas ou erradas neste questionário. Escolha as respostas que melhor descrevam como você esteve nas duas últimas semanas.

\section{TRABALHO FORA DE CASA}

Assinale a resposta que melhor se adapta a sua condição.

Eu: $\quad 1$ ( ) Sou um trabalhador assalariado e/ou autônomo.

2 ( ) Trabalho em casa sem remuneração (prendas domésticas).

3 ( ) Sou estudante.

4 ( ) Sou aposentado.

5 ( ) Estou desempregado.

Você geralmente trabalha mais de 15 horas por semana com remuneração?

1 ( ) $\operatorname{Sim} 2($ ) Não

Você trabalhou nestas duas últimas semanas com remuneração?

1 ( ) $\operatorname{Sim} 2$ ( ) Não

Assinale a resposta que melhor descreve sua situação nas duas últimas semanas.

1. Quantos dias de trabalho remunerado você perdeu nas duas últimas semanas?

1 ( ) Não perdi nenhum dia.

2 ( ) Perdi um dia

3 ( ) Perdi cerca de metade do tempo de trabalho.

4 ( ) Perdi mais de metade do tempo de trabalho, mas trabalhei pelo menos um dia

5 ( ) Não trabalhei nenhum dia

8 ( ) Estive de férias nesse periodo.

Se você não trabahou com remuneração em nenhum dia das duas últimas semanas passe para a Questão 7.

2. Você foi capaz de realizar seu trabalho nas duas últimas semanas?

1 ( ) Fiz meu trabalho muito bem.

- 2 ( ) Fiz meu trabalho bem, porém tive algumas pequenas dificuldades.

3 ( ) Necessitei de auxilio no trabalho e cerca de metade do tempo não o fiz adequadamente.

- 4 ( ) Fiz meu trabalho de maneira inadequada na maior parte do tempo.

5 ( ) Fiz meu trabalho de maneira inadequada durante o tempo todo.

3. Você se sentiu envergonhado de seu desempenho no trabalho nas duas últimas semanas?

1 ( ) Em nenhum momento me senti envergonhado.

2 ( ) Uma ou duas vezes me senti um pouco.

3 ( ) Cerca de metade do tempo me senti envergonhado.

4 ( ) Senti-me envergonhado a maior parte do tempo.

5 ( ) Senti-me envergonhado o tempo todo

4. Você teve algum tipo de discussão com as pessoas com quem você trabalha nas duas últimas sentanas?

1 ( ) Não tive nenhuma discussão e me relacionei muito bem.

2 ( ) Em geral, me rclacionei bem, mas tive pequenas discussões.

3 ( ) Tive mais de una discussão.

4 ( ) Tive várias discussões.

5 ( ) Tive discussões constantementc. 
5. Você se sentiu chateado, preocupado ou desconfortável enquanto realizava seu trabalho nas duas últimas semanas?

1 ( ) Em nenhum momento me senti assim

() Senti-me assim uma ou duas vezes.

3 ( ) Senti-me assim cerca de metade do tempo.

4 () Senti-me assim a maior parte do tempo.

5 ( ) Senti-me assim o tempo todo.

6. Você achou seu trabalho interessante nas duas últimas semanas?

1 ( ) Meu trabalho foi interessante praticamente o tempo todo

( ) Uma ou duas vezes meu trabalho não foi interessante.

3 ( ) Cerca de metade do tempo meu trabalho não foi interessante.

4. Mcu trabailho não foi interessante a maior parte do tempo

5 ( ) Meu trabalho não foi interessante o tempo todo

TRABALHO EM CASA

As donas de casa devem responder as questões de 7 a 12. Os demais sigam para a questão 13.

7. Quantos dias você realizou tarefas domésticas nas duas últimas semanas?

1 ( ) Diariamente.

2 () Realizei tarefas domésticas quase todos os dias.

3( Realizei tarefas domésticas cerca de metade do tempo.

4 ( ) Em geral, não realizei tarefas domésticas.

5 ( ) Fui totalmente incapaz de realizar tarefas domésticas.

8 () Estive ausente de casa nas duas últimas semanas.

8. Nas duas últimas semanas você foi capaz de realizar suas tarefas domésticas, tais como. cozinhar.

limpar, lavar, fazer compras, consertos caseiros. etc?

1 () Realizei as tarefas muito bem.

2 (.) Realizei as tarefas bem porém, tive pequenas dificuldades.

3 ( ) Necessitei de auxilio nas tarefas e cerca de metade do tempo não as fiz adequadamente.

( ) Fiz minhas tarefas de maneira inadequada na maior parte do tempo

5 ( ) Fiz minhas tarefas de maneira inadequada o tempo todo.

Você se sentiu envergonhado(a) de seu desempenho nas tarefas domésticas nas duas últimas semanas?

1 ( ) Em nenhum momento me senti enverginhado(a).

2 ( ) Uma ou duas vezes me senti um pouco envergonhado(a)

3 ( ) Cerca de metade do tempo me senti envergonhado(a).

4 ( ) Senti-me envergonhado(a) a maior parte do tempo.

5 ( ) Senti-me envergonhado(a) o tempo todo.

10. Você teve algum tipo de discussão com vendedores, comerciantes ou vizinhos nas duas últimas semanas?

1 ( ) Não tive nenhuma discussão e me relacionei muito bem.

2( ) Em geral, me relacionei bem, mas tive pequenas discussões.

3( ) Tive mais de uma discussão.

4. () Tive várias discussões.

5 ( ) Tive discussões constantes

11. Você se sentiu incomodado(a) com o seu trabalho doméstico nas duas últimas semanas?

1 ( ) Em nenhum momento me senti incomodado(a)

2 () Senti-me incomodado(a) uma ou duas vezes.

3 ( ) Senti-me incomodado(a) cerca de metade do tempo.

4 () Senti-me incomodado(a) a maior parte do tempo.

5 ( ) Senti-me incomodado(a) o tempo todo.

12. Você achou seu trabalho doméstico interessante nas duas últimas semanas?

1 ( ) Meu trabalho foi interessante na maior parte do tempo

2() Uma ou duas vezes meu trabalhop não foi interessante.

3 ( ) Cerca de metade do tempo meu trabalho não foi interessante.

4 ( ) Meu trabalho não foi interessante a maior parte do tempo. 
5 ( ) Meu trabalho não foi interessante o tempo todo.

\section{ESTUDANTES}

Responda as Questões 13-18 se você frequenta escola por meio periodo ou mais. Caso contrário passe para a Questão 19.

Quanto tempo você permanece na escola?

1 ( ) Periodo integral.

Assinale a resposta que melhor descreve sua situação nas últimas duas semanas.

13. Quantos dias de aula você perdeu nas duas últimas semanas?

1 ( ) Não perdi nenhum dia.

2 ( ) Perdi poucos dias de aula

3 ( ) Perdi cerca de metade do tempo de aula.

$f$ ( ) Perdi mais da metade do tempo de aula.

5 ( ) Năo fui à escola nenhum dia.

8 ( ) Estive de férias nesse período

14. Você foi capaz de realizar suas tarefas escolares nas duas últimas

1 ( ) Fiz minhas tarefas muito bem.

2 ( ) Fiz minhas tarefas porém tive pequenas dificuldades.

3 ( ) Necessitei de ajuda nas minhas tarefas e cerca de metade do tempo não as fiz adequadamente.

4 ( ) Fiz minhas tarefas de maneira inadequada na maior parte do tempo.

5( ) Fiz minhas tarefas de maneira inadequada o iempo todo.

15 . Você se sentiu envergonhado(a) de seu desempenho escolar nas duas últimas semanas?

I ( ) Em nenhum momento me senti envergonhado(a)

2 ( ) Uma ou duas vezes me senti envergonhado(a)

3 ( ) Cerca de metade do tempo me senti envergonhado(a)

4 ( ) Senti-me cnvergonhado(a) a maior parte do tempo.

5 ( ) Senti-me envergonhado(a) o tempo todo.

16. Você teve tipo de discussão com pessoas ligadas à escola nas duas últimas semanas?

1 ( ) Não tive nenhuma discussão e me relacionei muito bem.

2 ( ) Em geral, me rclacionei bem, mas tive pequenas discussões.

3 ( ) Tive mais de una discussão.

4 ( ) Tive várias discussões.

5 ( ) Tive discussões constantes.

8 ( ) Não se aplica, não frequentei a escola no periodo.

17. Você teve algum aborrecimento na escola nas duas últimas semanas?

1 ( ) Em nenhum momento senti-me aborrccido(a).

2 ( ) Senti-me aborrecido(a) una ou duas vezes.

3 ( ) Senti-me aborrecido(a) cerca de metade do tempo.

4 ( ) Senti-me aborrecido(a) a maior parte do tempo.

5 ( ) Senti-me aborrecido(a) o tempo todo.

8 ( ) Não se aplica, não frequentei a escola no periodo.

18. Você achou suas tarcfas escolares interessantes nas duas útimas semanas?

1 ( ) Minhas tarefas escolares foram interessanrtes o tempo todo.

2( ) Uma ou duas vezes minhas tarefas escolares não foram interessantes.

3 ( ) Cerca de metade do tempo minhas tarcfas escolares não foram interessantes.

4 ( ) Em geral, minhas tarefas escolares não foram intcressantes a maior parte do tempo.

5 ( ) Minhas tarefas cscolares não foram interessantes o tempo todo.

LAZER

Todos devern responder as questoes de 19 a 23.

Assinale a resposta que mehor descreve sua situação nas últimas duas semanas.

19. Quantos amigos você viu ou conversou ao telefone nas duas últimas semanas?

1 ( ) 9 ou mais amigos.

2 ( ) 5 a 8 amigos.

3 ( ) 2 a 4 amigos. 
4 ( ) Um amigo.

5 ( ) Nenhum anigo.

20. Voce foi capaz de conversar sobre seus sentimentos e problemas com pelo menos um amigo nas duas últimas semanas?

1( ) Posso sempre falar sobre meus sentimentos.

2( ) Em geral. posso falar sobre meus sentimentos

3 ( ) Consegui falar sobre meus sentimentos cerca de metade do tempo.

4 ( ) Com frequência não consegui falar sobre meus sentimentos.

5 ( ) Em nenhum momento consegui falar sobre meus sentimentos.

8 ( ) Não se aplica. não tenho amigos.

21. Nas duas ultimas semanas quantas vezes você saiu socialmente com outras pessoas? Por exemplo. visitou amigos, foi ao cinema, a restaurantes, à igreja, convidou amigos para sua casa?

1( ) mais de 3 vezes. 2( ) 3 vezes. 3( ) 2 vezes. 4( ) uma vez. 5( ) Nenhuma vez.

22. Quanto tempo você dedicou a suas atividades de lazer nas duas últimas semanas? Por exemplo, esportes. leitura, ouvir música.etc.

1 ( ) Dediquei a naior parte do tempo live ao lazer praticamente todos os dias

2( ) Dediquci parte do tempo livre ao lazer $\mathrm{cm}$ alguns dias.

3 ( ) Dediquei pouco tempo livre ao lazer.

4 ( ) Em geral, não dediquei nenhum tempo ao lazer, mas assisti televisão.

5 ( ) Não dediquei nenhum tempo ao lazer. nem assisti televisão.

23. Você teve algum tipo de discussão com seus anigos nas duas últimas semanas?

1 ( ) Não tive nenhuma discussão e me relacionei muito bem.

2( ) Em geral, me relacionei bem, mas tive pequenas discussões.

3 ( ) Tive mais de uma discussão.

4 ( ) Tive várias discussões.

5 ( ) Tive discussões constantes

8 ( ) Não se aplica, não tenho amigos.

24. Se seus sentimentos foram feridos ou se você foi ofendido por um amigo durante as duas últimas semanas, quanto isso 0 aretou?

1 ( ) Isso não me afctou ou não aconteceu.

2( ) Superei em poucas horas.

3 ( ) Superei em poucos dias.

4 ( ) Superei em uma semana.

5 ( ) Vai levar meses até que eu me recupere.

8 ( ) Não se aplica, não tenlı amigos.

25. Você se sentiu timido(a) ou desconfortável quando em companhia de outras pessoas nas duas últimas semanas?

1 ( ) Sempre me senti confortável.

2( ) Algumas vezes me senti desconfortável mas relaxei depois de pouco tempo.

3 ( ) Senti-me desconfortável cerca de metade do tempo.

4( ) Em geral, me senti desconfortável.

5 ( ) Senti-me desconfortável o tempo todo.

8 ( ) Não se aplica, não estive com outras pessoas.

26. Você se sentiu solitário (a) e desejando ter mais amigos durante as duas últimas semanas?

1 ( ) Não me senti solitário(a)

2 ( ) Senti-me solitário(a) algumas vezes.

3 ( ) Senti-me solitário(a) cerca de netade do tempo.

4 ( ) Em geral, me senti solitário(a)

5 () O iempo todo me senti solitário(a), desejando ter mais amigos.

27. Voce se sentiu aborrecido(a) em seu tempo live durante as duas últimas semanas?

1 ( ) Nunca me senti aborrecido(a)

2( ) Em geral, não me senti aborrecido(a).

3 () Senti-me aborecido(a) cerca de metade do tempo.

4( ) Em geral, me senti aborrecido(a) 
5 ( ) Senti-me aborrecido(a) o tempo todo.

Voce é solteiro, separado ou divorciado que nĩo mora com um parceiro sexual?

$\begin{array}{ll}1 \text { ( ) SIM, responda as questões } 28 \text { e } 29 . & 2 \text { ( ) NÃO, passe para a questão } 30 .\end{array}$

28. Quantas vezes você teve um encontro com intençōes amorosas

1) Mais de 3 vezes. 2( ) 3 vezes. 3( ) 2 vezes. 4( ) Uma vez. 5( ) Nenhuma vez.

29. Você se interessou por ter encontros amorosos nas duas últimas semanas? Se não os teve. gostaria de têlos tido?

1 ( ) Interessei-me por encontros o tempo todo.

2 ( ) A mair parte do tempo me interessei por encontros.

3 ( ) Cerca de metade do tempo me interessei por encontros.

4 ( ) Não me interessei por encontros a maior parte do tempo.

5 ( ) Estive totalmente desinteressado em encontros.

FAMILIA

Responda as Questões 30-37 sobre seus pais, irmāos, irmās, cunhados, sogros, e crianças que não

moram em sua casa. Você esteve em contato com algum deles was duas últimas semanas?

1 ( ) SIM, responda as questões $30-37$. 2( ) NÃO, passe para a questão 36.

30. Você teve algum tipo de discussão com seus parentes nas duas últimas scmanas?

1 ( ) Nos relacionamos bem o tempo todo.

2( ) Em geral. nos relacionamos bem. mas tive pequenas discussões.

3 ( ) Tive mais de uma discussão com pelo menos um parente.

4 ( ) Tive várias discussões.

5 ( ) Tive discussões constantes.

31. Você foi capaz. de conversar sobre seus sentimentos e problemas com pelo menos um parente nas duas ultimas semanas?

1 ( ) Posso sempre falar sobre meus sentimentos com pelo menos um parente.

2 ( ) Em geral, posso falar sobre meus sentimentos.

3 ( ) Consegui falar sobre meus sentimentos cerca de metade do tempo

4 ( ) Com frequência não consegui falar sobre meus sentimentos.

5 ( ) Nunca consegui falar sobre meus sentimentos.

32. Você evitou contato com seus familiares nas duas últimas semanas?

1 ( ) Procurei meus familiares regularmente.

2 ( ) Procurei algum familiar pelo menos uma vez.

3 ( ) Esperei que meus familiares me procurassem.

4 ( ) Evitei meus familiares mas eles me procurassem.

5 () Não tenho contato com nerhum familiar.

33. Você dependeu de seus familiares para obter ajuda, conselhos, dinheiro, ou afeto nas duas últimas semanas?

1 ( ) Em nenhum momento preciso ou dependo deles.

2 ( ) Em geral, não dependi deles.

3 ( ) Dependi deles cerca de metade do tempo.

4 () Dependo deles a maior parte do tempo.

5 ( ) Dependo completamente de meus familiares.

34. Você quis contrariar seus familiares a fim de provoca-los nas duas últimas semanas?

1 ( ) Não quis contrariá-los.

2 ( ) Una ou duas vezes quiz contrariá-los

3 () Quis contrariá-los cerca de metade do tempo.

4 ( ) Quis contrariá-los a maior parte do tempo.

5 ( ) Eu os contrariei o tempo todo.

35. Você se preocupou, sern nenhuma razão, com coisas que pudessem acontecer a seus familiares nas duas últimas semanas?

1 ( ) Não me preocupei sem razão.

2 ( ) Preocupei-me uma ou duas vezes. 
3 ( ) Preocupei-me cerca de metade do tempo.

4 ( ) Preocupei-me a maior pane do tempo

5 ( ) Preocupei-me o tempo todo.

8 ( ) Não se aplica, não tenho familiares.

Todos respondem as Questões 36 e 37, mesmo que não tenham familiares. 36. Nas duas últimas semanas você achou que decepcionou ou foi injusto(a) com seus familiares?

1 ( ) Não achei que os decepcionei em nada.

2 ( ) Em geril, não achei que os decepcionei.

3 ( ) Cerca de metade do tempo achei que os decepcionei.

4( ) A maior parte do tempo achei que os decepcionei.

5 ( ) O tempo todo achei que os decepcionei.

37. Em algum momento nas últimas duas semanas você achou que seus familiares o decepcionaram ou foram injusto com você.

1( ) En nenlum momento achei que eles me decepcionaram.

2 () Em geral, achei que eles não me decepcionaram.

3 ( ) Cerca de metade do tempo achei que eles me decepcionaram.

4 ( ) A maior parte do tempo achei que eles me decepcionaram.

5 ( ) Tenho muita mágoa porque eles me decepcionaram.

Você mora com seu cônjuge ou esta morando'cum ampanumirasazan: ${ }^{\text {" }}$

1 () SIM, responda as questões 38-46. 2 ( ) NÃO, passe para a qustão 47.

38. Você teve algum tipo de discussão com seu companheiro(a) nas duas últimas semanas?

1 ( ) Não tivemos nenhuma discussão e nos relacionamos muito bem.

2 ( Em geral, nos relacionamos bem, mas tivemos pequenas discussões.

3 ( ) Tivemos mais de una discussão.

4 () Tivemos várias discussões.

5 ( ) Tivemos discussões constantemente.

39. Você foi capaz de conversar sobre seus sentimentos e problemas com seu companheiro(a) nas duas últimas semanas?

1 ( ) Pude sempre falar sobre meus sentimentos liv remente.

2( ) Em geral, pude falar sobre meus sentimentos.

3 ( ) Consegui falar sobre meus sentimentos cerca de metade do tempo.

4 ( ) Com frequência não consegui falar sobre meus sentimentos.

5 () Em nenhum momento consegui falar sobre meus sentimentos.

40. Você exigiu que as coisas em casa fossem feitas do seu jeito nas duas últimas semanas?

1 ( ) Eu não insisti para que as coisas fossem feitas do meu jeito.

2 ( ) Em geral, eu não insisti para que as coisas.

3 ( ) Cerca da metade do tempo eu insisti para que as coisas fossem feitas do meu jeito.

4 () Em geral, cu insisti para que as coisas fossem feitas do meu jeito.

5 ( ) O tempo todo eu insisti para que as coisas fossem feitas do meu jeito.

41. Você sentiu que seu companheiro(a) foi autoritário com você ou ficou "pegando no seu pé " nas duas últimas semanas?

1 ( ) Quase nunca. 4 ( ) A maior parte do tempo.

2 ( ) De vez en quando.

5 () O icmpo 10 do.

3 ( ) Cerca de metade do tempo.

42. Você se sentiu dependente de seu companheiro(a) nas duas últimas semanas?

1 ( ) Senti-me independente.

2 () Em geral, senti-me indepedente.

3 () Senti-me um tanto depedente.

4 () Em geral, senti-me dependente.

5 ( ) Dependi de meu companheiro(a) para tudo.

43. Como voce se sentiu en relação a seu companheiro(a) nas duas últimas semanas?.

1 ( ) Senti afeto o tempo todo. $\quad+$ ( ) En geral. senti desagrado. 
2( ) Em geral, senti afeto.

5 ( ) Senti desagrado o tempo todo.

3 ( ) Cerca de melade do tempo senti afeto c cerca de metade do tempo senti desagrado. 44. Quantas vezes você e scu companheiro (a) tiveram relações sexuais?

1 ( ) Mais de 2 vezes por semana.

2 ( ) $1-2$ vezes por semana.

3 ( ) 1 vez cada duas semanas.

t( ) Menos de una vez a cada duas scmanas, mas pelo menos uma vez no último mês.

5 ( ) Nenhuma vez no último mês ou mais.

45. Você teve algum problema durante relações sexuais, tais como dor. nas duas últimas semanas?

1 ( ) Nenhum.

2( ) Uma ou duas vezes.

3 ( ) Cerca de metade das vezes.

4 ( ) A maior parte das vezes.

5 ( ) Todas as vezes.

8 ( ) Não se aplica, não tive relações sexuais nas duas últimas semanas.

46. Como você se sentiu quanto às relações sexuais nas duas ultimas semanas?

1 ( ) Senti prazer todas as vezes.

2( ) Em geral, senti prazer.

3 ( ) Senti prazer cerca de metade das vezes.

4( ) Em geral, não senti prazer.

5 ( ) Não senti prazer nenhuma das vezes.

\section{RLHOS}

Nas duas útimas semanas estiveram morando com voce filhos solteiros, adotivos ou enteados?

1 ( ) SIM, responda as questões $47-502$ ( ) Ñ̃O, passe para a questão 51

47. Você tem se interessado(a) pelas atividades de seus filhos, escola, lazer durante as duas últimas semanas?

1 ( ) Intercssei-me e estive ativamente envolvido o tempo todo.

2 ( ) Em geral, interessci-me e estive envolvido.

3 ( ) Cerca de metade do tempo interessei-me.

4 ( ) Estive desinteressado(a) o tempo todo.

48. Você foi capaz de conversar e ouvir seus filhos nas duas últimas semanas? (crianças maiores de 2 anos).

1 () Sempre consegui comunicar-me com eles.

2 ( ) Em geral, consegui comunicar-me com eles.

3 ( ) Cerca de metade das vezes consegui comunicar-ine com cles.

4 ( ) Em geral, não consegui comunicar-me com eles

5 ( ) Não consegui comunicar-me com eles.

8 ( ) Não se aplica, não tenho fithos maiores de 2 anos.

49. Como você se relacionou com seus fithos nas duas últimas semanas?

1 ( ) Não tive nenhuma discussão e me relacionei muito bem.

2 ( ) Em geral, me relacionei bem, mas tive pequenas discussões.

3 () Tive mais de uma discussão.

4 ( ) Tive várias discussões.

5 ( ) Tive discussões constantemente.

50. Como você se sentiu $\mathrm{cm}$ relação a seus filhos nas duas últimas semanas?

1 ( ) Senti afeto o tempo todo.

2 () Em geral senti afeto.

3 ( ) Cerca de metade do tempo senti afeto.

4 ( ) Em geral, não senti afeio.

5 ( ) Em nenhum momento seuti afeto.

VIDA FAMILIAR

Você já foi casado, viveu com um parceiro sexual ou teve filhos?

1 () SIM, responda as questóes 51-53. 2 ( ) NÃO, passe para a questão 54. 
51. Você se preocupou com seu companheiro(a) ou algum de seus filhos nenhuma razão nas duas últimas semanas, mesmo não estando morandojuntos atualmente?

1 ( ) Não me preocupei.

2 ( ) Preocupei-me uma ou duas vezes.

3 ( ) Preocupai-me cerca de metade do tempo.

4 ( ) Preocupai-me a maior parte do tempo.

5 ( ) Preocupei-me o tempo todo.

8 ( ) Não se aplica, não tenho companheiro ou filhos vivos.

52. Em algum momento nas duas últimas semanas você achou que decepcionou o seu parceiro ou algum de scus filhos?

1 ( ) Não achei que os decepcionei em nada.

2 ( ) Em geral, não senti que os decepcionei.

3 ( ) Cerca de metade do tempo achei que os decpcionei.

4 ( ) A maior parte do tempo achei que os decepcionci.

5 ( ) Eu os decepcionei completamente.

53. Em algum momento nas duas últimas semanas você achou que seu companheiro ou algum de seus fillhos o decepcionou?

1 ( ) Em nenhum momento achei que eles me decepcionaram.

2 ( ) Em geral, achei que eles não me decepcionaram

3 ( ) Cerca de metade do tempo achei que eles me decepcionaram.

4 () Em geral, achei que eles me decepcionaram.

5 ( ) Tenho muita mágoa porque cles me me decepcionaram.

\section{SITUAÇÃO FINANCEIRA}

Todos respondem à questão 54 .

54 . Você teve dinheiro suficiente para suprir suas necessidades e as de sua família nas duas últimas semanas?

1 ( ) Tive dinheiro suficiente para as necessidades básicas.

2 ( ) Em geral, tive dinheiro suficiente, porém com pequenas dificuldades.

3 ( ) Cerca de metade do tempo tive dificuldades financciras, porém não precisei pedir dinheiro emprestado.

4 ( ) Em geral, não tive dinheiro suficiente e precisei pedir dinheiro emprestado.

5 ( ) Tive sérias dificuldades financeiras. 
ATUALMENTE - freqüentemente eu apresento os seguintes comportamentos:

\begin{tabular}{|l|c|c|}
\hline \multicolumn{1}{|c|}{ COMPORTAMENTOS } & SIM & NÃO \\
\hline 1) Hiperatividade motora desde a infância (não paro de me mexer) & & \\
\hline 2) Déficits atencionais desde a infância (dificuldade em prestar atenção) & & \\
\hline 3) Labilidade Afetiva (mudo de humor rapidamente) & & \\
\hline $\begin{array}{l}\text { 4) Incapacidade para completar tarefas (não consigo terminar o que } \\
\text { comecei) }\end{array}$ & & \\
\hline 5) Temperamento quente ou explosivo (nervoso) & & \\
\hline $\begin{array}{l}\text { 6) Relacionamentos interpessoais prejudicados ou incapacidade de manter } \\
\text { relacionamentos ao longo do tempo }\end{array}$ & & \\
\hline 7) Impulsividade (atuo sem pensar) & & \\
\hline 8) Intolerância à frustração (não agüento situações desconfortáveis) & & \\
\hline
\end{tabular}

Fonte: Wender et al., 1981: "The Utah Criteria" Déficit de Atenção em Adultos " 
NA INFÂNCIA

\begin{tabular}{|l|l|l|l|l|l|}
\hline Quando criança, eu era (tinha)... & $\begin{array}{c}\text { Nada ou } \\
\text { muito } \\
\text { pouco }\end{array}$ & Um pouco & $\begin{array}{c}\text { Moderada- } \\
\text { mente }\end{array}$ & Muito & $\begin{array}{c}\text { Bastante } \\
\text { ou } \\
\text { totalmente }\end{array}$ \\
\hline 1) problemas de concentração & & & & & \\
\hline 2) ansioso, preocupado & & & & & \\
\hline 3) nervoso, impaciente & & & & & \\
\hline 4) desatento, sonhava acordado & & & & & \\
\hline 5) temperamento quente, pavio curto & & & & & \\
\hline 6) explosivo, acessos de raiva & & & & \\
\hline $\begin{array}{l}\text { 7) incapacidade de concluir tarefas } \\
\text { iniciadas }\end{array}$ & & & & & \\
\hline 8) teimoso, inflexível & & & & & \\
\hline 9) triste, deprimido, infeliz & & & & \\
\hline 10) desobediente, rebelde & & & & \\
\hline 11) Baixa auto-estima, desvalorizado & & & & & \\
\hline 12) irritável & & & & & \\
\hline 13) mau humorado, altos e baixos & & & & & \\
\hline 14) raiva & & & & & \\
\hline $\begin{array}{l}\text { 15) dificuldade em ver as coisas sob o } \\
\text { ponto de vista de outra criança }\end{array}$ & & & & & \\
\hline 16) agia sem pensar, impulsivo & & & & & \\
\hline 17) tendência a ser imaturo & & & & & \\
\hline 18) sentimentos de culpa, lamentos & & & & & \\
\hline 19) perda de controle de si próprio & & & & & \\
\hline 20) tendência a ser ou atuar irracionalmente & & & & & \\
\hline $\begin{array}{l}\text { 21) pouco popular com outras crianças, não } \\
\text { mantinha amizades por muito tempo, não } \\
\text { ficava com crianças por muito tempo }\end{array}$ & & & & & \\
\hline $\begin{array}{l}\text { 22) problemas com autoridades, problemas } \\
\text { na escola, visitas ao diretor do colégio }\end{array}$ & & & & & \\
\hline $\begin{array}{l}\text { 23) no geral eu era um aluno ruim, lento } \\
\text { para aprender }\end{array}$ & & & & & \\
\hline $\begin{array}{l}\text { 24) dificuldades com matemática ou } \\
\text { numeros }\end{array}$ & & & & & \\
\hline 25) não conseguia atingir meu potencial & & & & & \\
\hline
\end{tabular}

Fonte: Ward et al., 1993. Wender Utah Rating Scale (WURS). Am J Psychiatry 150:6 
NA INFÂNCIA: apresentou os seguintes comportamentos de uma forma não adaptada ao ambiente e inconsistente com o nível de desenvolvimento, persistindo por pelo menos seis meses (APA, 1994/1995):

\begin{tabular}{|c|c|c|c|}
\hline & COMPORTAMENTOS (Atenção) & SIM & NÃO \\
\hline & $\begin{array}{l}\text { freqüentemente deixava de prestar atenção a detalhes ou cometia erros por descuido em } \\
\text { atividades escolares, de trabalho ou outras. }\end{array}$ & & \\
\hline b) & Com freqüência tinha dificuldades para manter a atenção em tarefas ou atividades lúdicas & & \\
\hline c) & Com freqüência parecia não escutar quando Ihe dirigiam a palavra & & \\
\hline d) & $\begin{array}{l}\text { Com freqüência não seguia as instruções e não terminava seus deveres escolares, } \\
\text { tarefas domésticas ou deveres profissionais (exceto a comportamento de oposição ou } \\
\text { incapacidade de compreender instruções) }\end{array}$ & & \\
\hline e) & Com freqüência tinha dificuldade para organizar tarefas ou atividades & & \\
\hline f) & $\begin{array}{l}\text { Com freqüência evitava, antipatizava ou relutava a envolver-se em tarefas que exigiam } \\
\text { esforço mental constante (como tarefas escolares ou deveres de casa) }\end{array}$ & & \\
\hline & $\begin{array}{l}\text { Com freqüência perdia coisas necessárias para tarefas ou atividades (por ex., brinquedos, } \\
\text { tarefas escolares, lápis, livros ou outros materiais) }\end{array}$ & & \\
\hline h) & Era facilmente distraído por estímulos alheios à tarefa & & \\
\hline & Com freqüência apresentava esquecimento em atividades diárias & & \\
\hline
\end{tabular}

\begin{tabular}{|ll|c|c|}
\hline \multicolumn{1}{|c|}{ COMPORTAMENTOS (Hiperatividade/impulsividade) } & SIM & NÃO \\
\hline a) & Freqüentemente agitava as mãos ou os pés ou se remexia na cadeira & & \\
\hline b) & $\begin{array}{l}\text { Freqüentemente abandonava sua cadeira em sala de aula ou outras situações nas quais } \\
\text { se esperava que permanecesse sentado }\end{array}$ & \\
\hline c) & $\begin{array}{l}\text { Freqüentemente corria ou escalava em demasia, em situações nas quais isso era } \\
\text { inapropriado (sensação de inquietação) }\end{array}$ & & \\
\hline d) & $\begin{array}{l}\text { Com freqüência tinha dificuldade para brincar ou se envolver silenciosamente em } \\
\text { atividades de lazer }\end{array}$ & & \\
\hline e) & Estava freqüentemente "a mil" ou muitas vezes agia como se estivesse "a todo vapor" & & \\
\hline f) & Freqüentemente falava em demasia & & \\
\hline g) & $\begin{array}{l}\text { Freqüentemente dava respostas precipitadas antes de as perguntas terem sido } \\
\text { completadas }\end{array}$ & & \\
\hline h) & Com freqüência tinha dificuldade para aguardar sua vez & \\
\hline i) & $\begin{array}{l}\text { Freqüentemente interrompia ou se metia em assuntos de outros (por. ex., intrometia-se } \\
\text { em conversas ou brincadeiras) }\end{array}$ & \\
\hline
\end{tabular}




\section{ESCALA DE INTENSIDADE DA DEPENDÊNCIA DE COCAÍNA}

Nome:

RgHC:
Data: 1

Aval $\mathrm{n}^{\circ}$ :

\begin{tabular}{|c|c|c|}
\hline & SIM & NÃQ \\
\hline Você vem tendo dificuldade de recusar cocaína quando esta the é oferecida? & & \\
\hline $\begin{array}{l}\text { Você tem a tendência de consumir toda a quantidade de cocaína que têm em mãos, mesmo quando } \\
\text { deseja guardar um pouco para outra ocasião? }\end{array}$ & & \\
\hline Você já tentou parar seu consumo de cocaína, mas viu que "alguma coisa" fazia sempre você recair? & & \\
\hline Você às vezes fica consumindo cocaína durante 12 ou 24 horas seguidas? & & \\
\hline Você precisa ter consumido cocaína para poder se sentir bem ("estar legal")? & & \\
\hline Você acha, ou mesmo tem medo de, que as coisas fiquem aborrecidas e você infeliz sem a cocaina? & & \\
\hline Você teme que não seria capaz de cumprir suas obrigações e funções sem o consumo de cocaina? & & \\
\hline $\begin{array}{l}\text { Ver cocaina, pensamentos sobre a droga ou a simples menção do nome despertam em você um desejo } \\
\text { irresistivel de usar cocaina? }\end{array}$ & & \\
\hline Algumas vezes você chega a ficar preocupado com seus pensamentos sobre a cocaina? & & \\
\hline Você sente, pelo menos às vezes, uma compulsão irresistível de consumir cocaína? & & \\
\hline Você se acha psicologicamente dependente da cocaína? & & \\
\hline Você às vezes se sente culpado ou envergonhado por consumir cocaína? Isto faz com que se sinta mal? & & \\
\hline $\begin{array}{l}\text { Você tem ficado mais isolado ou passado menos tempo com pessoas "caretas" desde que tem } \\
\text { consumido cocaina? }\end{array}$ & & \\
\hline Yocê têm medo do poder do seu hábito de consumir a cocaína? & & \\
\hline $\begin{array}{l}\text { Você tende a passar seu tempo com determinadas pessoas ou freqüenta "certos" lugares por saber } \\
\text { que a cocaina estará disponivel? }\end{array}$ & & \\
\hline Você consome cocaína durante o trabalho? (inclui para ir trabalhar e nos intervalos) & & \\
\hline $\begin{array}{l}\text { Algumas pessoas têm falado que o scu comportamento ou sua personalidade mudou, mesmo } \\
\text { que estas pessoas não saibam de seu consumo de cocaina? }\end{array}$ & & \\
\hline Seu consumo de cocaina resultou em abuso de álcool? & & \\
\hline Você costuma dirigir automóvel sob o efeito (intoxicado) por cocaína? & & \\
\hline Você deixou (negligenciou) alguma responsabilidade em casa ou no trabalho por causa do consumo? & & \\
\hline $\begin{array}{l}\text { Você percebe que alguns (ou vários) dos valores que você tinha antes mudaram após você ter } \\
\text { começado a consumir a cocaina? }\end{array}$ & & \\
\hline $\begin{array}{l}\text { Você já se envolveu com tráfico para ter dinheiro para comprar cocaína? } \\
\text { (Inclui pequeno tráfico e para amigos) }\end{array}$ & & \\
\hline Você acha que usaria maior quantidade de cocaina se tivesse mais dinheiro ou tivesse acesso mais fácil? & & \\
\hline $\begin{array}{l}\text { Você esconde seu consumo de cocaína de seus amigos mais próximos ou de sua família por temer as } \\
\text { reações destes? }\end{array}$ & & \\
\hline Você se desinteressou por atividades "saudáveis" que antes você tinha? (exercício, esportes, lazer) & & \\
\hline Você se desinteressou por seu trabalho ou sua carreira profissional desde que consome cocaina? & & \\
\hline Você percebe que às vezes mente ou dá desculpas estranhas por causa do seu consumo de cocaina? & & \\
\hline Você tende a diminuir ou negar a intensidade do consumo de cocaína e dos problemas que este causou? & & \\
\hline Você foi incapaz de interromper o consumo quando percebeu que esta estava the trazendo problemas? & & \\
\hline Seu consumo prejudicou seriamente seu trabalho ou carreira profissional? & & \\
\hline Você acha que não conseguiria ter uma vida "normal" e satisfatória sem consumir a cocaína? & & \\
\hline Você têm tido problemas financeiros devido ao seu consumo de cocaína? & & \\
\hline Você têm tido problemas com seu companheiro(a) ou cônjuge por causa de seu consumo de cocaína? & & \\
\hline Seu consumo de cocaína causou resultados negativos ou algum problema na sua saúde fisica? & & \\
\hline A cocaína têm alterado scu estado de humor, ânimo ou outra função de seu estado mental? & & \\
\hline Suz atividade sexual têm sido prejudicada (em intensidade ou satisfação) por seu uso de cocaina? & & \\
\hline Você tomou-se menos sociável após ter aumentado seu consumo de cocaina? & & \\
\hline Você perdeu dias de trabalho ou de escola pelo consumo de cocaína? & & \\
\hline
\end{tabular}

TOTAL: (Sim) / 38 


\section{PERFIL DO CONSUMO DE COCAIINA}

Nome:

RgHC:

Data:

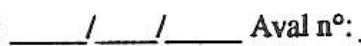

\section{CONSUMO DE COCAIINA}

1. Quando consumiu cocaina pela primeira vez?

2. Qual a via utilizada inicialmente? [ ] cheirada [ ] fumada (crack) [ ] endovenosa

3. Por quanto tempo, até quando consumiu cocaína de modo ocasional, até que tornou-se mais intenso e regular?

4. Alguma vez fumou crack (pasta, pedra)? [ ] ] ] sim [ ] não [ ] não
5. Alguma vez injetou-se cocaina?

6. Atualmente, qual a via utilizada? [ ] cheirada [ ] fumada (crack) [ ] endovenosa

7. Em média, qual a quantidade de cocaina consumida por semana (em gramas)? gramas.

8. Qual o gasto semanal, em reais, com cocaina?

9. Em média, quantos dias por semana consome cocaina?

[ ]1 (um) [ ]2 (dois) [ ]3 (três) [ ] 4 (quatro) [ ]5 (cinco) [ ]6 (seis) [ ] 7 (sete)

10. O consumo de cocaína costuma ocorrer em "binges"? (episódios de consumo intenso, ininterrupto por várias horas ou dias, de grande quantidade de cocaina, seguindo-se por dias de abstinência)

$$
\text { [ ] sim [ ] não }
$$

Se a resposta for positiva, qual a duração dos binges (em dias)?

Quantos gramas são em média consumidos em um "binge"?

dias ou gramas

11. Em que situações o consumo costuma ocorrer? (assinale todas as alternativas que se apliquem)
[ ] Sozinho [ ] Com amigos [ ] Com cônjuge
[ ] Em casa [ ] Em festas [ ] No trabalho
[ ] Com outro parceiro sexual
[ ] Outras:

12. Em que período do dia o consumo tende a ocorrer? (assinale todas as alternativas que se apliquem)
[ ] Pela manhã
[ ] À tarde
[ ] Inicio da noite
[ ] Madrugada/ fim de noite

13. Desde que começou o consumo regular, qual o maior período que o paciente permaneceu abstinente? meses

14. Assinale todas as complicaçðes físicas abaixo que apresentou pelo consumo de cocaina:
[ ] Diminuição de energia [ ] Problemas de sono
[ ] Tosse [ ] Sangramento nasal [ ] Sinusite
[ ] Náusea / vômitos
[ ] Catarro escuro
[ ] Palpitaçðes
[ ] Perda de peso excessiva
[ ] Tremor de mão
[ ] Coriza
[ ] Cefaléia
[ ] Hepatite [ ] Outras infecções

[ ] Perda de consciência (coma)

[ ] Outras

15. Assinale abaixo qualquer resultado negativo do consumo de cocaína sobre as funçðes mentais e estados de humor
[ ] Irritação
[ ]Explosões [ ] Depressão [ ] Problemas de memória
[ ] Ataques de pânico
[ ] Paranóia [ ] Diminuição interesse sexual
[ ] Impulsos de violência [ ] Ansiedade / nervosismo

16. Assinale abaixo qualquer resultado negativo do consumo de cocaina sobre o relacionamento com outras pessoas

[ ] Causou discussð̃es com cônjuge / parceiro [ ] Cônjuge / parceiro ameaçou deixar o paciente

[ ] Rompimento de relacionamento afetivo [ ] Paciente isolou-se dos outros

[ ] Prejudicou capacidade de conversar honesta e abertamente com os outros

[ ] Prejudicou a interação social

17. Assinale abaixo as conseqüências do consumo sobre o trabalho ou estudo: [ ] Atrasos na escola / trabalho [ ] Perda de dia de escola / trabalho 
[ ] Redução da produtividade no trabalho / aproveitamento escolar

[ ] Foi despedido / expulso da escola

[ ] Prejudicou relacionamento com chefe / professores

[ ] Tempo excessivo nos intervalos

[ ] Foi despedido / expulso da escola

[ ] Outras:

18. Assinale abaixo qualquer efeito do consumo de cocaina na situação econômica / financeira do paciente:

[ ] Gastou todo dinheiro guardado que tinha [ ] Passou a vender objetos pessoais

I I Incapacidade de arcar com suas despesas e contas

[ ] Ficou com dividas

[ ] Envolvimento com atividades ilicitas para obter dinheiro para o consumo

( ) Outras:

19. Assinale qualquer conseqüência legal do consumo: '

[ ] Detido por porte/posse [ ] Prisão por tráfico

[ ] Prisão por outras atividades ilícitas ligadas ao consumo

[ ] Outras:

20. O consumo de cocaína promoveu alguma das situaçðes abaixo (assinale todas as que ocorreram):

[ ] Acidente automobilístico [ ] Brigas (fisicas) com outras pessoas

[ ] Ter uma relação sexual indesejada [ ] Feriu fisicamente outra pessoa

[ ] Isolamento da familia [ ] Isolamento dos amigos

[ ] Envolvimento com tráfico (mesmo pequeno tráfico) [ ] Ausência do trabalho

[ ] Tentativa de suicidio

\section{CONSUMO DE OUTRAS DROGAS}

1.Assinale abaixo as drogas que o paciente já consumiu:

[ ] Maconha [ ] Anfetaminicos

[ ] Heroina [ ] Morfina ou derivados [ ] LSD

[ ] Outras:

2. Assinale no quadro abaixo as substâncias que o paciente consumiu nos últimos 30(trinta)dias, bem como a freqüência de consumo:

SUBSTANCLA
Maconha
Anfetaminicos
LSD / outros alucinógenos
Diazepan / calmantes
Heroina / derivados de Morfina
Álcool
Tabaco
Outras
3. O paciente sente-se dependente de alguma destas substâncias ?
Caso a resposta seja positiva anote, nas palavras do paciente, porquê sente-se dependente:

4. O paciente teve algum problema pelo uso destas substâncias no passado: [ ] ] sim [ ] não Caso a resposta seja positiva anote por quê:

5. O paciente consumiu alguma destas substâncias de forma regular por período mínimo de 1 mês ou mais? [ ] sim [ ] não 
Quais: [ ] Maconha [ ] Afetamínico [ ]LSD

[ ] Álcool

[ ] Tabaco

[ ] Heroína [ ] Morfina ou derivados [ ] Valium, diazepan ou outros calmantes

6. O paciente faz uso de medicaçóes prescritas por médico? [ ] sim [ ] não

Caso a resposta seja positiva, favor anotar a subsıncia prescrita, a especialidade do médico e a indicação

TRATAMENTO ANTERIOR PARA ABUSO DE ÁLCOOL / DROGAS

1. O paciente já realizou tratamento anterior? [ ] sim [ ] não

\begin{tabular}{|l|c|c|}
\hline $\begin{array}{c}\text { PERIODO EM } \\
\text { TRATAMENTO }\end{array}$ & $\begin{array}{c}\text { PROGRAMA DE } \\
\text { TRATAMENTO }\end{array}$ & $\begin{array}{c}\text { TIPO DE TRATAMENTO } \\
\text { (psicoterapia, médico, AA, etc.) }\end{array}$ \\
\hline & & \\
\hline & $\vdots$ & \\
\hline & & \\
\hline & & \\
\hline
\end{tabular}

2. O paciente já freqüentou $\mathrm{AA}$, NA ou CA ou outro grupo de auto-ajuda? [ ] sim [ ] não Caso positivo, indicar periodo de tratamento: 


\title{
Auto ESA - Escala de Acompanhamento de Alcoolistas e Farmacodependentes
}

\author{
Nome: \\ RgHC \\ Data: \\ Aval n:

\section{QUESTIONÁRIO DE AUTO-AVALIAÇ̃̃O} \\ Assinale um $X$ na alternativa que melhor descreve sua situação quanto a cada uma das questões propostas. \\ (Todas as respostas são sigilosas e só serão conhecidas pela equipe médica)
}

A. Como tem sido seu uso de droga nas últimas 4 semanas?

1. ( ) Não consumi.

2. ( ) Usei apenas nos finais de semana.

3. ( ) Usei nos finais de semana e em alguns dias da semana.

4. ( ) Usei todo dia, mas apenas em alguns períodos do dia.

5. ( ) Usei todo dia, o dia inteiro.

A.1. Qual a via de uso?

1. ( ) Injetável.

2. ( ) Outra via.

3. ( ) Injetável e outra via.

B. Como tem sido seu uso de álcool nas últimas 4 semanas?

1. ( ) Não bebi.

2. ( ) Bebi até no máximo 2 vezes durante a semana.

3. ( ) Bebi de 3 a 5 vezes durante a semana.

4. ( ) Bebi diariamente, com poucos episódios de embriaguez.

5. ( ) Bebi quase todo o tempo, com muitos episódios de embriaguez.

C. Como tem conseguido seu dinheiro?

1. ( )Trabalho estável. Sustento a mim e a minha familia.

2. ( ) Trabalho irregular. Problemas com as atividades, envolvendo bicos.

3. ( ) Sem rendimentos própios. O dinheiro vem da familia ou previdência.

4. ( ) Atividades ilicitas não ligada as drogas ( $\mathrm{p} / \mathrm{ex}$. roubo).

5. ( ) Atividades ilícitas ligadas a drogas.

D. Quais sao suas atividades de lazer?

1. ( ) Atividades gratificantes não ligadas a drogas ou álcool, sempre.(esportes, leitura, música, etc.)

2. ( ) Atividades gratificantes não ligadas a drogas ou álcool, irregular.

3. ( ) Dedico-me a poucas atividades gratificantes além do consumo.

4. ( ) Meu único ou principal passatempo é o uso da droga ou álcool.

2. Como vão seus estudos? (se voce e estudante)

1. ( )Estudo regular, bom aproveitamento.

2. ( ) Estudo irregular, bom aproveitamento.

3. ( ) Estudo irregular, mau aproveitamento.

4. ( ) Repetirei algumas disciplinas ou o ano

5. ( ) Abandonei os estudos. 
F. Qual seu desempenho em atividades cotidianas?

1. ( ) Dou conta plena e satisfatoriamente de minhas atividades domésticas.

2. ( ) Realizo pouco satisfatoriamente minhas atividades cotidianas.

3. ( ) Só realizo minhas atividades quando cobrado ou estimulado.

4. ( ) Não faço nada, ou tenho apenas atividades em companhia de pessoas que usam drogas ou álcool.

5. ( ) Minha única atividade é o uso das drogas.

G. Como estão suas condições de moradia?

1. ( ) Moro em casa.

2. ( ) Moro em casa de parentes que nao meus pais.

3. ( ) Moro numa pensão ou hotel, tenho companhia.

4. ( ) Moro sozinho.

5. ( ) Não tenho endereço fixo ou onde ficar.

H. Como estão suas relações com a familia?

1. ( ) Tenho bom relacionamento com a família.

2. ( ) Mantenho pouco ou nenhum contato com os familiares.

3. ( ) Ocorrem brigas e agressð̋es verbais entre mim e meus familiares.

4. ( ) Ocorrem agressð̃es fisicas entre mim e meus familiares.

5. ( ) Fui expulso ou saí de casa por brigas com os familiares.

I. Você praticou atividade ilegal ou se envolveu com a polícia?

1. ( ) Não tive nenhum desse problemas.

2. ( ) Fui pego por porte para consumo próprio.

3. ( ) Tenho pego coisas em casa para vender ou trocar por drogas.

4. ( ) Pratiquei uma vez roubo, assalto ou tráfico de drogas.

5. ( ) Pratiquei duas ou mais vezes roubo, assalto ou tráfico.

J. Como está sua saúde nos últimos 3 meses?

1. ( ) Sem qualquer doença. Nâo precisei procurar médicos.

2. ( ) Tenho doença sem sintomas (diabetes, HIV, etc.), em acompanhamento médico.

3. ( ) Tenho doença sem sintomas, sem acompanhamento médico regular.

4. ( ) Tenho doença com sintomas ( AIDS, hepatite, etc.), em acompanhamento médico.

5. ( ) Tenho doença com sintomas, sem acompanhamento médico regular. 


\section{APÊNDICE}

\section{Bateria de Avaliação Neuropsicológica (Folhas de Respostas)}




\section{GRUPO DE ESTUDOS DE ÁLCOOL E DROGAS - GREA - IPq - HC - FMUSP}

PROTOCOLO DE AVALIAÇÃO NEUROPSICOLÓGICA
Projeto de Pesquisa: "ALTERAÇÔES NEUROPSICOLÓGICAS EM DEPENDENTES DE
COCAÍNA"

\section{DADOS PESSOAIS}

Nome: Nascimento: Idade:

Escolaridade: Profissão:

Endereço Tel:

Nível Sócio-econômico (Renda familiar mensal): Sexo: $\square \mathrm{M} \square \mathrm{F}$ Etnia: Lateralidade: $\square$ Destro $\square$ Canhoto Ambidestro

\begin{tabular}{|c|c|c|c|}
\hline SIM & $\mathbf{N} \mathbf{A} \mathbf{O}$ & \multicolumn{2}{|c|}{ Critérios de inclusão/exclusão: } \\
\hline & & \multicolumn{2}{|c|}{ dependência de cocaína } \\
\hline & & \multicolumn{2}{|c|}{ dependência de outras substâncias psicoativas; } \\
\hline & & \multicolumn{2}{|c|}{ problemas significativos no nascimento ou no desenvolvimento psicomotor; } \\
\hline & & \multicolumn{2}{|c|}{ outros diagnósticos psiquiátricos do eixo I do DSM-IV (APA, 1994); } \\
\hline & & \multicolumn{2}{|c|}{ uso atual de medicamentos psicoativos; } \\
\hline & & \multicolumn{2}{|c|}{ história de traumatismo crânio-encefálico ou outros problemas neurológicos; } \\
\hline & & \multicolumn{2}{|c|}{ problemas médicos que comprometam de alguma forma o sistema nervoso central; } \\
\hline & & \multicolumn{2}{|c|}{ história de dist. de aprendizagem, retardo mental ou classes especiais. } \\
\hline \multicolumn{3}{|c|}{$\square$ Controle $\left(\mathbf{N}^{\circ}\right.}$. & 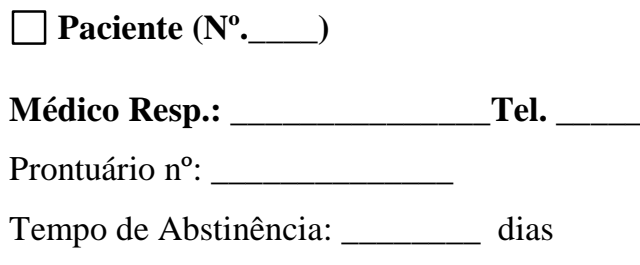 \\
\hline
\end{tabular}




\section{AVALIAÇÃO: Termo de Consentimento ( )}

Conferir material antes de aplicar: Protocolo, Folhas separadas para testes (Trail e Desenhos Alternados de Luria, FAB, SRQ-20 e termo de consentimento) e 4 folhas em branco. Materiais para testes: Stroop (cartelas); cubos (cartões); Wisconsin (cartas); Boston (cartelas); Figura de Rey; Figuras (Memória Visual-WMS/R). Lápis (coloridos e preto), caneta, apontador, cronômetro.

\begin{tabular}{|l|l|l|l|}
\hline Horário & Testes Neuropsicológicos & Horário & Testes Neuropsicológicos \\
\hline & 1. Dígitos (WMS-R) & & 10. FAS (Fluência verbal) \\
\hline & 2. Reprodução Visual I (WMS-R) & & 11. Figura de Rey \\
\hline & 3. Memória Lógica I (WMS-R) & 13. Wisconsin Card Sorting Test \\
\hline & 4. Trail Making Test & 12. Selective Remind Test (SRT) Reconh. \\
\hline & 5. Stroop Color Word Test & 14. Figura de Rey II \\
\hline & 7. Boston Naming Test. & 15. Cubos (WAIS-R) \\
\hline & 8. Reprodução Visual II (WMS-R) & 16. Códigos (WAIS-R): 90" \\
\hline & 9. Memória Lógica II (WMS-R) & 17. Desenhos alternados (Luria) \\
\hline & Escalas DDA-TDAH-WURS & 18. Bateria Frontal (8-10 min)/SRQ-20 \\
\hline
\end{tabular}




\section{HOSPITAL DAS CLÍNICAS}

DA

FACULDADE DE MEDICINA DA UNIVERSIDADE DE SÃO PAULO

\section{TERMO DE CONSENTIMENTO LIVRE E ESCLARECIDO}

O exame que será realizado faz parte de um amplo processo de investigação dos problemas relacionados ao uso de drogas. É constituído por uma série de testes que avaliarão sua atenção, memória, linguagem, bem como seus processos de raciocínio e pensamento, e tem a duração de cerca de duas horas e meia. Estes dados irão ajudar a compreender melhor o seu funcionamento mental, e estas informações serão importantes para ajudar outras pessoas, que apresentam ou não sintomas relacionados ao abuso de drogas.

Para tanto, é necessário agrupar os dados dos exames de várias pessoas para compararmos e obtermos uma idéia mais clara dos problemas que o uso de drogas pode provocar no funcionamento da mente.

Se concordar com este termo, poderemos utilizar as informações deste exame sem que você seja identificado. Podem ser escritos artigos que serão publicados ou apresentados em congressos científicos, mas seu nome nunca será revelado.

Caso não esteja de acordo, o exame não será realizado e não haverá qualquer prejuízo ao seu atendimento neste serviço.

Declaro que, após convenientemente esclarecido pelo pesquisador e ter entendido o que me foi explicado, consinto em participar do presente Protocolo de Pesquisa.

São Paulo, de de 2004.

Nome: $R G$ :

assinatura do voluntário da pesquisa

$\overline{\text { assinatura do pesquisador }}$
(carimbo ou nome Legível)


DÍGITOS (WMS-R)

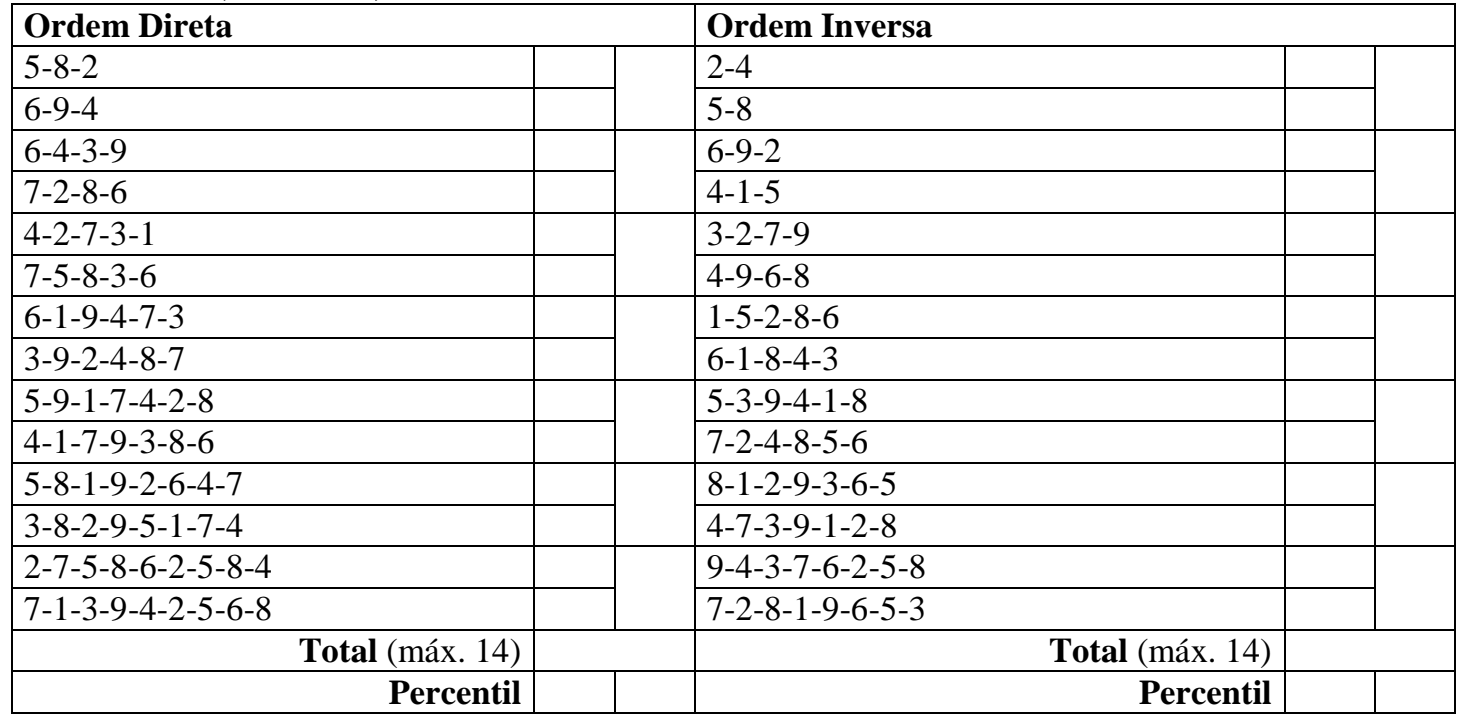

OBS:

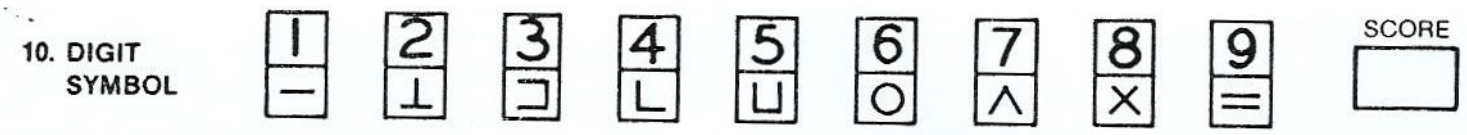

\begin{tabular}{|c|c|c|c|c|c|c|c|c|c|c|c|c|c|c|c|c|c|c|c|c|c|}
\hline \multicolumn{6}{|c|}{ SAMPLES } & \multirow[b]{2}{*}{2} & \multirow{2}{*}{\multicolumn{2}{|c|}{5113}} & \multirow{2}{*}{32} & \multirow{2}{*}{\begin{tabular}{|l|l|}
1 & 4 \\
\end{tabular}} & \multirow[b]{2}{*}{2} & \multirow{2}{*}{\multicolumn{2}{|c|}{$3:$}} & \multirow[b]{2}{*}{2} & \multirow{3}{*}{3} & & \multirow{3}{*}{4} & \multirow{3}{*}{5} & \multirow{3}{*}{\multicolumn{2}{|c|}{\begin{tabular}{l|l|}
6 & 3 \\
\end{tabular}}} & \multirow{3}{*}{12} \\
\hline 2 & 1 & 3 & 7 & 212 & 48 & & & & & & & & & & & & & & & & \\
\hline & & & & & & & & & & & & & & & & & & & & & \\
\hline & 5 & 4 & 2 & 76 & 613 & 35 & 7 & 2 & 8 & $5 / 4$ & 76 & 3 & 7 & 2 & 8 & & $\begin{array}{ll} \\
\end{array}$ & 5 & 82 & & 73 \\
\hline & & & & & & & & & & & & & & & & & & & & & \\
\hline
\end{tabular}
\begin{tabular}{|l|l|l|l|l|l|l|l|l|l|l|l|l|l|l|l|l|l|l|}
\hline 6 & 2 & 5 & 1 & 9 & 2 & 8 & 3 & 7 & 4 & 6 & 5 & 9 & 4 & 8 & 3 & 7 & 2 & 6 \\
\hline
\end{tabular}

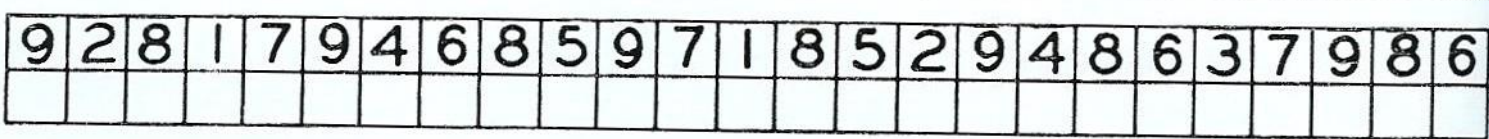




\section{REPRODUÇÃO VISUAL I E II (WMS-R)}

\begin{tabular}{|c|c|c|c|c|c|}
\hline \multicolumn{3}{|l|}{ FIGURA A } & \multicolumn{3}{|l|}{ FIGURA D } \\
\hline Linhas: & $\mathbf{I}$ & II & Retângulos & $\mathbf{I}$ & II \\
\hline 1. inteiras/retas/proporcionais & & & 1. não se encostam/intersectam & & \\
\hline 2. intersecção no centro & & & 2. ângulos interiores 90 graus & & \\
\hline 3. cruzadas com ângulos retos & & & 3. sem rotação (15 graus) & & \\
\hline 4. sem rotação (15 graus) & & & 4. dois menores à direita do maior & & \\
\hline \multicolumn{3}{|l|}{ Bandeiras: } & 5. retângulo mais alto é mais largo & & \\
\hline 5. direção correta & & & 6. bases do maior e menor no mesmo nível & & \\
\hline 6. um lado faz parte da linha & & & 7. topo do maior mais alto do que os menores & & \\
\hline 7. configuração de quadrado & & & 8. bases dos três \pm mesmo tamanho & & \\
\hline Total & & & 9. altura do maior $>$ largura & & \\
\hline \multirow{2}{*}{\multicolumn{3}{|c|}{ FIGURA B }} & 10. altura dos menores < largura & & \\
\hline & & & \multicolumn{3}{|l|}{ Semi-círculo } \\
\hline Círculos: & $\mathbf{I}$ & II & 11. figura à direita dos retângulos & & \\
\hline 1. círculo maior & & & 12. curva do arco para a direita & & \\
\hline 2. círculo médio dentro do maior & & & 13. simetria/proporção & & \\
\hline 3. círculo pequeno dentro do médio & & & 14. sem rotação (15 graus) & & \\
\hline 4. círcs. maior e médio encostados no alto & & & \multicolumn{3}{|l|}{ Triângulo } \\
\hline 5. círcs. pequeno e médio juntos na base & & & 15. figura à direita do semi-círculo & & \\
\hline 6. redondos/fechados & & & 16. vértice encosta no ponto central & & \\
\hline 7. proporção correta & & & 17. contém ângulo de 90 graus & & \\
\hline Total & & & 18. sem rotação (15 graus) & & \\
\hline \multirow{2}{*}{\multicolumn{3}{|c|}{ FIGURA C }} & \multirow{2}{*}{\multicolumn{3}{|c|}{ Total }} \\
\hline & & & & & \\
\hline Quadrado Maior: & $\mathbf{I}$ & II & TOTAL GERAL & $\mathbf{I}$ & II \\
\hline 1. configuração de quadrado & & & Pontuação Bruta $(\mathrm{A}+\mathrm{B}+\mathrm{C}+\mathrm{D})$ & & \\
\hline 2. linhas verticais e horizontais & & & Percentil & & \\
\hline 3. sem rotação (15 graus) & & & Sinal & & \\
\hline 4. cada quadrante tem 4 pontos & & & \multirow{8}{*}{\multicolumn{3}{|c|}{ Observações: }} \\
\hline \multicolumn{3}{|l|}{ Quadrados médios: } & & & \\
\hline \multicolumn{3}{|l|}{ 5. não encostam nos 4 quadrantes } & & & \\
\hline \multicolumn{3}{|l|}{ 6. configuração de quadrado } & & & \\
\hline \multicolumn{3}{|l|}{ 7. linhas verticais e horizontais } & & & \\
\hline \multicolumn{3}{|l|}{ 8. sem rotação (15 graus) } & & & \\
\hline \multicolumn{3}{|l|}{ 9. lados proporcionais } & & & \\
\hline Total & & & & & \\
\hline
\end{tabular}




\section{MEMÓRIA LÓGICA I (WMS-R)}

História A:

\section{Pontos:}

História B:

\section{Pontos:}

\section{MEMÓRIA LÓGICA II (WMS-R)}

História A:

\section{Pontos:}

História B:

\section{Pontos:}

Obs:

Hist. $A+B=$ Percentil: $(\quad)$ 
TRAIL MAKING TEST (TMT)

Parte A: "Vc vai ligar os números na seqüência e na ordem crescente (1 ao 8) procurando não tirar o lápis do papel e o mais rápido possível" (apresentar o exemplo A). Acionar o cronômetro assim que apresentar o teste.

Tempo: s Erros:

Parte B: "Aqui vc vai fazer a mesma coisa, só que você vai ligar os números às letras, também em ordem crescente" (apresentar o exemplo B).

Tempo: s Erros:

Obs:

\section{STROOP TEST}

Parte 1: "Vou te mostrar um cartão e quero que você me diga o nome das cores o mais rápido que você conseguir da esquerda para a direita, como se estivesse lendo um texto". Acionar o cronômetro assim que der o cartão. Quando errar, anotar na folha de resposta qual foi a cor citada e corrigir imediatamente caso o sujeito não o fizer espontaneamente.

\begin{tabular}{|cccc|}
\hline $\mathrm{Vd}$ & $\mathrm{Ro}$ & $\mathrm{Az}$ & $\mathrm{Ma}$ \\
$\mathrm{Ro}$ & $\mathrm{Ma}$ & $\mathrm{Vd}$ & $\mathrm{Az}$ \\
$\mathrm{Az}$ & $\mathrm{Vd}$ & $\mathrm{Ro}$ & $\mathrm{Ma}$ \\
$\mathrm{Ma}$ & $\mathrm{Ro}$ & $\mathrm{Az}$ & $\mathrm{Vd}$ \\
$\mathrm{Ro}$ & $\mathrm{Az}$ & $\mathrm{Vd}$ & $\mathrm{Ma}$ \\
$\mathrm{Ma}$ & $\mathrm{Vd}$ & $\mathrm{Az}$ & $\mathrm{Ro}$ \\
\hline
\end{tabular}

Tempo:

Erros:

Parte 2: "Agora você vai fazer a mesma coisa: me dizer o nome das cores". Se não entender que não é para ler a palavra, repetir as instruções e cronometrar.

\begin{tabular}{|cccc|}
\hline $\mathrm{Vd}$ & $\mathrm{Ro}$ & $\mathrm{Az}$ & $\mathrm{Ma}$ \\
$\mathrm{Ro}$ & $\mathrm{Ma}$ & $\mathrm{Vd}$ & $\mathrm{Az}$ \\
$\mathrm{Az}$ & $\mathrm{Vd}$ & $\mathrm{Ro}$ & $\mathrm{Ma}$ \\
$\mathrm{Ma}$ & $\mathrm{Ro}$ & $\mathrm{Az}$ & $\mathrm{Vd}$ \\
$\mathrm{Ro}$ & $\mathrm{Az}$ & $\mathrm{Vd}$ & $\mathrm{Ma}$ \\
$\mathrm{Ma}$ & $\mathrm{Vd}$ & $\mathrm{Az}$ & $\mathrm{Ro}$ \\
\hline
\end{tabular}

Tempo:

Erros:

Parte 3: Ídem parte 2

\begin{tabular}{|cccc|}
\hline $\mathrm{Vd}$ & $\mathrm{Ro}$ & $\mathrm{Az}$ & $\mathrm{Ma}$ \\
$\mathrm{Ro}$ & $\mathrm{Ma}$ & $\mathrm{Vd}$ & $\mathrm{Az}$ \\
$\mathrm{Az}$ & $\mathrm{Vd}$ & $\mathrm{Ro}$ & $\mathrm{Ma}$ \\
$\mathrm{Ma}$ & $\mathrm{Ro}$ & $\mathrm{Az}$ & $\mathrm{Vd}$ \\
$\mathrm{Ro}$ & $\mathrm{Az}$ & $\mathrm{Vd}$ & $\mathrm{Ma}$ \\
$\mathrm{Ma}$ & $\mathrm{Vd}$ & $\mathrm{Az}$ & $\mathrm{Ro}$ \\
\hline
\end{tabular}

Tempo:

Erros:

Obs: 


\section{CUBOS (WAIS-R)}

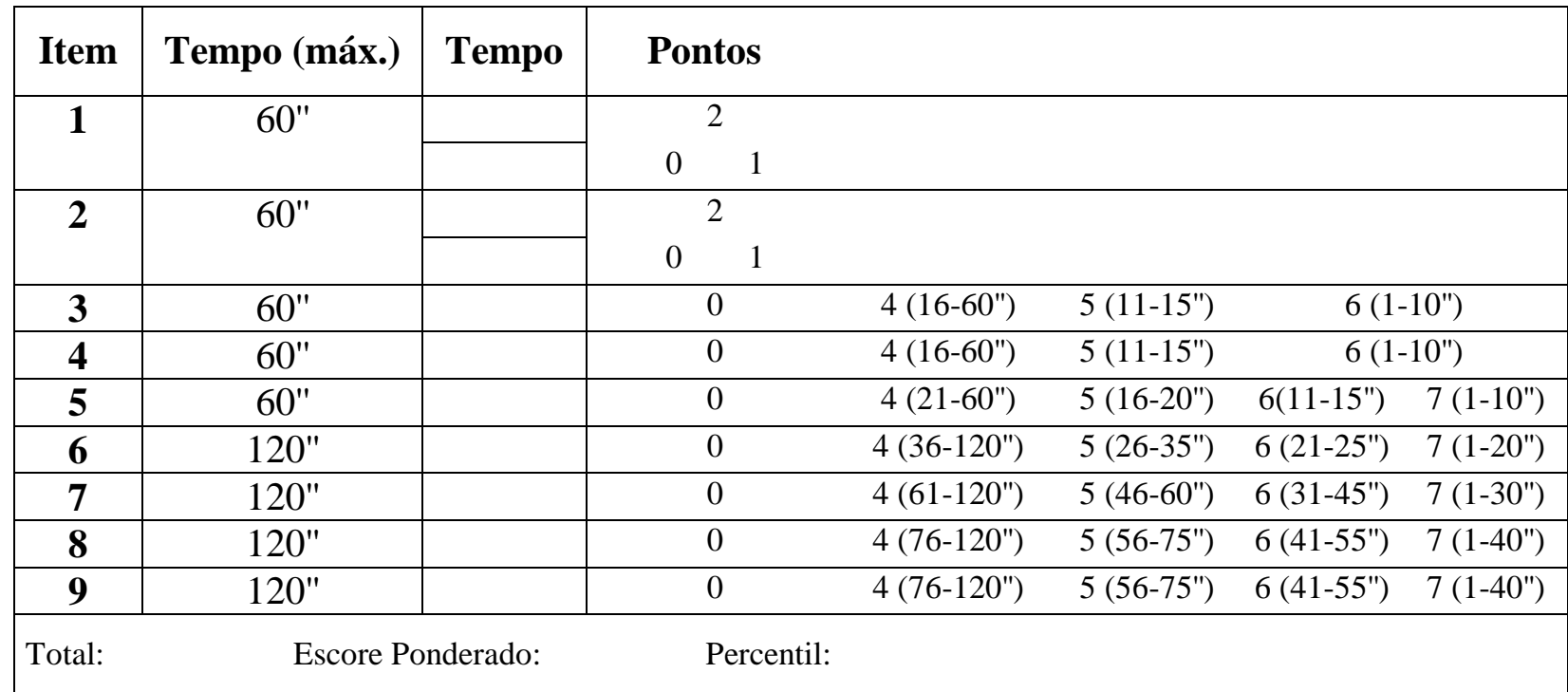

\section{FLUÊNCIA VERBAL/FAS (1 min)}

\begin{tabular}{|l|l|l|}
\hline \multicolumn{1}{|c|}{ ANIMAIS } & \multicolumn{1}{c|}{ COMIDAS } & \multicolumn{1}{c|}{ ROUPAS } \\
\hline & & \\
\hline & & \\
\hline & & \\
\hline & & \\
\hline Sub-total: & & Sub-total: \\
\hline Total: & Sub-total: & \\
\hline
\end{tabular}

\begin{tabular}{|l|l|l|}
\hline \multicolumn{1}{|c|}{ letra F } & \multicolumn{1}{c|}{ letra A } & \multicolumn{1}{c|}{ letra S } \\
\hline & & \\
\hline & & \\
\hline & & \\
\hline & & \\
\hline & & Sub-total: \\
\hline Sub-total: & Sub-total: & \\
\hline Total: & & \\
\hline
\end{tabular}


BOSTON NAMING TEST (BNT)

\begin{tabular}{|c|c|c|c|c|c|c|c|}
\hline Figura & $\mathrm{S} / \mathrm{P}$ & Est & Fon & Figura & S/P & Est & Fon \\
\hline 1. Cama (peça de mobília) & & & & 31. Elefante (um animal) & & & \\
\hline 2. Árvore (cresce lá fora) & & & & 32. Cajú (uma fruta) & & & \\
\hline 3. Lápis (usado p/ escrever) & & & & 33. Iglu, Oca ou Forno (tipo de casa) & & & \\
\hline 4. Casa (um tipo de edifício) & & & & 34. Pernas-de-pau (usado p/ficar alto ) & & & \\
\hline 5. Apito (usado p/ assobiar) & & & & 35. Dominó (um jogo) & & & \\
\hline 6. Tesoura (usado $\mathrm{p} /$ cortar) & & & & 36. Cactus (uma planta) & & & \\
\hline 7. Pente (usado p/ arrumar o cabelo) & & & & 37. Escada-rolante (você anda nela) & & & \\
\hline 8. Flor (cresce no jardim) & & & & 38. Violino (instrumento musical) & & & \\
\hline 9. Serrote (usado por marceneiros) & & & & 39. Rede (você deita nela) & & & \\
\hline 10. Escova (usada na boca) & & & & 40. Relógio-cuco (parte de relógio) & & & \\
\hline 11. Helicóptero (usado p/ voar) & & & & 41. Peru (uma ave) & & & \\
\hline 12. Vassoura (usada p/ limpeza) & & & & 42. Termômetro (os médicos usam ) & & & \\
\hline 13. Polvo(um animal marinho) & & & & 43. Cristo Redentor (está no Rio - RJ) & & & \\
\hline 14. Cogumelo( algo p/ comer) & & & & 44. Focinheira (cachorro usa) & & & \\
\hline 15. Cabide (usa no armário) & & & & 45. Saci (personagem do folclore) & & & \\
\hline 16. Cadeira de rodas (tem em hospital) & & & & 46. Funil (usado com líquidos) & & & \\
\hline 17. Camelo (um animal) & & & & 47. Sanfona (instrumento musical) & & & \\
\hline 18. Máscara (parte de fantasia) & & & & 48. Forca (usada pelo carrasco) & & & \\
\hline 19. Brigadeiro - Bolo (algo p/ comer) & & & & 49. Beterraba, nabo, cebola (legume) & & & \\
\hline 20. Banco (usado p/ sentar) & & & & 50. Grampeador (p/ prender papéis) & & & \\
\hline 21. Raquete (usa em esportes) & & & & 51. Tranca/Trinco/Tra-mela (tem na porta) & & & \\
\hline 22. Caracol / Lesma (um animal) & & & & 52. Fita métrica, Trena (pedreiro usa) & & & \\
\hline 23. Vulcão (um tipo de montanha) & & & & 53. Lupa (usado p/ ver coisas aumentadas) & & & \\
\hline 24. Cavalo-marinho (animal- marinho) & & & & 54. Pegador, Pinça de gelo ( utensílio) & & & \\
\hline 25. Dardo/Flecha (você atira ele) & & & & 55. Pão de Açúcar (tem no Rio -RJ) & & & \\
\hline 26. Canoa / Bote (usado na água) & & & & 56. Estribo (usado em animais) & & & \\
\hline 27. Globo-terrestre (um tipo de mapa) & & & & 57. Treliça,Cerca, Gra de (tem no jardim) & & & \\
\hline 28. Buque / Arranjo (usado p/ decorar) & & & & 58. Estojo ou caixa d. lápis(p/ desenho) & & & \\
\hline 29. Tamanduá (um animal) & & & & 59. Furadeira (usada $\mathrm{p} /$ perfurar) & & & \\
\hline 30. Gaita (instrumento musical) & & & & 60. Ampulheta (usado para medir tempo) & & & \\
\hline
\end{tabular}

\begin{tabular}{|l|l|}
\hline Pontuação & Total \\
\hline Respostas corretas espontâneas (s/p) & \\
\hline Pistas-estímulo fornecidas & \\
\hline Acertos após pistas-estímulo (est) & \\
\hline
\end{tabular}

\begin{tabular}{|l|c|}
\hline Pontuação & Total \\
\hline Pistas fonêmicas fornecidas & \\
\hline Acertos após pistas fonêmicas (fon) & \\
\hline Total de corretas (s/p+est+fon) & \\
\hline Total de confabulações visuais & \\
\hline
\end{tabular}

\section{OBS:}




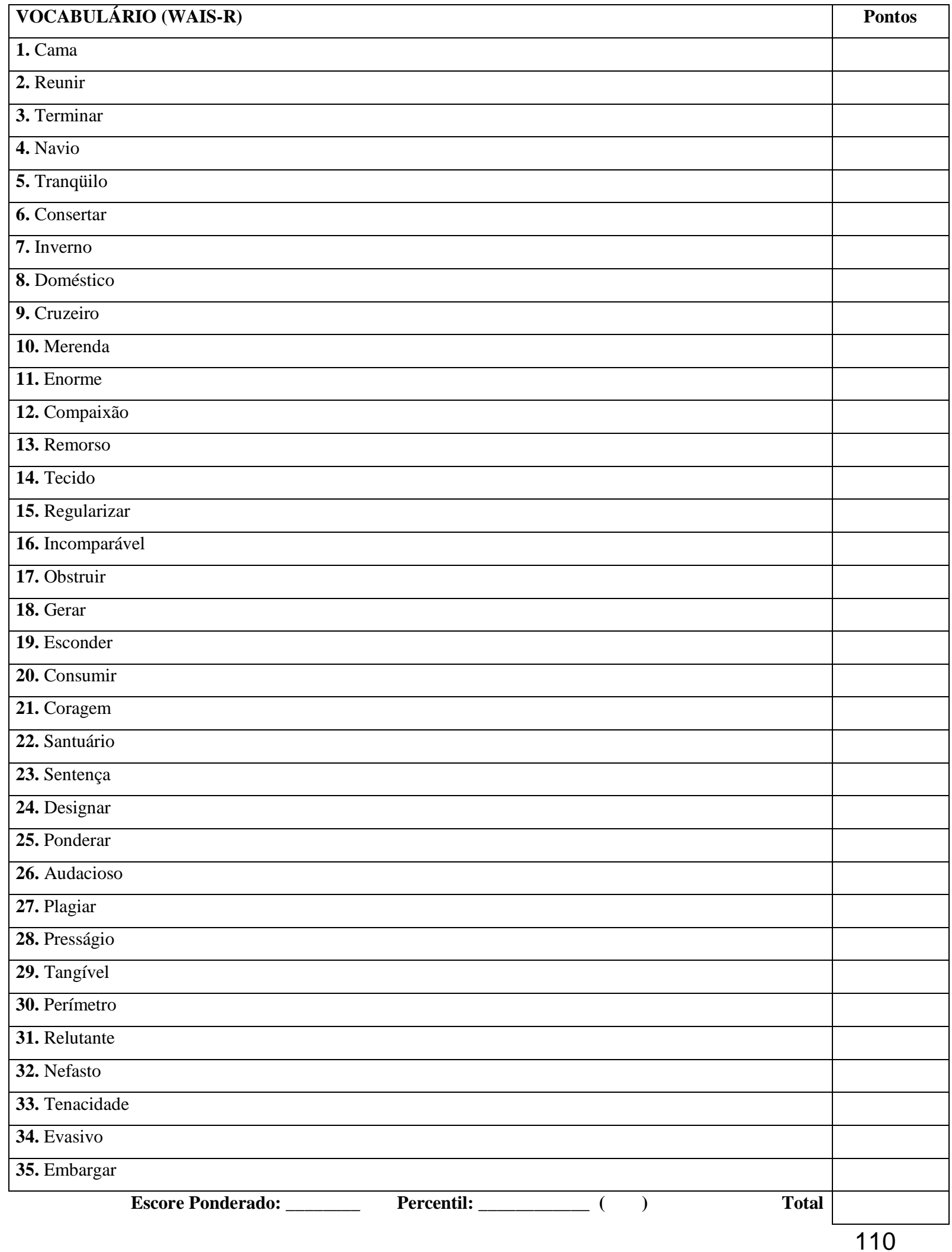




\section{FIGURA DE REY (CÓPIA)}

"Vou lhe mostrar esse desenho e você vai copiá-lo o mais parecido possível" (balão para baixo na posição do sujeito). "Não é necessário fazer a cópia exata; no entanto, é preciso prestar atenção às proporções e, sobretudo, não esquecer nada. Não é necessário ter pressa. Comece com este lápis". Ao final, perguntar se está pronto.

Ordem das cores: $1^{\mathrm{a}}$ ) $\left.2^{\mathrm{a}}\right)$ $\left.3^{\mathrm{a}}\right)$ $\left.4^{\mathrm{a}}\right)$

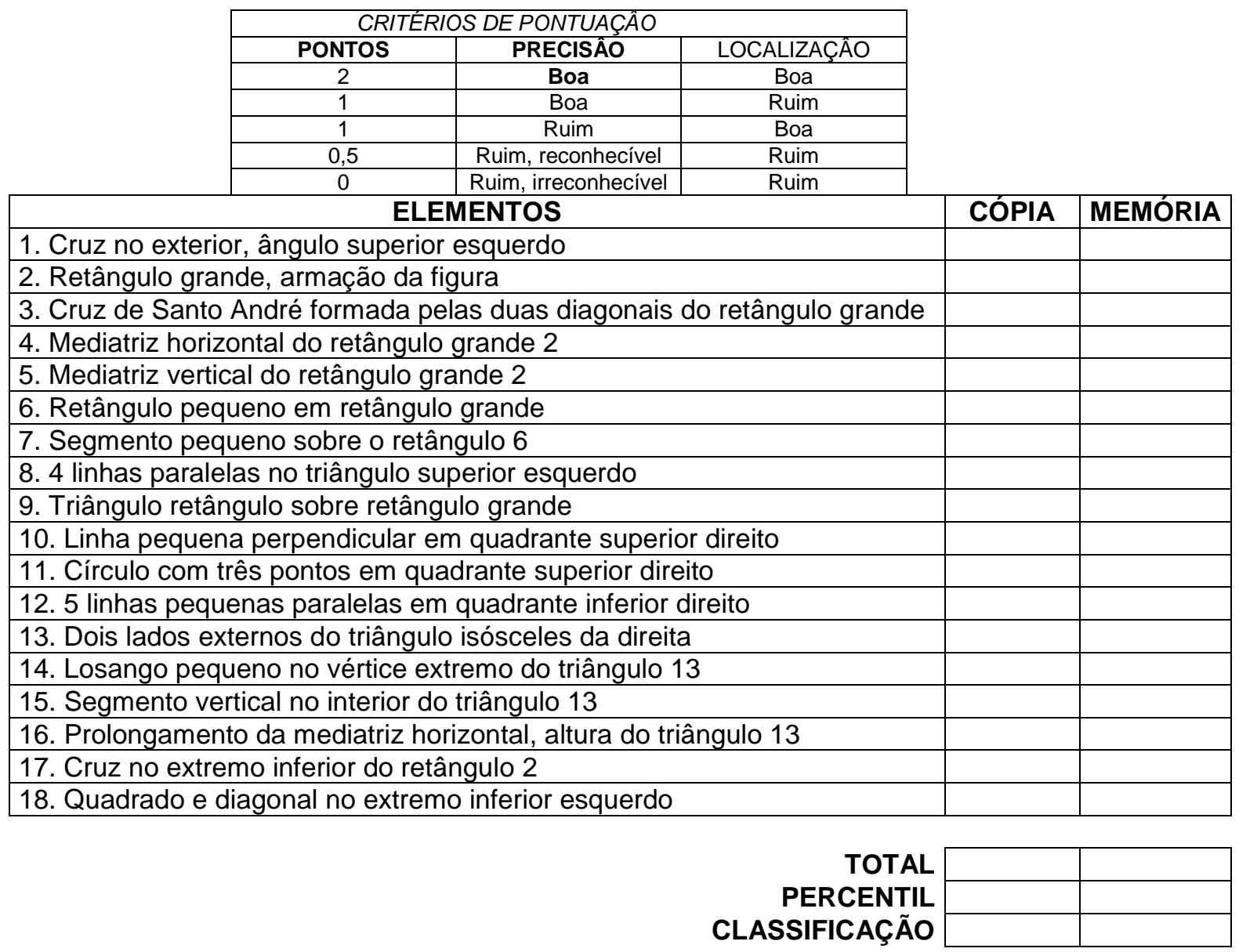

Tipo de cópia: I II III IV $\mathrm{V}$ VI VII VIII $\quad$ IX $\quad \mathrm{X}$ Obs:

\section{FIGURA DE REY (MEMÓRIA/30 MIN.)}

Obs: 
SELECTIVE REMINDING TEST (SRT)

\begin{tabular}{|c|c|c|c|c|c|c|c|c|c|c|c|c|c|c|}
\hline & & & & & & & & & & & & & \multicolumn{2}{|c|}{ Recuperação } \\
\hline & 01 & 02 & 03 & 04 & 05 & 06 & 07 & 08 & 09 & 10 & 11 & 12 & Livre. & Reconhec \\
\hline \multicolumn{15}{|l|}{\begin{tabular}{|l|} 
PROBLEMA \\
\end{tabular}} \\
\hline \multicolumn{15}{|l|}{ LIVRO } \\
\hline \multicolumn{15}{|l|}{ BANCO } \\
\hline \multicolumn{15}{|l|}{ TELEFONE } \\
\hline \multicolumn{15}{|l|}{ EXPLOSÃO } \\
\hline \multicolumn{15}{|l|}{ CABEÇA } \\
\hline \multicolumn{15}{|l|}{ GAROTA } \\
\hline \multicolumn{15}{|l|}{ PRAIA } \\
\hline \multicolumn{15}{|l|}{ VIDRO } \\
\hline \multicolumn{15}{|l|}{ COMIDA } \\
\hline \multicolumn{15}{|l|}{\begin{tabular}{|l|} 
PORTA \\
\end{tabular}} \\
\hline \multicolumn{15}{|l|}{ RELÓGIO } \\
\hline & & & & & & & & & & & & & Total: & Total: \\
\hline & & & & & & & & & & & & & & \\
\hline & & & & & & & & & & & & & & \\
\hline & & & & & & & & & & & & & & \\
\hline & & & & & & & & & & & & & & \\
\hline & & & & & & & & & & & & & & \\
\hline & & & & & & & & & & & & & & \\
\hline & & & & & & & & & & & & & & \\
\hline & & & & & & & & & & & & & & \\
\hline & & & & & & & & & & & & & & \\
\hline
\end{tabular}

\begin{tabular}{|l|l|l|l|l|l|l|l|l|l|l|l|l|l|}
\hline RESULTADOS & $\mathbf{0 1}$ & $\mathbf{0 2}$ & $\mathbf{0 3}$ & $\mathbf{0 4}$ & $\mathbf{0 5}$ & $\mathbf{0 6}$ & $\mathbf{0 7}$ & $\mathbf{0 8}$ & $\mathbf{0 9}$ & $\mathbf{1 0}$ & $\mathbf{1 1}$ & $\mathbf{1 2}$ & TOTAL \\
\hline Recuperação & & & & & & & & & & & & & \\
\hline LTR & & & & & & & & & & & & & \\
\hline STR & & & & & & & & & & & & & \\
\hline LTS & & & & & & & & & & & & & \\
\hline CLTR & & & & & & & & & & & & & \\
\hline RLTR & & & & & & & & & & & & \\
\hline REMINDER & & & & & & & & & & & & & \\
\hline INTRUSÕES & & & & & & & \multicolumn{8}{|c|}{ Memória após 15 min. } \\
\end{tabular}

OBS: 


\section{WISCONSIN CARD SORTING TEST (WCST)}

\begin{tabular}{|cccl|llll|llll|llll|}
\hline C & $F$ & $N$ & $O$ & $C$ & $F$ & $N$ & $O$ & $C$ & $F$ & $N$ & $O$ & $C$ & $F$ & $N$ & $O$ \\
$C$ & $F$ & $N$ & $O$ & $C$ & $F$ & $N$ & $O$ & $C$ & $F$ & $N$ & $O$ & $C$ & $F$ & $N$ & $O$ \\
$C$ & $F$ & $N$ & $O$ & $C$ & $F$ & $N$ & $O$ & $C$ & $F$ & $N$ & $O$ & $C$ & $F$ & $N$ & $O$ \\
$C$ & $F$ & $N$ & $O$ & $C$ & $F$ & $N$ & $O$ & $C$ & $F$ & $N$ & $O$ & $C$ & $F$ & $N$ & $O$ \\
$C$ & $F$ & $N$ & $O$ & $C$ & $F$ & $N$ & $O$ & $C$ & $F$ & $N$ & $O$ & $C$ & $F$ & $N$ & $O$ \\
$C$ & $F$ & $N$ & $O$ & $C$ & $F$ & $N$ & $O$ & $C$ & $F$ & $N$ & $O$ & $C$ & $F$ & $N$ & $O$ \\
$C$ & $F$ & $N$ & $O$ & $C$ & $F$ & $N$ & $O$ & $C$ & $F$ & $N$ & $O$ & $C$ & $F$ & $N$ & $O$ \\
$C$ & $F$ & $N$ & $O$ & $C$ & $F$ & $N$ & $O$ & $C$ & $F$ & $N$ & $O$ & $C$ & $F$ & $N$ & $O$ \\
$C$ & $F$ & $N$ & $O$ & $C$ & $F$ & $N$ & $O$ & $C$ & $F$ & $N$ & $O$ & $C$ & $F$ & $N$ & $O$ \\
$C$ & $F$ & $N$ & $O$ & $C$ & $F$ & $N$ & $O$ & $C$ & $F$ & $N$ & $O$ & $C$ & $F$ & $N$ & $O$ \\
\hline
\end{tabular}

\begin{tabular}{|c|c|c|c|c|c|c|c|c|c|c|c|c|}
\hline C & $\mathrm{F}$ & $\mathrm{N}$ & 0 & $\mathrm{C}$ & $\mathrm{F}$ & $\mathrm{N}$ & $\mathrm{O}$ & $\mathrm{C}$ & $\mathrm{F}$ & $\mathrm{N}$ & $\mathrm{O}$ & AVALIAÇÃO \\
\hline C & $\mathrm{F}$ & $\mathrm{N}$ & $\mathrm{O}$ & $\mathrm{C}$ & $\mathrm{F}$ & $N$ & $\mathrm{O}$ & C & $F$ & $\mathrm{~N}$ & $\mathrm{O}$ & \multirow{2}{*}{ Acertos } \\
\hline C & $\mathrm{F}$ & $\mathrm{N}$ & 0 & $\mathrm{C}$ & $\mathrm{F}$ & $\mathrm{N}$ & $\mathrm{O}$ & $\mathrm{C}$ & $\mathrm{F}$ & $\mathrm{N}$ & $\mathrm{O}$ & \\
\hline C & $\mathrm{F}$ & $\mathrm{N}$ & 0 & $\mathrm{C}$ & $\mathrm{F}$ & $\mathrm{N}$ & $\mathrm{O}$ & \multirow[t]{8}{*}{$\mathrm{C}$} & $F$ & $\mathrm{~N}$ & $\mathrm{O}$ & Erros \\
\hline C & $\mathrm{F}$ & $\mathrm{N}$ & 0 & $\mathrm{C}$ & $\mathrm{F}$ & $\mathrm{N}$ & $\mathrm{O}$ & & & & & \multirow[b]{2}{*}{ Erros Pers. } \\
\hline C & $\mathrm{F}$ & $\mathrm{N}$ & 0 & $\mathrm{C}$ & $\mathrm{F}$ & $\mathrm{N}$ & $\mathrm{O}$ & & & & & \\
\hline C & $\mathrm{F}$ & $\mathrm{N}$ & $\mathrm{O}$ & C & $\mathrm{F}$ & $N$ & $\mathrm{O}$ & & & & & \multirow[t]{2}{*}{ Erros ñ-pers. } \\
\hline C & $\mathrm{F}$ & $\mathrm{N}$ & O & C & $\mathrm{F}$ & $\mathrm{N}$ & $\mathrm{O}$ & & & & & \\
\hline C & $\mathrm{F}$ & $\mathrm{N}$ & $\mathrm{O}$ & $\mathrm{C}$ & $\mathrm{F}$ & $N$ & $\mathrm{O}$ & & & & & R. Persev. \\
\hline \multirow[t]{2}{*}{ C } & \multirow[t]{2}{*}{$\mathrm{F}$} & \multirow[t]{2}{*}{$N$} & \multirow[t]{2}{*}{0} & \multirow[t]{2}{*}{ C } & \multirow[t]{2}{*}{$\mathrm{F}$} & \multirow[t]{2}{*}{$\mathrm{N}$} & \multirow[t]{2}{*}{$\mathrm{O}$} & & & & & Perdas de set \\
\hline & & & & & & & & & & & & Categorias \\
\hline
\end{tabular}

OBS:

IOWA GAMBLING TASK 
Folha de Respostas - Bateria de Avaliação Frontal (FAB)

Nome:

\begin{tabular}{|l|l|}
\hline 1. Semelhanças: "De que modo _e e_cão semelhantes?" & Pontos \\
\hline a) banana laranja*: & \\
* No caso de falha total: "eles não são parecidos" ou parcial : "ambos têm...", \\
ajudar o paciente dizendo "banana e laranja são ... "; mas 0 pontos para este \\
ítem; não ajudar o paciente nos dois ítens seguintes \\
\hline b) mesa e cadeira: & \\
\hline c) tulipa, rosa e margarida: & \\
\hline
\end{tabular}

Total: $\square 0 \quad \square 1 \quad \square 2 \quad \square 3$

2. Fluência Verbal (flexibilidade mental): "Diga o máximo de palavras que conseguir começando com a letra S, quaisquer palavras exceto nomes próprios".

Total: $\square 0$ (<3 palavras) $\square 1$ (3-5 palavras) $\square 2$ (6-9 palavras) $\square 3$ (>9 palavras)

\section{Séries Motoras (programação)}

"Olhe com muita atenção o que vou fazer": realizar punho-palma-lado três vezes com a mão esquerda. "Agora, com sua mão direita faça as mesmas séries, primeiro comigo, e depois sozinho". O examinador realiza as séries três vezes com o paciente, e então diz: "Agora, continue sozinho"

Total: $\square 0$ (0 acompanhando) $\square 1$ (3 acompanhando) $\square 2$ (3 sozinho) $\square 3$ (seis sozinho)

\section{Instruções conflitantes (sensibilidade à interferência)}

"Bata duas vezes quando eu bater uma" (1-1-1)

"Bata uma vez quando eu bater duas" (2-2-2)

Começar: 1-1-2-1-2-2-2-1-1-2.

Total: $\square 0$ (faz como o examinador) $\square 1$ (> 2 erros) $\square 2$ (1-2 erros) $\square 3$ (sem erros)

\section{Vai-Não Vai (Go-No Go)}

"Bata uma vez quando eu bater uma" (1-1-1)

"Não bata quando eu bater duas" (2-2-2)

Começar: 1-1-2-1-2-2-2-1-1-2.

Total: $\square 0$ (repete pelo menos 4 vezes) $\square 1$ (>2 erros) $\square 2$ (1-2 erros) $\square 3$ (sem erros)

\section{Comportamento de preensão manual}

"Não pegue as minhas mãos" (frente a frente): Paciente com as mãos sobre seus joelhos, com as palmas para cima. Tocar as palmas de ambas as mãos do paciente, para ver se ele(a) irá espontaneamente pegá-las. Se o paciente pegar as mãos, o examinador tentará de novo depois solicitando: "Agora, não pegue minhas mãos".

Total: $\square 0$ (pega, mesmo após instrução) $\square 1$ (pega) $\square 2$ (hesita e pergunta) $\square 3$ (não pega)

Total Geral: pontos 


\section{Trail Making Test \\ Parte A}

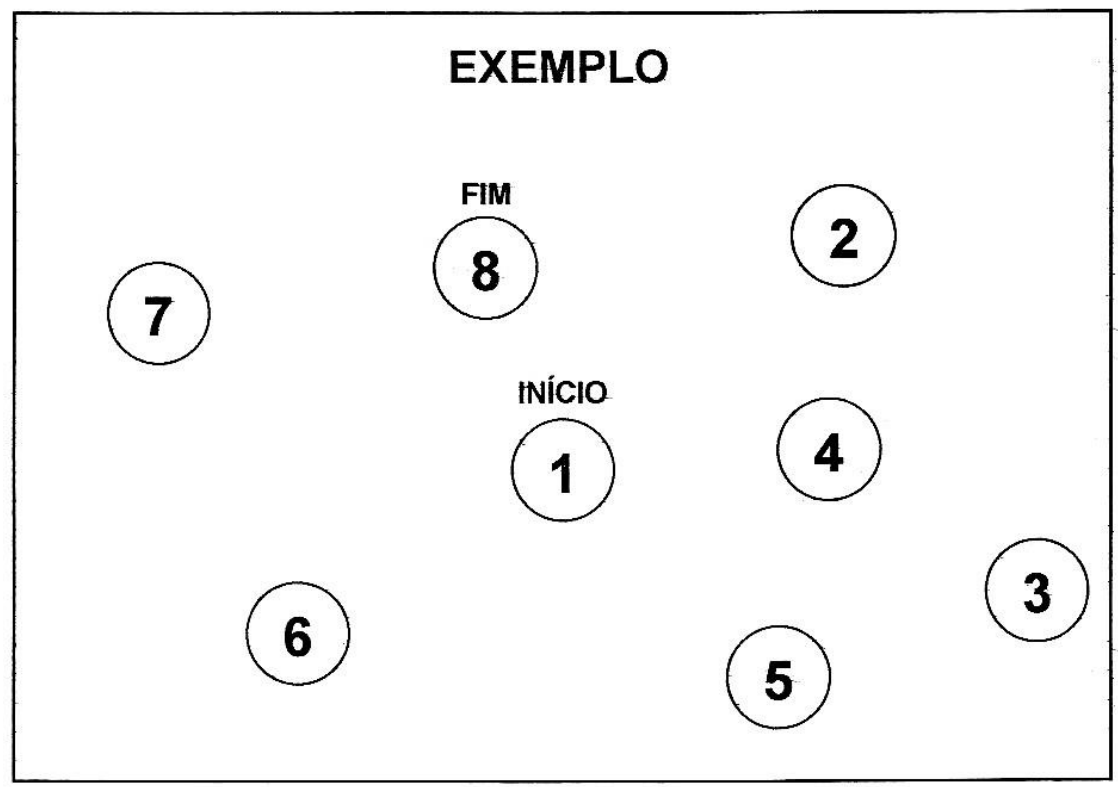


(15)

(17)

(21)

20

(19)

(16)

18

(5) 42

(13)

(6)

(14)

(14)

INicio

(2)

(8) 10

(3)

(9)

(11)

24

(1)

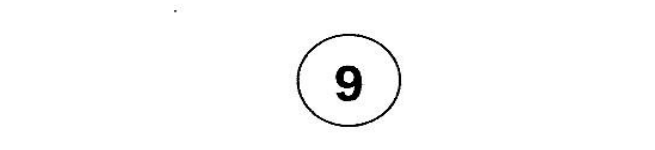

(12)

23 


\section{Trail Making Test \\ Parte B}

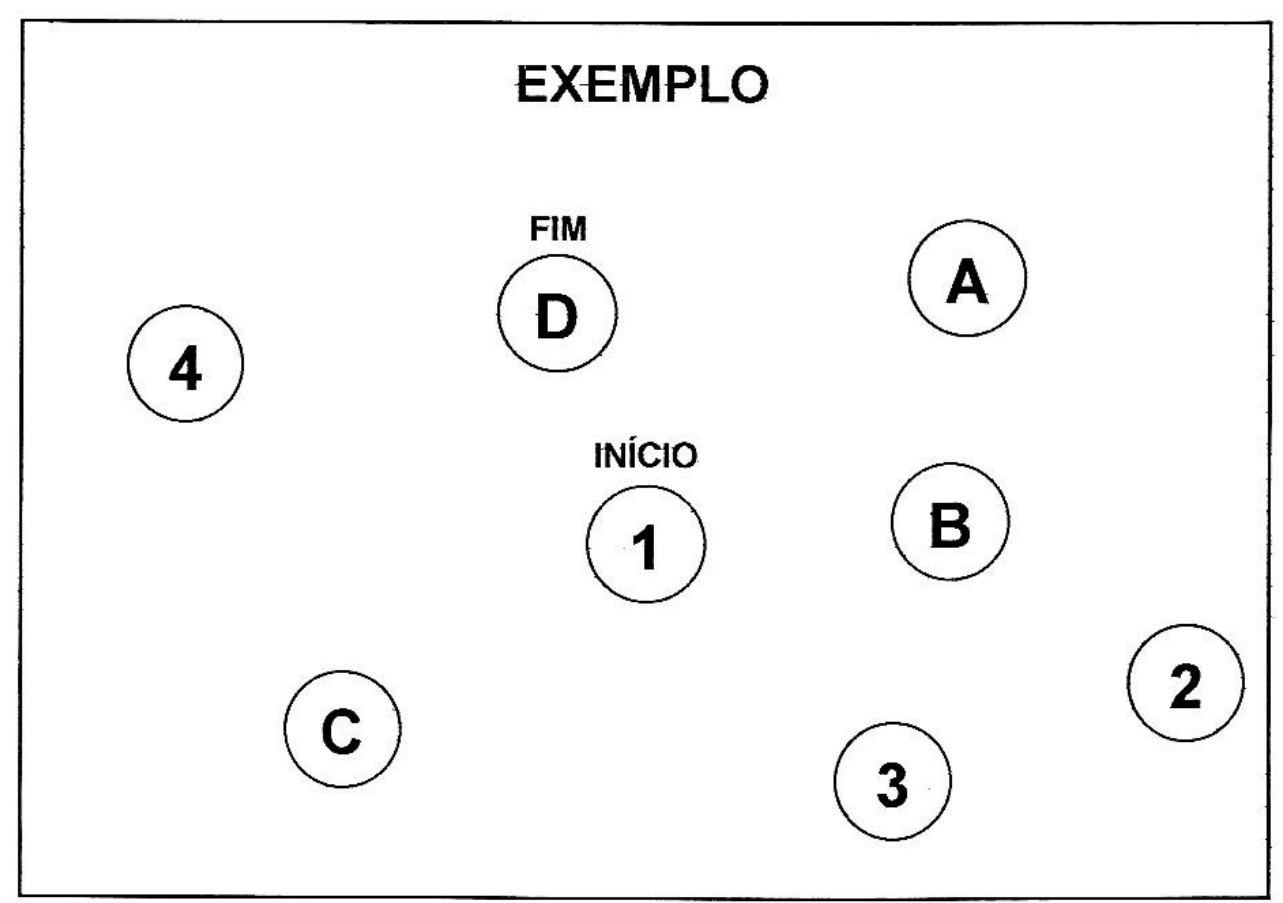


13

(8) (B) (D)

10

3

12

(H)

(7) (1) 5

G

(2)

(A)

(J)

M

(6)

(F)

(E)

(L)

(11) 

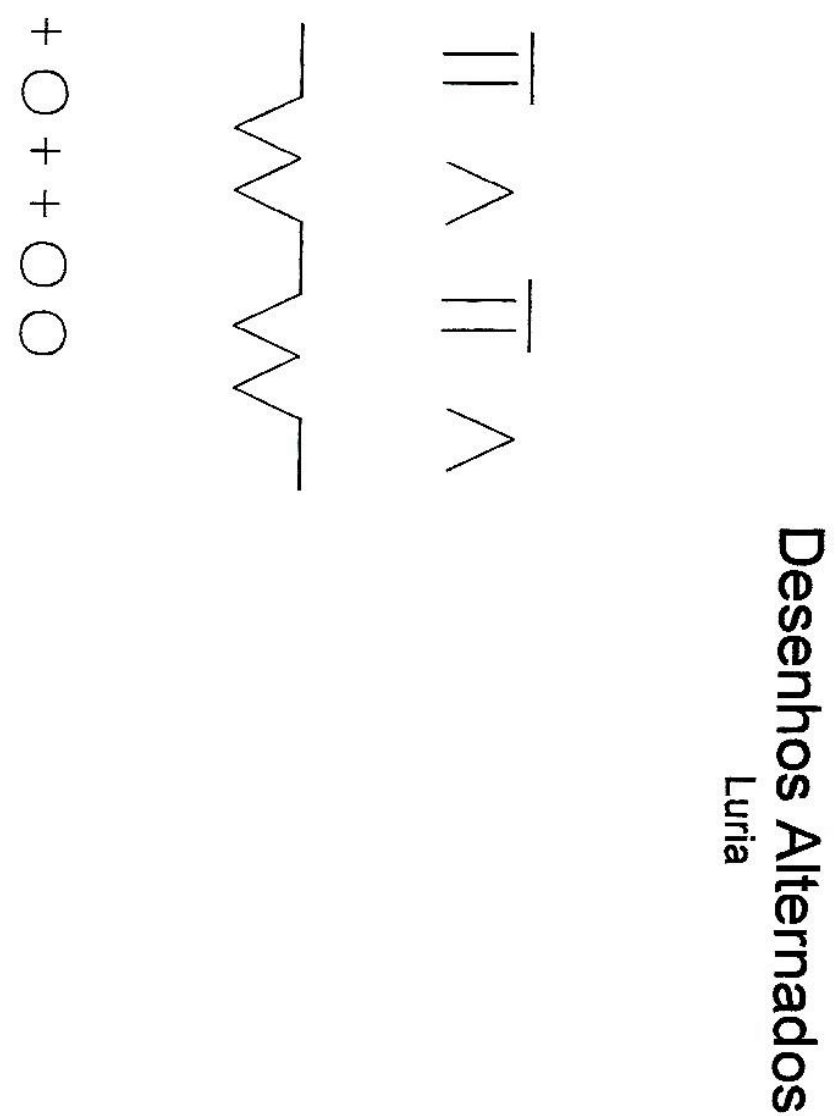


\section{APÊNDICE}

Testes Neuropsicológicos (Descrição) 
Apêndice 4.3. Testes Neuropsicológicos (Descrição)

\section{Atenção e funções executivas:}

- Trail Making Test (TMT): este instrumento é constituído de duas partes, em que se mede o tempo gasto (em segundos) pelo indivíduo até o final da tarefa. A primeira parte (parte A) consiste em ligar círculos contendo números de 1 a 25 seqüencialmente, no menor intervalo de tempo que o indivíduo conseguir. É sensível a déficits de sustentação da atenção e velocidade de processamento de informações. Já a segunda parte (parte B), consiste em ligar 25 círculos com números (1 a 13) e letras ( $\mathrm{A}$ a $\mathrm{M})$, alternadamente, obedecendo simultaneamente às duas seqüências, no menor intervalo de tempo possível. Esta tarefa é sensível a déficits de atenção dirigida, dividida e sustentação da atenção, além de flexibilidade mental (Horner, 1999; Lezak, 1995).

- Stroop Color Word Test: é constituído por três partes, e em cada uma delas cronometra-se o tempo e anota-se o número de erros. Na primeira parte, o indivíduo deve verbalizar as cores do cartão no menor tempo possível. Na segunda, o paciente é solicitado a nomear a cor em que cada palavra foi escrita, independentemente do conteúdo verbal do estímulo. Na terceira parte, o estímulo apresentado é semelhante ao da segunda parte, mas os estímulos verbais são nomes de cores que não correspondem à cor da impressão, devendo o paciente ignorar o conteúdo verbal do estímulo e nomear a cor em que cada palavra foi impressa, no menor tempo possível. É um teste que avalia atenção seletiva, 
sustentação da atenção, inibição de resposta, flexibilidade mental e pode ser sensível a disfunções frontais ou subcorticais cerebrais (Horner, 1999; Lezak, 1995).

D Dígitos - Wechsler Memory Scale-Revised - WMS-R (Wechsler, 1987): esta tarefa consiste em repetir uma série de números apresentados oralmente em ordem direta e ordem inversa. Avalia atenção dirigida, amplitude atencional, controle mental e memória operativa ou "working memory" (Horner, 1999; Lezak, 1995). Contabiliza-se o número de seqüências repetidas corretamente pelo paciente.

口 Wisconsin Card Sorting Test (WCST): inicialmente são colocadas 4 cartas de estímulo diante do paciente (variando na cor, forma geométrica e número de figuras) e the é dado um jogo de 64 cartas de resposta, com padrões semelhantes aos das cartas de estímulo. O entrevistador, sem revelar a regra (cor, forma e número, nesta seqüência), instrui o paciente a associar uma carta recebida a cada carta de estímulo, buscando o máximo de respostas corretas. O entrevistador informa apenas se cada tentativa está correta ou não. O princípio de associação (cor, forma ou número) é modificado a cada dez acertos. Avalia-se o número de categorias completadas (seqüência de dez acertos para cada associação) e o número de erros perseverativos (insistência em utilizar o critério da categoria anterior, que não é mais correto). Este teste avalia a habilidade para formar conceitos abstratos e a flexibilidade mental (funções executivas), que é a capacidade de mudar e manter esse conjunto de conceitos (Heaton et al., 1993; Lezak, 1995). 
口 Frontal Assessment Battery (FAB): bateria breve de avaliação neuropsicológica (apenas 10 minutos para aplicação), que compreende seis subtestes que examinam a capacidade de abstração, fluência verbal (flexibilidade cognitiva), coordenação motora, suscetibilidade à distração, controle inibitório e autonomia. É considerada uma medida útil para o rastreamento de disfunção executiva e/ou alterações pré-frontais cerebrais.

\section{Memória:}

Memória Lógica (WMS-R): avalia memória verbal, examinando a habilidade de retenção e evocação de duas histórias apresentadas oralmente. A parte I tem como objetivo pesquisar a memória verbal imediata, e a parte II memória tardia (após 30 minutos) (Wechsler, 1984).

$\quad$ Reprodução Visual (WMS-R): avalia memória visual. Neste teste, o sujeito deve recuperar imediatamente de memória quatro figuras geométricas que são expostas brevemente (parte I) e, após 30 minutos, tentar evocá-las novamente (parte II) (Wechsler, 1984).

$\quad$ Figura Complexa de Rey: avalia memória visual. O procedimento envolve a cópia da figura de Rey e então, sem aviso prévio, após 30 minutos, o sujeito deve reproduzir a mesma figura através de suas habilidades mnemônicas (Rey, 1999).

\section{Processos de aprendizagem:}


$\square$ Buschke Selective Reminding Test (SRT): mede aprendizado verbal e memória. Neste teste, o examinador lê uma lista de 12 palavras e pede para o sujeito recordar o maior número de palavras possível. O teste termina após 12 tentativas ou se o indivíduo acertar a lista inteira por três vezes consecutivas. Após o período de 15 minutos, destinado à distração do sujeito, o examinador solicita novamente que a pessoa se recorde da lista, e, por fim, há a etapa de reconhecimento. O teste permite a avaliação de vários sub-componentes da memória, como a recuperação a curto e longo prazos (STR e LTR), evocação randômica e consistente a longo prazo (RLTR e CLTR), entre outros (Spreen \& Strauss, 1998).

\section{Funções Viso-Motoras:}

口 Desenhos Alternados (Luria, 1966): consiste na apresentação de três desenhos, a que os indivíduos devem dar continuidade até o final da folha de resposta. Avalia-se o traçado, com atenção especial aos erros perseverativos.

$\square \quad$ Códigos - WAIS-R: o indivíduo deve, em 90 segundos, preencher espaços vazios com símbolos referentes ao modelo impresso no enunciado da folha de resposta. O teste avalia a coordenação viso-motora, mas várias funções cognitivas parecem contribuir para a execução desta tarefa (Spreen \& Strauss, 1998).

\section{Praxia Construtiva:}


口 Cópia da Figura de Rey (Rey, 1999): permite o estudo de vários processos cognitivos, tais como planejamento, organização, estratégia de solução de problemas, percepção e função motora. Consiste na cópia de uma figura complexa. Inicialmente é mostrada uma figura, que a pessoa deve copiar numa folha de papel. Para que a estratégia de desenho do paciente seja mais facilmente analisada, utilizam-se lápis coloridos. A cada seção do desenho concluída, o examinador dará uma outra cor ao paciente, anotando-se a ordem das cores (Spreen \& Strauss, 1998).

Cubos - WAIS/R (Wechsler, 1981): O teste dos cubos consiste na apresentação para o indivíduo de cubos vermelhos e brancos e na solicitação de construção de uma réplica da figura mostrada pelo examinador ou de desenhos feitos em menor escala (Spreen \& Strauss, 1998).

\section{Linguagem:}

$\square \quad$ Boston Naming Test (BNT): O propósito deste teste é verificar a habilidade em nomear figuras de objetos. O teste é composto por 60 figuras, que abrangem desde nomes freqüentes no vocabulário até palavras mais raras. As figuras são apresentadas uma a uma, e podem ser fornecidas pistas semânticas ou fonológicas, caso o sujeito não as identifique prontamente.

a Controlled Oral Word Association (COWA): O objetivo deste teste é avaliar a produção espontânea de palavras iniciadas por uma determinada 
letra ou de uma dada categoria de palavras, dentro de um determinado tempo (1 minuto).

Vocabulário - WAIS-R (Wechsler, 1981): consiste de uma lista de 35 palavras, para avaliar a habilidade verbal da pessoa. $O$ sujeito deve tentar explicar o significado das palavras e, de acordo com o conteúdo da explicação, ele pode receber 0,1 ou 2 pontos.

\section{Tomada de Decisão:}

口 lowa Gambling Task (IGT): teste administrado no computador, baseado em quatro conjuntos de cartas ( $A, B, C$ e D), em que os indivíduos devem escolher as cartas mais vantajosas, envolvendo lucros e perdas monetárias, ao longo de 100 tentativas. Mede a capacidade de tomada de decisões e a habilidade de avaliar e considerar as conseqüências futuras das ações, em detrimento das conseqüências imediatas do comportamento. 